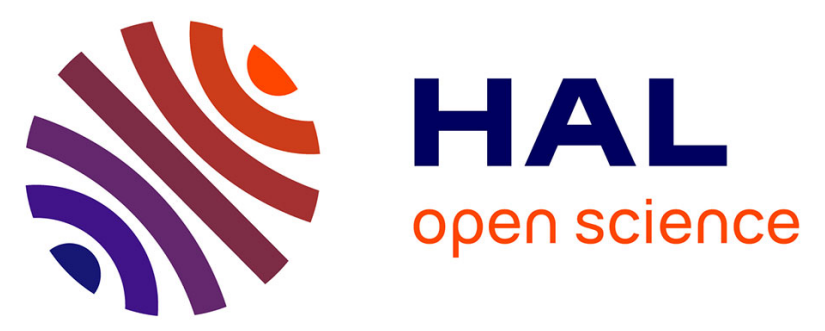

\title{
Chronic sodium bromide treatment relieves autistic-like behavioral deficits in three mouse models of autism
}

Cécile Derieux, Audrey Léauté, Agathe Brugoux, Déborah Jacaz, Jean-Philippe Pin, Julie Kniazeff, Julie Le Merrer, Jerome A.J. Becker

\section{- To cite this version:}

Cécile Derieux, Audrey Léauté, Agathe Brugoux, Déborah Jacaz, Jean-Philippe Pin, et al.. Chronic sodium bromide treatment relieves autistic-like behavioral deficits in three mouse models of autism. 2021. hal-03379576

\author{
HAL Id: hal-03379576 \\ https://hal.science/hal-03379576
}

Preprint submitted on 15 Oct 2021

HAL is a multi-disciplinary open access archive for the deposit and dissemination of scientific research documents, whether they are published or not. The documents may come from teaching and research institutions in France or abroad, or from public or private research centers.
L'archive ouverte pluridisciplinaire HAL, est destinée au dépôt et à la diffusion de documents scientifiques de niveau recherche, publiés ou non, émanant des établissements d'enseignement et de recherche français ou étrangers, des laboratoires publics ou privés. 
Derieux et al.

1 Chronic sodium bromide treatment relieves autistic-like behavioral

2 deficits in three mouse models of autism

3 Cécile Derieux ${ }^{1,2,4}$, Audrey Léauté ${ }^{1}$, Agathe Brugoux ${ }^{1,2}$, Déborah Jacaz ${ }^{3}$, Jean-Philippe

$4 \mathrm{Pin}^{4}$, Julie Kniazeff ${ }^{4}$, Julie Le Merrer ${ }^{1,2 \dagger^{*}}$, Jerome AJ Becker $^{1,2 \uparrow^{*}}$

5 1Physiologie de la Reproduction et des Comportements, INRAE UMR0085, CNRS UMR7247, IFCE, Université de Tours, Inserm, 37380 Nouzilly, France.

2UMR1253, iBrain, Université de Tours, Inserm, CNRS, Faculté des Sciences et Techniques, Parc de Grandmont, 37200 Tours, France.

3Unité Expérimentale de Physiologie Animale de l'Orfrasière, INRAE UE0028 37380

Nouzilly, France.

${ }^{4}$ Institut de Génomique Fonctionnelle (IGF), Université de Montpellier, CNRS, Inserm, 34094 Montpellier, France.

$\dagger$ These authors contributed equally to this work.

Corresponding authors:

*Julie Le Merrer

Inserm U-1253 iBrain, Université de Tours, CNRS, Faculté des Sciences et Techniques, Parc de Grandmont, F-37200 Tours, France.

Email: julie.le-merrer@inserm.fr

*Jerome Becker, PhD,

Inserm U-1253 iBrain, Université de Tours, CNRS, Faculté des Sciences et Techniques, Parc de Grandmont, F-37200 Tours, France.

Email: Jerome.becker@inserm.fr

Number of words in abstract: 210

Number of words in text: 5930

Number of figures: 7

Supplemental material: $\mathbf{1 1}$ figures, 2 tables 
Derieux et al.

\section{Abstract}

Autism Spectrum Disorders (ASD) are neurodevelopmental disorders whose diagnosis relies on deficient social interaction and communication together with repetitive behavior. To date, no pharmacological treatment has been approved that ameliorates social behavior in patients with ASD. Based on the excitation/inhibition imbalance theory of autism, we hypothesized that bromide ions, long used as an antiepileptic medication, could relieve core symptoms of ASD. We evaluated the effects of chronic sodium bromide $(\mathrm{NaBr})$ administration on autistic-like symptoms in three genetic

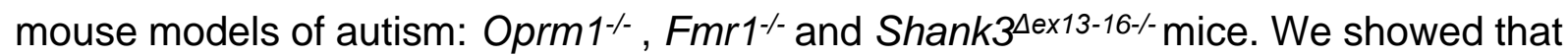
chronic $\mathrm{NaBr}$ treatment relieved autistic-like behaviors in these three models. In Oprm $1 \%$ mice, these beneficial effects were superior to those of chronic bumetanide administration. At transcriptional level, chronic $\mathrm{NaBr}$ in Oprm1 null mice was associated with increased expression of genes coding for chloride ions transporters, $\mathrm{GABA}_{\mathrm{A}}$ receptor subunits, oxytocin and mGlu4 receptor. Lastly, we uncovered synergistic alleviating effects of chronic $\mathrm{NaBr}$ and a positive allosteric modulator (PAM) of mGlu4 receptor on autistic-like behavior in Oprm1\% mice. We evidenced in heterologous cells that bromide ions behave as PAMs of mGlu4, providing a molecular mechanism for such synergy. Our data reveal the therapeutic potential of bromide ions, alone or in combination with a PAM of mGlu4 receptor, for the treatment of ASDs. 列

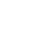


Derieux et al.

\section{INTRODUCTION}

Autism Spectrum Disorders (ASD) are neurodevelopmental diseases with high heterogeneity and heritability. Their diagnostic is reached in presence of impaired social communication and interaction together with a restricted, repetitive repertoire of behaviors, interests and activities (1). Alongside core symptoms, ASD are often associated with neurobehavioral comorbidities, such as high anxiety, cognitive and motor deficits or epilepsy (2-5). Despite the identification of vulnerability genes and environmental risk factors (6-8), the etiology of ASD remains essentially unknown, making the development of pharmacological treatments for these pathologies a true challenge.

Excitation/inhibition (E/I) imbalance appears as a common mechanistic feature in $\operatorname{ASD}(9,10)$. The heuristic hypothesis of excessive $E / l$ ratio in ASD was initially formulated by Rubenstein and Merzenich (11) and raised significant interest as accounting well for reduced GABAergic signaling $(12,13)$ and high prevalence of epilepsy (10-30\%) (3) in these pathologies. Indeed, epilepsy is one of the most frequent comorbid medical condition in autism $(5,14)$ and the prevalence of epileptiform EEG or altered resting-state is even higher $(15,16)$, suggesting shared risk factors and/or pathophysiological mechanisms $(17,18)$. However, the excessive $E / l$ hypothesis in ASD has been challenged by studies in animal models showing instead decreased excitation, which led to a more general concept of altered $\mathrm{E} / \mathrm{I}$ homeostasis $(10,19)$.

Compromised $\mathrm{E} / \mathrm{I}$ balance in ASD may result from several neuropathological mechanisms. On the excitation side, glutamatergic transmission was found altered both in patients and animal models, although in different directions depending on genetic mutations/models $(9,20,21)$. On the inhibition side, and consistent with 
Derieux et al.

impaired GABAergic signaling, decreased levels of GABA (22) and expression of $\operatorname{GABA}_{A}$ and $\operatorname{GABA}_{B}(23,24)$ receptors as well as genetic polymorphisms in $\mathrm{GABA}_{A}$ receptor subunits $(25,26)$ have been detected in patients with autism. Accordingly, decreased GABAergic neurotransmission has been reported in several ASD models (27-31). Moreover, preclinical studies showed that low doses of benzodiazepines, behaving as positive allosteric modulators (PAMs) of the GABAA receptor $(31,32)$, or the $G A B A_{B}$ receptor agonist arbaclofen improve autistic-like behaviors in animal models $(33,34)$. Disappointingly, these results failed to translate to Fragile $X$ syndrome in clinical trials $(35,36)$. Alternatively, it was proposed that GABA neurons remain immature in ASD, failing to shift from high to low intracellular concentrations of chloride ion $\left(\mathrm{Cl}^{-}\right)$, resulting in maintained depolarizing $\mathrm{Cl}^{-}$efflux through activated $\mathrm{GABA}_{A}$ receptor (37). Intracellular $\mathrm{Cl}^{-}$concentration is under the control of the main $\mathrm{Cl}^{-}$importer NKCC1 $\left(\mathrm{Na}^{+}-\mathrm{K}^{+}-2 \mathrm{Cl}^{-}\right.$cotransporter) and the main chloride exporter $\mathrm{KCC} 2$. Therefore blocking NKCC1 using the loop diuretic and antiepileptic drug $(38,39)$ bumetanide appeared a promising therapeutic approach in ASD. Accordingly, bumetanide improved autistic-like phenotype in rodent models of ASD (40) and relieved autistic behavior in small cohorts of patients $(41,42)$ but failed to demonstrate clinical benefit in a larger clinical trial, except for a reduction of repetitive behavior (43).

Bromide ion $\left(\mathrm{Br}^{-}\right)$was the first effective treatment identified for epilepsy (44), long used also as an anxiolytic and hypnotic medication (45). With the advent of novel antiepileptic and anxiolytic drugs, the use of $\mathrm{Br}^{-}$was progressively dropped down, although it remains a valuable tool to treat refractory seizures $(46,47)$. As regards its mechanism of action, $\mathrm{Br}^{-}$shares similar chemical and physical properties with $\mathrm{Cl}^{-}$, allowing it substituting $\mathrm{Cl}^{-}$in multiple cellular mechanisms. These include anion efflux through activated $\mathrm{GABA}_{A}$ receptor, with higher permeability to $\mathrm{Br}^{-}$compared to $\mathrm{Cl}^{-}$ 
Derieux et al.

resulting in neuronal hyperpolarization (48), and transport through the NKCC and KCC cotransporters $(49,50)$. In view of the $E / I$ imbalance theory, these properties point to $\mathrm{Br}^{-}$as an interesting candidate for ASD treatment.

In the present study, we assessed the effects of chronic sodium bromide administration on core autistic-like symptoms: social deficit and stereotypies, as well as on a frequent comorbid symptom: anxiety, in three genetic mouse models of autism: Oprm1\% , Fmr1\% and Shank3 ${ }^{\text {ex } 13-16-/}$ mice, by means of thorough behavioral assessment. Altered E/I balance and/or modified expression of genes involved in this balance have been reported for these three models $(30,51-55)$; the Oprm1 knockout model presents the advantage of limited impact on learning performance (52), allowing better disentangling autistic features from cognitive deficit. We evidenced that $\mathrm{Br}^{-}$ treatment alleviates most of the behavioral deficits observed in these mice, and increases expression of various genes within the social brain circuit. We unraveled that Br- not only increases mGlu4 receptor gene expression but also potentiates the effects of the mGlu4 PAM VU0155041 as well as its agonist glutamate, in Oprm1 1 - mice and in heterologous cells. Our data reveal the therapeutic potential of $\mathrm{Br}^{-}$administration and its combination with a positive allosteric modulator (PAM) of mGlu4 receptor for the treatment of ASD.

\section{RESULTS}

\section{Chronic sodium bromide was more efficient than bumetanide to relieve social}

\section{behavior deficits in Oprm1 $1^{-/}$mice}

We first assessed the effects of $\mathrm{NaBr}$ administration over a wide range of doses (10 to $500 \mathrm{mg} / \mathrm{kg}$ ) in Oprm1\% mice and their WT counterparts, and compared with 
Derieux et al.

bumetanide administration ( 0.5 and $2 \mathrm{mg} / \mathrm{kg}$ ) (Fig. 1A). Treatment was given chronically to mimic clinical conditions.

Social interaction was evaluated after 9 days of chronic $\mathrm{NaBr}$ treatment (Fig. 1B, more parameters in Fig. S2A). Oprm1\% mice exhibited a severe decrease in social interaction; chronic $\mathrm{NaBr}$ administration from the dose of $125 \mathrm{mg} / \mathrm{kg}$ dose-dependently relieved this deficit in mutant mice, as evidenced by restored number (genotype $x$ treatment: $\left.F_{6,163=13.2,} p<0.0001\right)$ and mean duration (genotype $x$ treatment: $\left.F_{6,163=31.6,} p<0.0001\right)$ of nose contacts and normalized number (genotype $x$

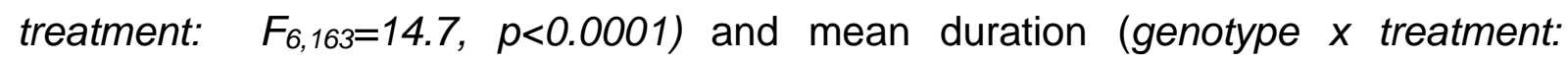
$\left.F_{6,163}=14.5, p<0.0001\right)$ of paw contacts. Chronic $\mathrm{NaBr}$ also increased the number of following episodes in both mouse lines (treatment: $F_{6,163}=5.6, p<0.0001$ ) and normalized the frequency of grooming after social contact in mutants, since the dose of $70 \mathrm{mg} / \mathrm{kg}$ (genotype $x$ treatment: $F_{6,163}=32.2, p<0.0001$ ). In contrast, a single acute injection of $\mathrm{NaBr}(250 \mathrm{mg} / \mathrm{kg}$ ) had little effect on social interaction parameters (Fig. S2B). When given chronically, $\mathrm{NaBr}$ (over $70 \mathrm{mg} / \mathrm{kg}$ ) produced relieving effects that were still detectable one week after cessation of treatment, as evidenced by preserved

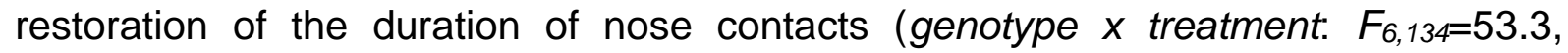
$p<0.0001$ ) and maintained suppression of grooming after social contact (genotype $x$

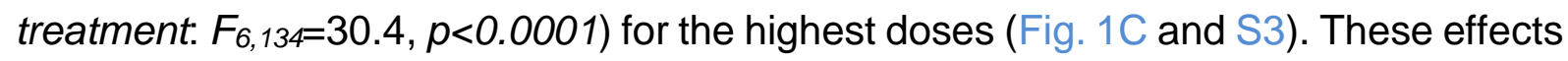
had mostly vanished after two weeks (Fig. S3). 
Derieux et al.
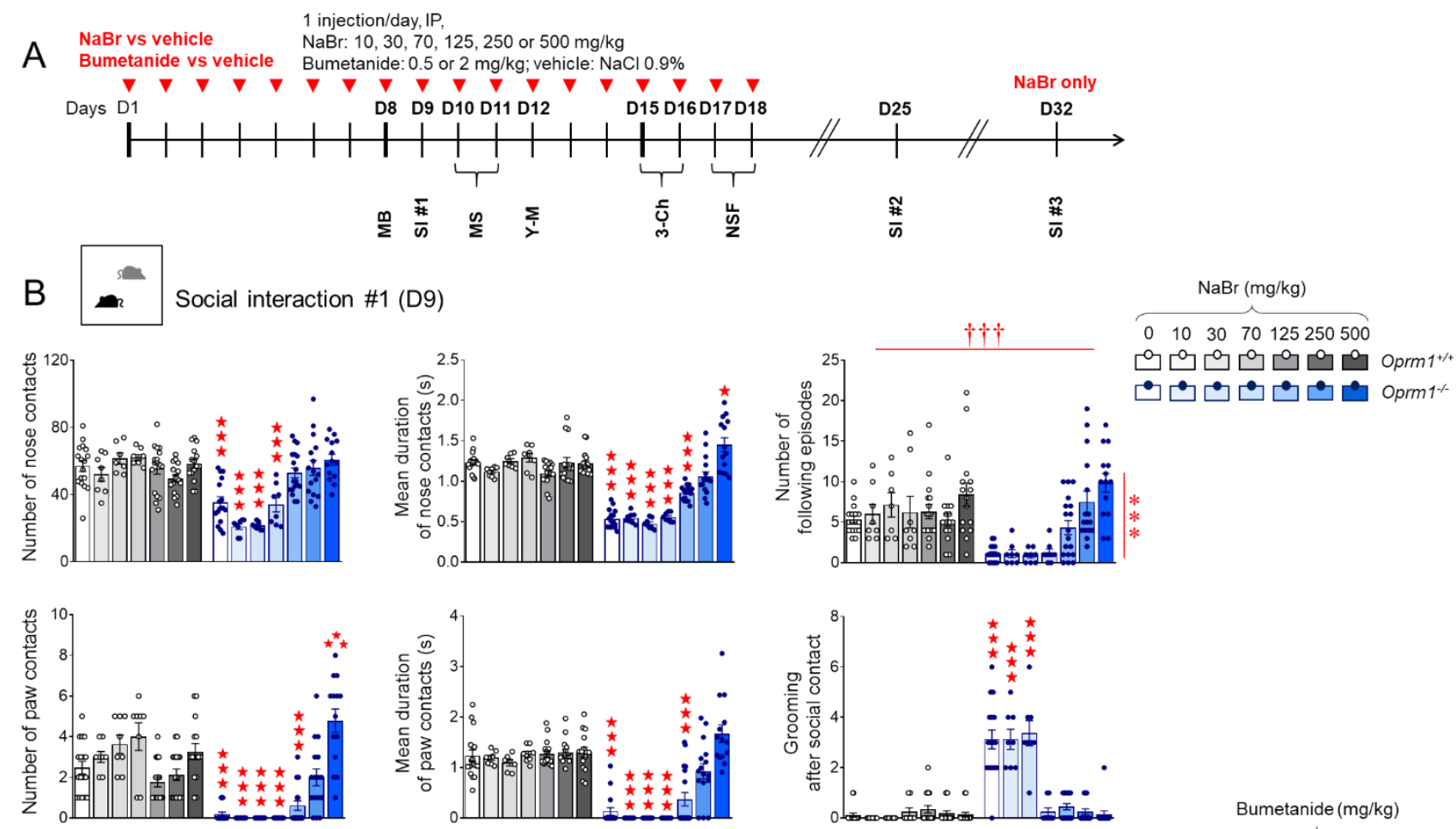

umetanide $(\mathrm{mg} / \mathrm{kg})$
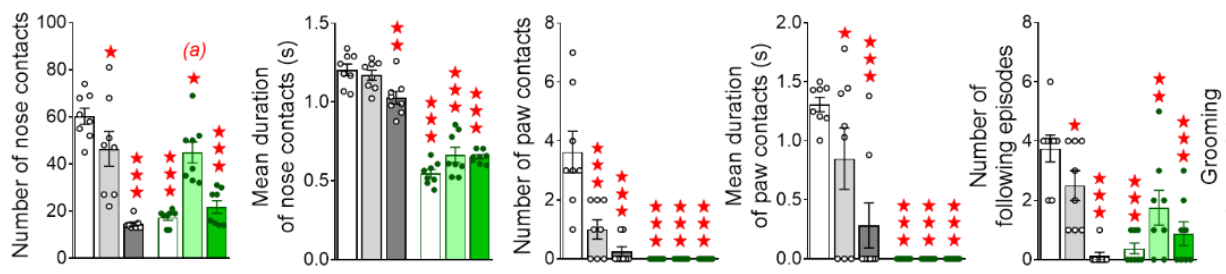

$\begin{array}{lll}0 & 0.52 & 2\end{array}$

C Social interaction \#2 (D25)
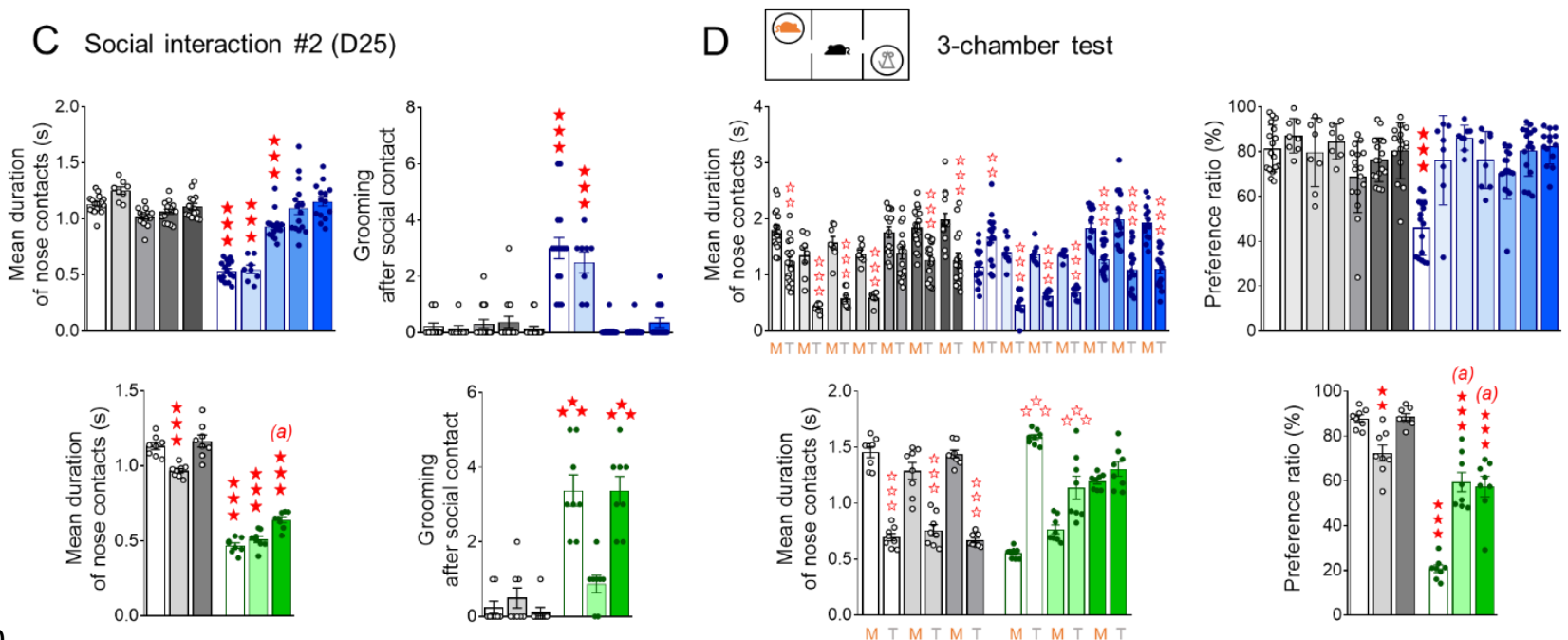

Fig 1. Chronic sodium bromide dose-dependently relieved social behavior deficits in Oprm1-

treated either with $\mathrm{NaBr}(0,125-500 \mathrm{mg} / \mathrm{kg}: \mathrm{n}=14-20$ mice per genotype and dose; $10-70 \mathrm{mg} / \mathrm{kg}: \mathrm{n}=8$ 
Derieux et al.

and 2 weeks after cessation of chronic administration. (B) In the direct social interaction test (D9), chronic $\mathrm{NaBr}$ administration relieved social deficits of Oprm1 null mice in a dose-dependent manner for doses over $125 \mathrm{mg} / \mathrm{kg}$; it had no detectable effect in Oprm $1^{+/+}$mice. Bumetanide had only partial effects, increasing the number of nose contacts (low dose) and suppressing grooming after social contact; at the highest dose, it impaired social interaction in wild-type controls. (C) One week after cessation of treatment, beneficial effects of bromide administration were preserved for doses over $125 \mathrm{mg} / \mathrm{kg}$; effects of bumetanide one duration of nose contacts and grooming after social contact were still detectable. (D) In the three-chamber test, $\mathrm{NaBr}$ treatment rescued social preference in Oprm1 mutants since the dose of $10 \mathrm{mg} / \mathrm{kg}$, while bumetanide increased their interest for the mouse without reducing their abnormal interest for the object. Results are shown as scatter plots and mean \pm sem. Daggers: genotype effect, asterisks: treatment effect, solid stars: genotype $\mathrm{x}$ treatment interaction (comparison to wild-type vehicle condition), open stars: genotype $\mathrm{x}$ treatment $\mathrm{x}$ stimulus interaction (mouse versus object comparison), (a) genotype $x$ treatment interaction (comparison with knockout vehicle condition, $p<0.001$ ) (two-way ANOVA or three-way ANOVA with stimulus as repeated measure, followed by Newman-Keuls post-hoc test). One symbol: $p<0.05$, two symbols: $p<0.01$; three symbols: $p<0.001$. More behavioral parameters in Fig. S2. 3-Ch: 3-chamber test, M: mouse, MB: marble burying, MS: motor stereotypies, NSF: noveltysuppressed feeding, SI: social interaction, T: toy, Y-M: Y-maze.

Compared with chronic $\mathrm{NaBr}$, chronic bumetanide increased the number of nose contacts (genotype $x$ treatment: $F_{2,42}=22.6, p<0.0001$ ) and following episodes at low dose (genotype $x$ treatment: $F_{2,42}=12.9, p<0.0001$ ) but failed to increase significantly the duration of nose contacts (genotype $x$ treatment: $F_{2,42}=22.6, p<0.0001$ ) or the number (genotype $x$ treatment: $F_{2,42}=14.9, p<0.0001$ ) and duration (genotype $x$ treatment: $\left.F_{2,42}=7.3, p<0.0001\right)$ of paw contacts. Finally, bumetanide suppressed grooming episodes, notably those occurring after social contact, since the lowest dose tested (genotype $x$ treatment: $F_{2,42}=80.7, p<0.0001$ ). Of note, chronic bumetanide treatment showed deleterious effects on social interaction parameters in WT controls. One week after cessation of treatment, beneficial effects of bumetanide were still 
Derieux et al.

183

184

185

186

187

188

189

190

191

192

193

194

195

196

197

198

199

200

201

202

203

204

205

206

detectable notably on the duration of nose contacts (genotype $x$ treatment: $F_{2,42}=9.3$, $p<0.0001$ ) and grooming episodes after social contact (genotype $x$ treatment: $\left.F_{2,42}=16.4, p<0.0001\right)$, depending on the dose (Fig.1 C and S3).

In the 3-chamber test (Fig. 1D, more parameters in Fig. S2C), Oprm1\% mice showed a severe impairment in social preference, as evidenced by equivalent number of nose contacts made with the mouse and the toy, and even longer nose contacts made with the toy over the mouse. Chronic $\mathrm{NaBr}$ completely restored social preference in mutant mice, which displayed more frequent (genotype $x$ treatment $x$ stimulus: $F_{6,160}=3.5$, $p<0.001)$ and longer (genotype $x$ treatment $x$ stimulus: $F_{6,160}=8.9, p<0.0001$ ) nose contacts with the mouse since the lowest dose of bromide administered. This resulted in a normalization of their preference ratio from $10 \mathrm{mg} / \mathrm{kg} \mathrm{NaBr}$ and over (genotype $x$

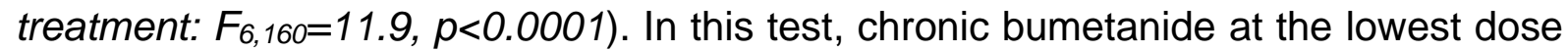
restored a preference for making more frequent nose contacts with the mouse over the toy (genotype $x$ treatment $x$ stimulus: $F_{2,42}=17.7, p<0.0001$ ). Bumetanide treatment in mutant mice dose-dependently increased the duration of nose contacts with the mouse, but failed to reduce the duration of nose contacts with the toy (genotype $x$ treatment $x$ stimulus: $\left.F_{2,42}=32.5, p<0.0001\right)$ leading to significant but partial recovery of social preference ratio in Oprm1- mice (genotype $x$ treatment: $F_{2,42}=38.4$, $p<0.0001)$

In conclusion, chronic but not acute $\mathrm{NaBr}$ treatment restored social behavior in Oprm 1/- mice in a dose-dependent manner, and these beneficial effects were superior to those of chronic bumetanide treatment.

\section{Sodium bromide reduced stereotypic behaviors and anxiety in Oprm1 ${ }^{-/-}$mice}


Derieux et al.

We next assessed the effects of chronic bromide on non-social behaviors in the same cohorts of Oprm1- mice (timeline in Fig. 1A, more parameters in Fig. S4).

Regarding stereotypic behavior, Oprm1\% mice displayed spontaneous stereotypic circling and head shakes (Fig. 2A) that were decreased under $\mathrm{NaBr}$ treatment since the lowest dose, more consistently for the former (genotype $x$ treatment: $F_{6,161}=4.6$, $p<0.001)$ than for the latter (genotype $x$ treatment: $\left.F_{6,161}=7.0, p<0.0001\right)$. In Oprm $1^{+/+}$ control mice, $\mathrm{NaBr}$ dose-dependently increased the number of grooming episodes (genotype $x$ treatment: $F_{6,161}=4.5, p<0.001$ ) and head shakes (genotype $x$ treatment: $F_{6,161}=7.0, p<0.0001$ ); in both mouse lines, $\mathrm{NaBr}$ increased the number of rearing episodes in a dose-dependent manner (treatment: $F_{6,161}=13.2, p<0.0001$ ). Under the same conditions, bumetanide suppressed circling and head shakes in mutant mice, and reduced the number of rearing episodes in both mouse lines. In the marble burying test (Fig. 2B), NaBr treatment did not suppressed excessive burying in mutant mice (genotype: $F_{6,163}=13.6, p<0.001$ ) and globally increased burying (treatment: $F_{6,163=2.4 \text {, }}$ $p<0.05)$. Similarly, chronic bumetanide failed to suppress excessive marble burying in Oprm1 $\%$ mice (genotype: $F_{2,46}=14.7, p<0.001$ ). In the $Y$-maze exploration test (Fig. 2C), bromide decreased the number of perseverative same arm returns in Oprm1 null mice to wild-type levels since the dose of $30 \mathrm{mg} / \mathrm{kg}$ (genotype $x$ treatment: $F_{6,161}=6.7$, $p<0.0001$ ) while bumetanide globally failed to suppress those (genotype: $F_{2,46}=19.7$, $p<0.001$ ), despite a tendency for a decrease observed for the dose of $0.5 \mathrm{mg} / \mathrm{kg}$. 
Derieux et al.

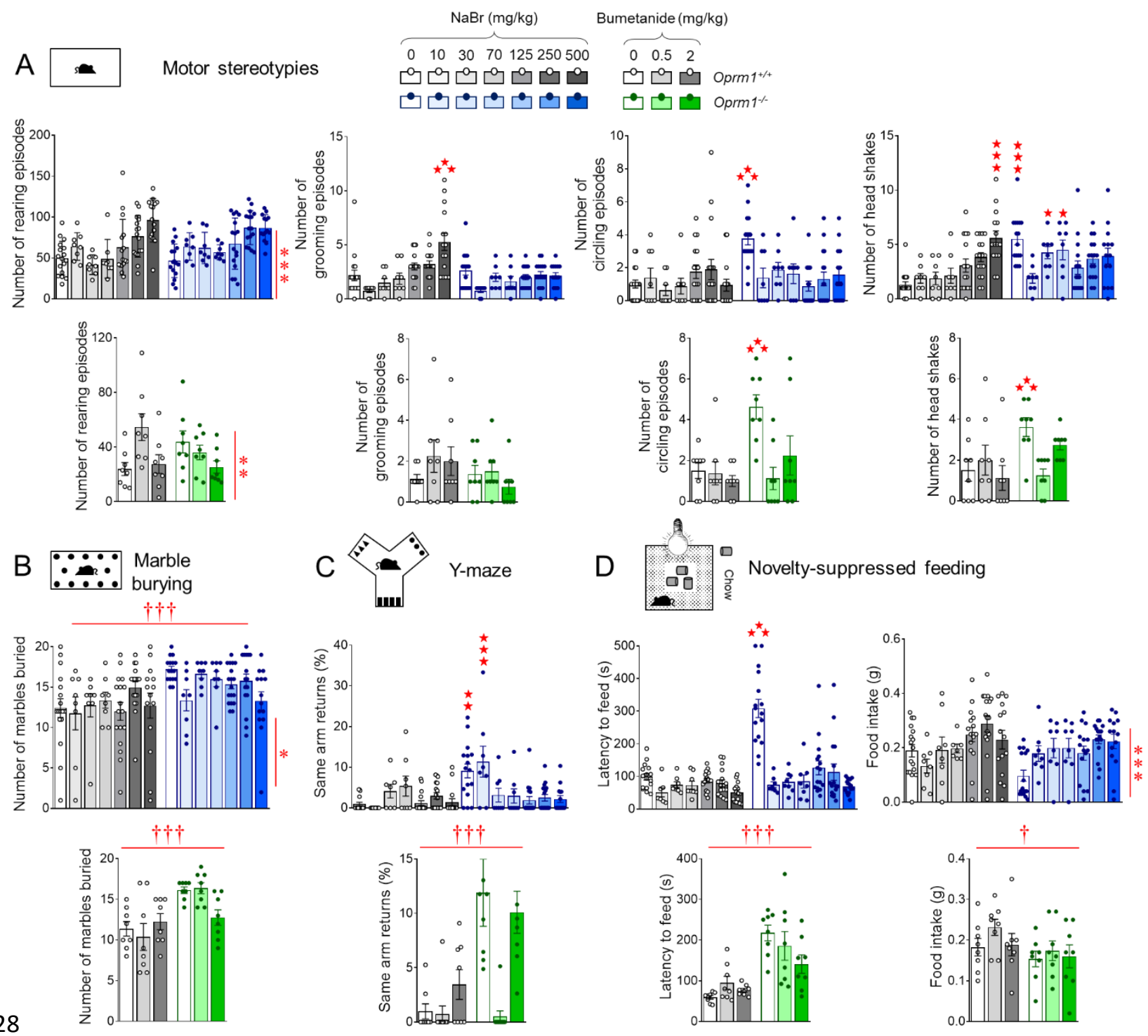

Fig. 2. Chronic sodium bromide treatment reduced stereotypic behaviors and anxiety in Oprm1-

1- mice. See timeline of experiments and animal numbers in Fig. 1A. (A) Chronic $\mathrm{NaBr}$ administration suppressed stereotypic circling episodes in Oprm 1\% mice since the dose of $10 \mathrm{mg} / \mathrm{kg}$ and less consistently reduced the number of head shakes (doses over $125 \mathrm{mg} / \mathrm{kg}$ ). In wild-type controls, $\mathrm{NaBr}$ at $500 \mathrm{mg} / \mathrm{kg}$ increased the frequency of grooming episodes and head shakes. Bumetanide suppressed stereotypic circling and head shakes. (B) In the marble burying test, chronic bromide globally increased the number of buried marbles in both mouse lines; bumetanide failed to demonstrate significant effects. (C) In the $\mathrm{Y}$-maze, $\mathrm{NaBr}$ suppressed perseverative same arm returns from the dose of $70 \mathrm{mg} / \mathrm{kg}$; bumetanide had not significant effect despite an obvious tendency for the dose of $0.5 \mathrm{mg} / \mathrm{kg}$ to relieve perseveration. (D) In the novelty-suppressed feeding test, sodium bromide normalized the latency to feed in Oprm1 null mice to wild-type levels since the lowest dose tested and increased food intake in all 
Derieux et al.

mice; bumetanide had no significant effect in this test. Results are shown as scatter plots and mean \pm sem. Daggers: genotype effect, asterisks: treatment effect, solid stars: genotype $\mathrm{x}$ treatment interaction (comparison with wild-type vehicle condition) (two-way ANOVA followed by Newman-Keuls post-hoc test). One symbol: $p<0.05$, two symbols: $p<0.01$; three symbols: $p<0.001$. More behavioral parameters in Fig. S4.

We assessed anxiety levels in Oprm $1^{-/-}$mice and their WT counterparts using the novelty suppressed feeding test (Fig. 2D). Mutant mice displayed exaggerated anxiety in this test, with increased latency to eat and reduced food intake once back in their home cage. Chronic bromide normalized eating latency (genotype $x$ treatment: $\left.F_{6,160}=6.7, p<0.0001\right)$ to wild-type levels in Oprm1 knockout mice and increased food intake in both mouse lines (treatment: $\left.F_{6,160}=7.0, p<0.0001\right)$ since the lowest dose tested. Chronic bumetanide had no detectable effect on either latency to eat (genotype: $\left.F_{2,42}=27.1, p<0.0001\right)$ or food intake (genotype: $\left.F_{2,42}=5.6, p<0.05\right)$ in this test.

Together, these results indicate that chronic bromide and bumetanide treatments both reduced stereotypic behavior in Oprm1- mice but only bromide treatment demonstrated anxiolytic effects.

In a next series of experiments, we verified that $\mathrm{NaBr}$ administered via oral route (oral gavage 4-5 days, $250 \mathrm{mg} / \mathrm{kg}$ once per day) relieved autistic-like deficits and motor stereotypies in Oprm1\% mice in a similar way as it did after intra-peritoneal injection (Figure S5). Also, we assessed the behavioral effects of chronic administration of another bromide salt, $\mathrm{KBr}$. A dose of $\mathrm{KBr}$ equivalent to $250 \mathrm{mg} / \mathrm{kg} \mathrm{NaBr}$ being toxic in pilot experiments, we thus lowered the dose to $145 \mathrm{mg} / \mathrm{kg} \mathrm{KBr}$, equivalent to $125 \mathrm{mg} / \mathrm{kg}$ $\mathrm{NaBr}$. Beneficial effects of $\mathrm{NaBr}$ treatment in Oprm1\% mice were fully replicated, if not exceeded, by $\mathrm{KBr}$ in tests assessing social, repetitive and anxious behavior (Figure 
Derieux et al.

S6). Thus, therapeutic effects of $\mathrm{NaBr}$ or $\mathrm{KBr}$ in Oprm1\% mice were attributable to bromide ions.

\section{Chronic sodium bromide relieved social behavior deficits, stereotypies and} excessive anxiety in $\mathrm{Fmr1}^{-/-}$and Shank3 $3^{\perp e x 13-16-/-}$ mice

We then questioned whether beneficial effects of $\mathrm{NaBr}$ on autistic-like symptoms may generalize to other mouse models of ASD, here the Fmr1 null and Shank3 $3^{\operatorname{sex} 13-16}$ knockout mouse lines. To this purpose, we evaluated the effects of chronic $\mathrm{NaBr}$ administration at the dose of $250 \mathrm{mg} / \mathrm{kg}$ on autism-sensitive behaviors in these lines (Fig. 3A, more parameters in Fig. S7 and S8).

As concerns social behavior, during a direct social interaction test (Fig. 3B), chronic bromide in $F m r 1^{-1}$ as well as Shank $3^{\operatorname{ex} 13-16-\digamma}$ mice restored the duration of nose (genotype $x$ treatment $-F m r 1: F_{1,30}=49.5, p<0.0001$; Shank3 ${ }^{\text {sex13-16: }} F_{1,28}=73.0$, $p<0.0001$ ) and paw contacts (genotype $x$ treatment- Fmr1: $F_{1,30}=17.7, p<0.0001$; Shank3 $\left.{ }^{\text {ex13-16: }} F_{1,28}=23.2, p<0.0001\right)$, normalized the number of following episodes (genotype $x$ treatment - Fmr1: $F_{1,30}=13.7, p<0.0001$; Shank3 ${ }^{\Delta e x 13-16:} F_{1,28}=11.8$, $p<0.0001$ ) and suppressed grooming after social contact (genotype $x$ treatment- Fmr1: $F_{1,30}=30.1, \quad p<0.0001$; Shank3 $\left.3^{\operatorname{ex} 13-16}: F_{1,28}=25.0, \quad p<0.0001\right)$. One week after interruption of $\mathrm{NaBr}$ treatment (Fig. 3C), significant beneficial effects were still detected on the duration of paw contacts (genotype $x$ treatment: $F 1_{30}=132.7, p<0.0001$ ) and number of grooming episodes after a social contact (genotype $x$ treatment: $F_{1,30=87.0 \text {, }}$ p <0.0001) in Fmr1 null mice. In Shank3 ${ }^{\Delta e \times 13-16}$ mice, no effect of previous bromide treatment was longer detected on the duration of paw contacts (genotype: $F_{1,28}=388.2$, 
Derieux et al.

289

290

291

292

293

294

295

296

297

298

299

300

301

302

303

304

305

306

307

$p<0.0001$ ), whereas grooming after social contact remained efficiently suppressed (genotype $x$ treatment: $\left.F_{1,28}=55.3, p<0.0001\right)$.

We further assessed social behavior under chronic bromide exposure using the 3chamber test (Fig. 3D). Although Fmr1 knockout mice made more frequent nose contacts with the mouse versus the object in this test, they spent as much time in contact with the living mouse as with the object and made longer nose contacts with the object, which demonstrates disrupted social preference. Chronic $\mathrm{NaBr}$ treatment restored a preference for spending more time exploring the mouse (genotype $x$ treatment $x$ stimulus: $\left.F_{1,29}=4.5, p<0.05\right)$ and making longer nose contacts with the mouse versus the object (genotype $x$ treatment $x$ stimulus: $F_{1,29}=18.4, p<0.001$ ) in Fmr1 mutants, which normalized their preference ratio (genotype $x$ treatment:

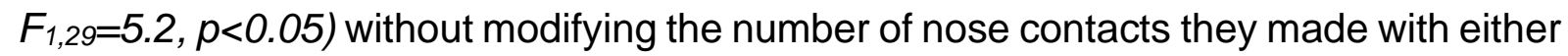

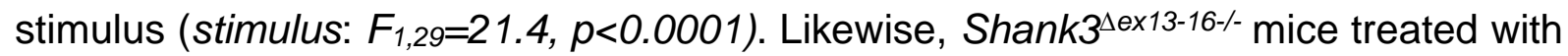
vehicle failed to spend more time with the mouse over the toy in this test; they made more frequent nose contacts with the mouse but of equivalent duration with both stimuli. In contrast, mutants treated with $\mathrm{NaBr}$ spent more time in contact with the mouse (genotype $x$ treatment $x$ stimulus: $F_{1,28}=4.5, p<0.05$ ) and made longer nose contacts with their congener versus the toy (genotype $x$ treatment $x$ stimulus: $F_{1,28}=$ 26.9, $p<0.0001$ ), resulting in increased preference ratio (genotype $x$ treatment: $F_{1,28}=5.9, p<0.05$ ) with no change in the number of nose contacts (stimulus: $F_{1,28}=37.4$, p <0.0001). Thus, chronic $\mathrm{NaBr}$ administration rescued social behavior deficits in Fmr1 null and Shank3 $3^{\operatorname{ex} 13-16}$ knockout mice. 
Derieux et al.

A $\quad \mathrm{NaBr}$ vs vehicle 1 injection/day, IP,
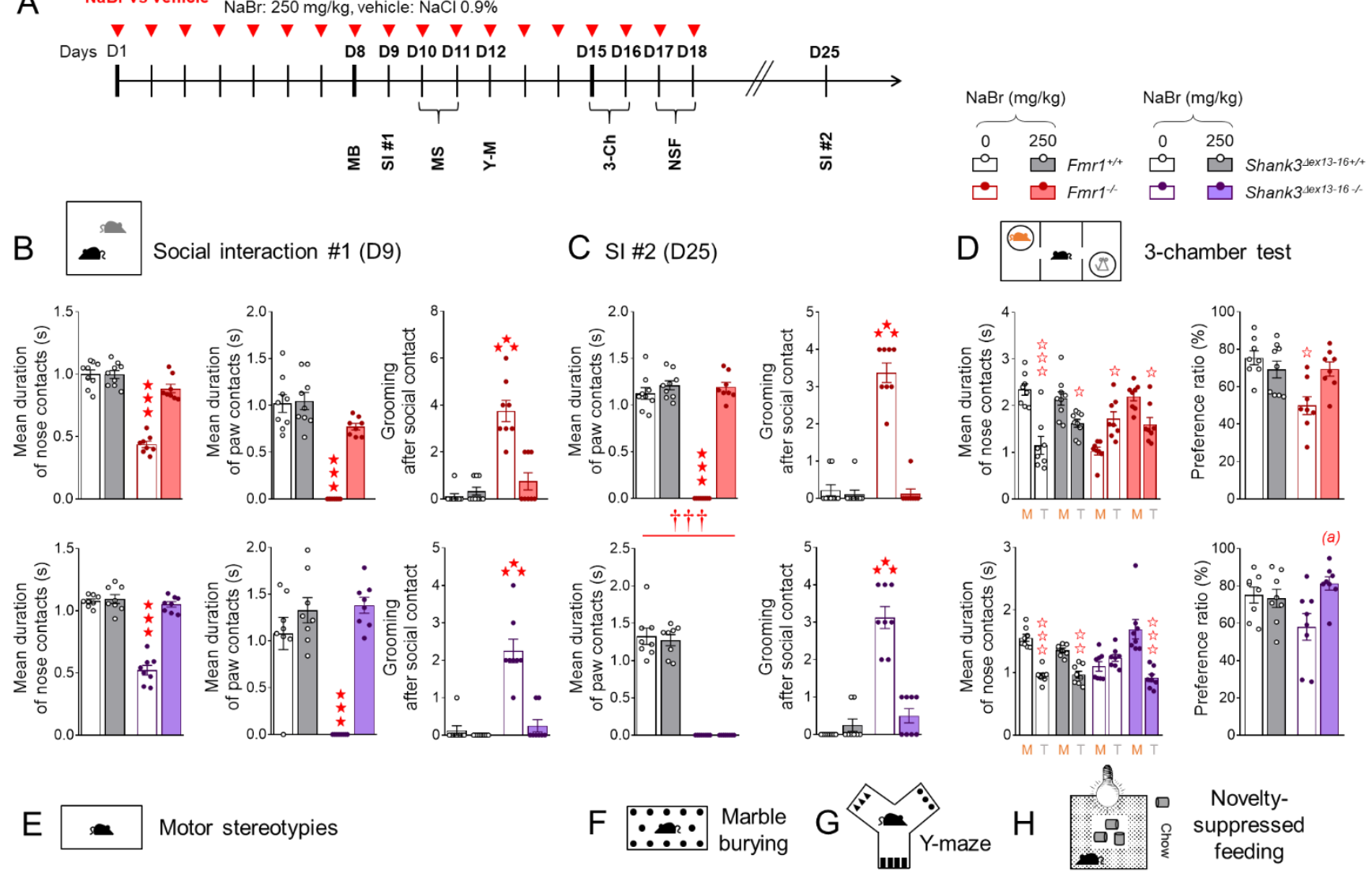

\section{Novelty-} suppressed
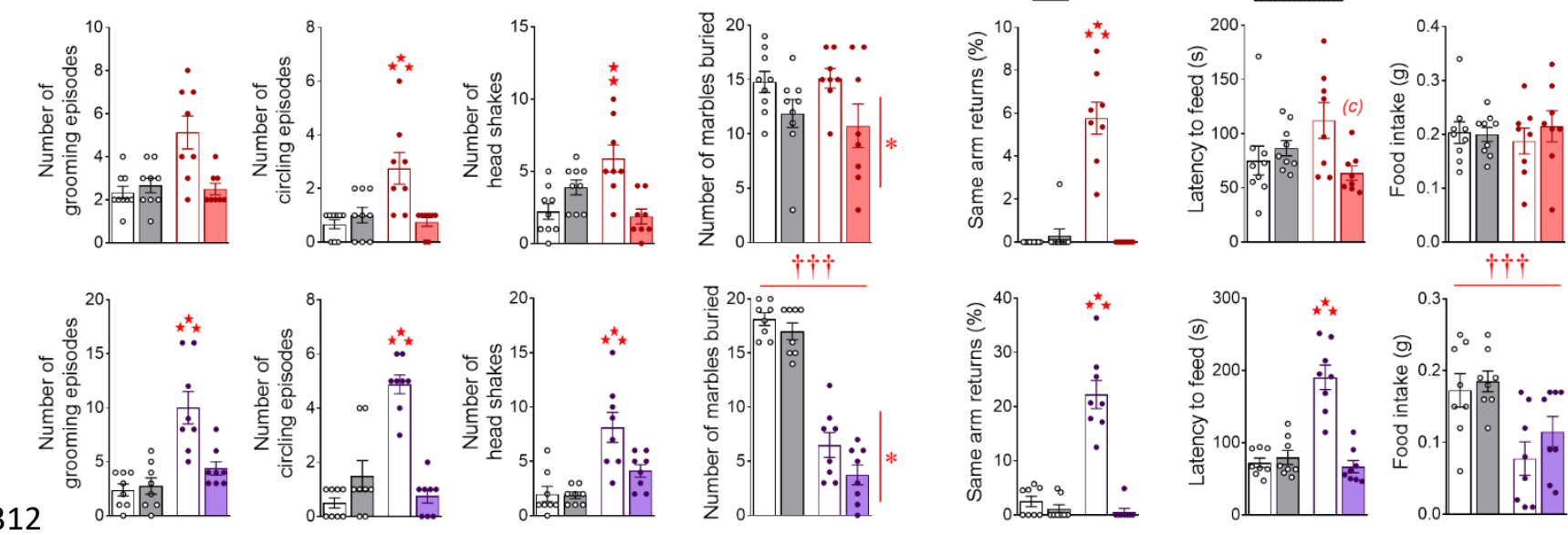

Fig. 3. Chronic sodium bromide administration relieved social behavior deficits, stereotypies

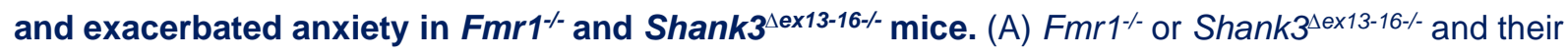
respective wild-type counterparts were treated with $\mathrm{NaBr}$ (0 or $250 \mathrm{mg} / \mathrm{kg} ; \mathrm{n}=8$ mice per genotype and treatment) once daily for 18 days. Behavioral testing started on D8; social interaction was retested 1 week (D25) after cessation of chronic administration.

(B) In the direct social interaction test, chronic $\mathrm{NaBr}$ treatment normalized interaction parameters to wild-type levels in both Fmr1 and Shank3 mutant lines. (C) One week after cessation of treatment, these beneficial effects were fully maintained in Fmr1-

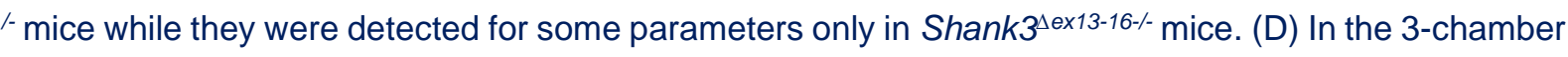


Derieux et al.

test, chronic $\mathrm{NaBr}$ administration rescued preference for making longer nose contacts with the mouse in Shank3 $3^{\Delta e x 13-16-1-}$ mice, resulting in increased preference ratio. (E) Chronic sodium bromide treatment suppressed stereotypic circling and head shakes in $\mathrm{Fmr1}^{-/}$and Shank3 ${ }^{\text {sex13-16-/ }}$ mice and normalized grooming in the latter. (F) $\mathrm{NaBr}$ reduced marble burying in $\mathrm{Fmr1}^{-1-}$ and $\mathrm{Fmr1}^{+/+}$while it had no effect on

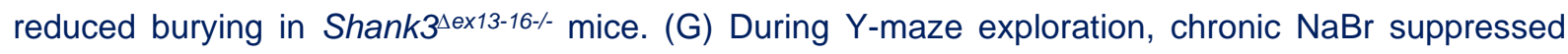
perseverative same arm returns in both Fmr1 and Shank3 mutant lines. (H) Finally, in the noveltysuppressed feeding test, sodium bromide-treated Fmr1\% or Shank3 $3^{\Delta e x 13-16-\%}$ mice displayed reduced or normalized latency to feed, respectively, but no modification in their food intake. Results are shown as scatter plots and mean \pm sem. Daggers: genotype effect, solid stars: genotype $\mathrm{x}$ treatment interaction (comparison to wild-type vehicle condition), open stars: genotype $\mathrm{x}$ treatment $\mathrm{x}$ stimulus interaction (mouse versus object comparison), (a) genotype $\mathrm{x}$ treatment interaction (comparison with knockout vehicle condition, $\mathrm{p}<0.001$ ), (c) genotype $\mathrm{x}$ treatment interaction (comparison to knockout vehicle condition, $\mathrm{p}<0.05$ ) (two-way ANOVA or three-way ANOVA with stimulus as repeated measure, followed by Newman-Keuls post-hoc test). One symbol: $p<0.05$, two symbols: $p<0.01$; three symbols: $p<0.001$. More behavioral parameters in Fig. S7 and S8. 3-Ch: 3-chamber test, AAR: alternate arm returns, M: mouse, MB: marble burying, MS: motor stereotypies, NSF: novelty-suppressed feeding, SAR: same arm returns, SPA: spontaneous alternation, SI: social interaction, T: toy, Y-M: Y-maze.

As regards stereotypic behavior, Fmr1\% and Shank3 ${ }^{\text {sex13-16-/ }}$ mice displayed more frequent spontaneous grooming (significant in the latter only), circling episodes and head shakes than WT controls (Fig. 3E). Chronic NaBr treatment normalized all these parameters to WT levels (Fmr1 - circling, genotype $x$ treatment: $F_{1,30}=11.9, p<0.01$; head shakes, genotype $x$ treatment: $F_{1,30}=68.0, p<0.001$; Shank3 $3^{\Delta e \times 13-16}$ - grooming, genotype $x$ treatment: $F_{1,28}=10.2, p<0.01$, circling, genotype $x$ treatment: $F_{1,28}=48.4$, $p<0.0001$; head shakes, genotype $x$ treatment: $\left.F_{1,28}=5.3, p<0.05\right)$. In the marble burying test (Fig. 3F), chronic $\mathrm{NaBr}$ reduced the number of buried marbles in both Fmr1 ${ }^{+/+}$and $F m r 1^{-/-}$mice (treatment effect: $F_{1,30}=7.3, p<0.05$ ); Shank3 ${ }^{\Delta e x 13-16-\gamma_{-}}$mice displayed a severe deficit in marble burying (genotype effect: $F_{1,28}=198.7, p<0.0001$ ) 
Derieux et al.

and bromide treatment decreased burying in both mutant and WT mice (treatment effect: $\left.F_{1,28}=4.8, p<0.05\right)$. In the Y-maze (Fig. 3G), Fmr1 null and Shank3 ${ }^{\text {sex13-16 }}$ knockout mice displayed more frequent perseverative same arm returns that were suppressed under chronic bromide ( $F m r 1$ - genotype $x$ treatment: $F_{1,30=61.9}$, $p<0.0001$; Shank3 $3^{\operatorname{sex} 13-16}$ - genotype $x$ treatment: $\left.F_{1,28}=47.5, p<0.0001\right)$. Thus, chronic $\mathrm{NaBr}$ treatment reduced stereotypic and perseverative behaviors in $\mathrm{Fmr1}$ andShank3 ${ }^{\text {sex13-16-/- mice. }}$

As regards anxiety, a tendency for Fmr1 null mice for increased latency to eat in the novelty-suppressed feeding test (Fig. $3 \mathrm{H}$ ) did not reach significance; however chronic bromide reduced this latency (genotype $x$ treatment: $F_{1,30}=6.7, p<0.05$ ). Shank3 $3^{\Delta e x 13-}$ 16-- mice took significantly longer to eat in the center of the arena and $\mathrm{NaBr}$ administration normalized this latency to WT levels (genotype $x$ treatment: $F_{1,28}=35.0$, $p<0.0001)$. Bromide treatment had no effect on food intake, reduced in Shank3 ${ }^{\text {ex13-16 }}$ knockout mice (genotype: $F_{1,28}=15.6, p<0.001$ ). Therefore, chronic $\mathrm{NaBr}$ administration demonstrated anxiolytic properties in Fmr1/- and Shank3 ${ }^{\Delta e x 13-16-/-}$ mice.

\section{Chronic sodium bromide modulates transcription in the reward circuit of Oprm1-} I- mice

To shed light on the molecular mechanism involved in beneficial effects of chronic sodium bromide administration, we assessed the effects of a 2-week $\mathrm{NaBr}$ treatment on gene expression in Oprm1 null mice across five regions of the brain reward/social circuit: NAc, CPu, VP/Tu, MeA and VTA/SNc. Mice underwent a first session of social interaction after one week under treatment and a second 45 min before sacrifice for qRT-PCR experiment (Fig. 4A). We focused primarily on genes coding for chloride transporters (Slc12a2 [NKCC1], Slc12a4,5,6,7 [KCC1,2,3,4, respectively], ClCa1), 
Derieux et al.

GABAA $_{A}$ receptor subunits (Gabra1,2,3,4,5, Gabrb1,2) and glutamate receptors $($ Grm2,4,5) and subunits $(G r i n 2 a, 2 b)$. In addition, we evaluated the expression of marker genes of neuronal expression and plasticity (Fos, Bdnf), social behavior (Oxt) and striatal projection neurons (SPNs; Crh, Drd1a, Drd2, Htr6, Pdyn, Penk).

We performed hierarchical clustering analysis of qRT-PCR data for each brain region to visualize the influence of $\mathrm{NaBr}$ treatment on gene expression (Fig. 4B, Table S2). Overall, transcriptional profiles in Oprm $1 \%$ mice under vehicle and $\mathrm{NaBr}$ treatment differed the most, while mRNA levels correlated poorly with social interaction parameters (Fig. S9). These results indicate that bromide induced transcriptional changes on its own rather than it normalized gene expression in Oprm1 knockouts (as observed for behavioral parameters). This was particularly true in the $\mathrm{CPu}$, where Oprm $1 \%$ mice under bromide treatment displayed predominant up-regulated gene expression (clusters a and c).

This overall profile was confirmed when focusing on candidate genes (Fig. 4C). We ought to acknowledge here that the sample number of mice allocated to each experimental condition was low to address the complex influences of genotype and pharmacological treatment, which may have limited the statistical power. For this reason, we focused our attention on gene expression regulations affecting either several brain regions for the same gene, or several genes of the same family. Strikingly, chronic $\mathrm{NaBr}$ administration increased the expression of all tested chloride transporters in Oprm1\% mice. Indeed, the expression of S/c12a2 was decreased in all brain regions but the VP/Tu of mutant mice, and normalized under bromide treatment. Chronic NaBr up-regulated the expression of S/c12a5 and S/c12a7 in the NAc, CPu and MeA of Oprm1 null mice for the former, together with the VP/Tu for the latter. In mutant mice, C/Ca1 mRNA levels were increased in the NAc, MeA and VTA/SNc while 
Derieux et al.

399

400

401

402

403

404

405

406

407

408

409

410

411

reduced in the VP/Tu; they were normalized by $\mathrm{NaBr}$ treatment in the NAc, increased in the VP/Tu and maintained high in the MeA and VTA/SNc. In the CPu, bromide increased $\mathrm{ClCa} 1$ transcription in mice of both genotypes. As regards the GABAergic system, chronic $\mathrm{NaBr}$ in Oprm1\%- mice stimulated the expression of Gabra2, coding for the $\alpha 2$ subunit of the $\mathrm{GABA}_{\mathrm{A}}$ receptor, in the NAc and $\mathrm{CPu}$ and left this expression high in the VP/TU and MeA. Remarkably, bromide consistently upregulated the expression of Gabra3, Gabra4, Gabra5, Gabrg1 and Gabrb2 in the CPu of mutant mice (Table S2). Bromide treatment down-regulated the expression of the early gene Fos in the NAc and VP/Tu and maintained it low in the CPu of Oprm1 knockouts. Oxt (coding for oxytocin) mRNA levels were decreased in the NAc and VP/Tu of Oprm1 1 - mice and normalized by $\mathrm{NaBr}$ in the former and partially in the latter; bromide induced $\mathrm{Oxt}$ expression in the MeA and VTA/SNc. Finally, chronic NaBr upregulated the expression of Grm4, coding for the metabolic glutamate receptor mGlu4, in all brain regions but the VTA/SNc of mutant mice, and in the NAc of wild-type controls. Transcriptional results thus indicate that bromide administration had a major impact on the expression of $\mathrm{Cl}^{-}$transporters; meanwhile it also regulated the expression of several key players of the GABA system, marker genes of neuronal activity and plasticity, and genes more specifically involved in the control of social behavior. 
Derieux et al.

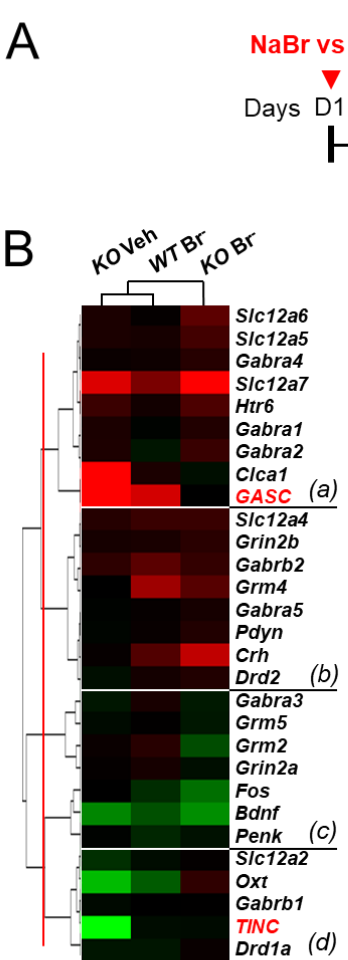

NAc

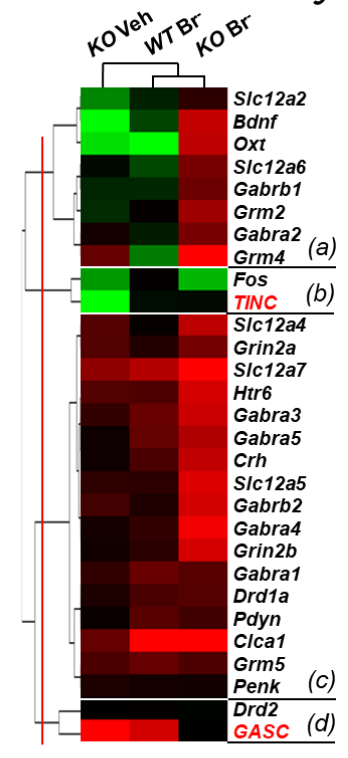

$\mathrm{CPu}$

1 injection/day, IP

$\mathrm{Na} \mathrm{Br}$ : 0 or $250 \mathrm{mg} / \mathrm{kg}$

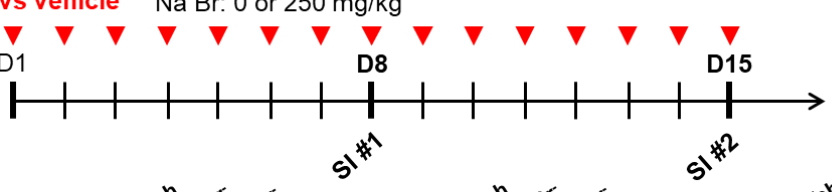

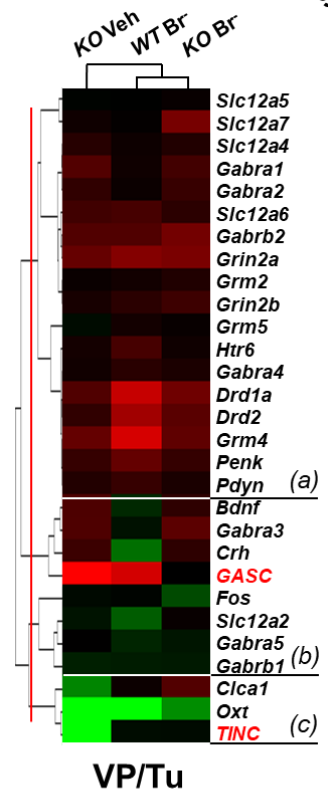

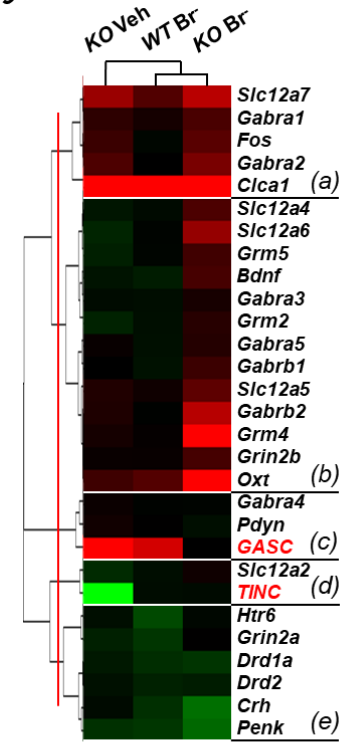

MeA
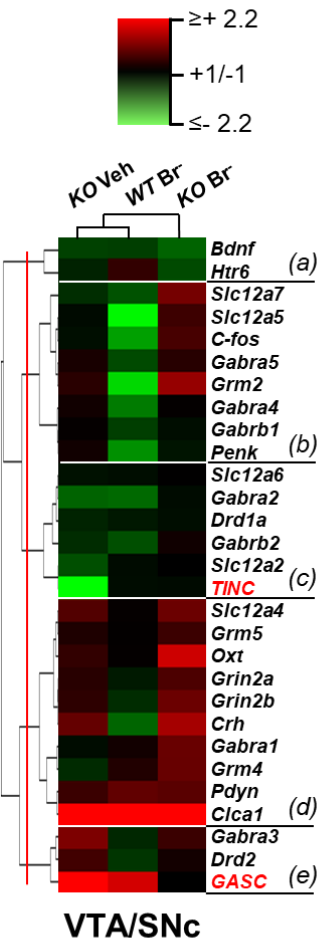

SIc12a5 (kcc2)

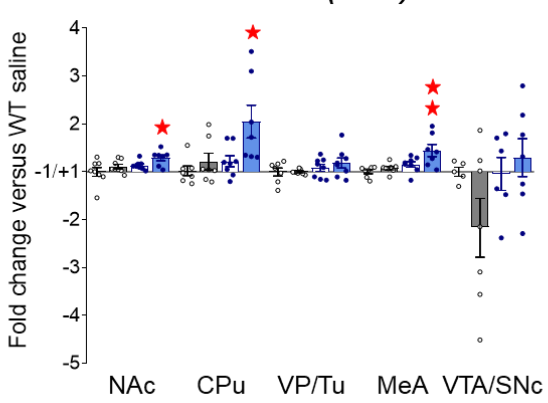

Gabra2

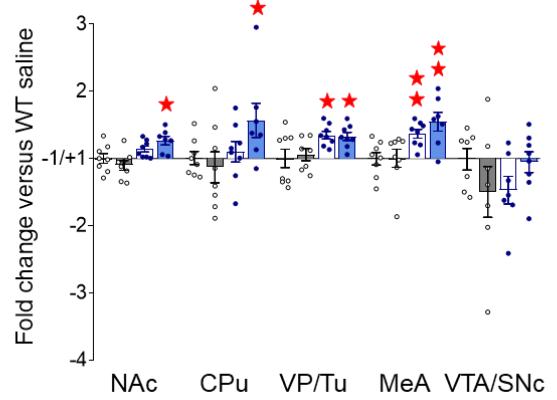

Grm4

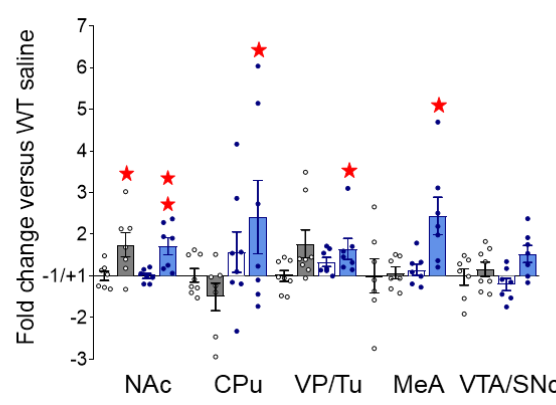

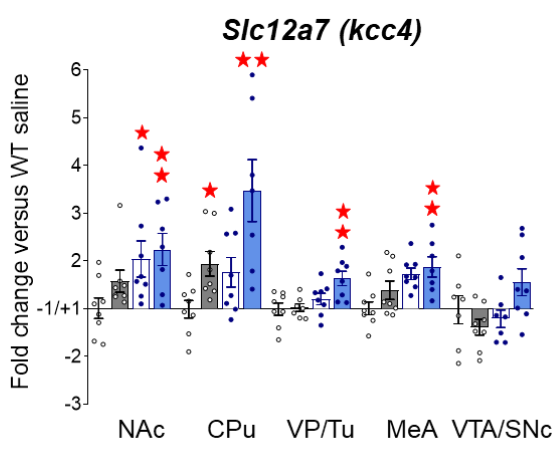

Fos

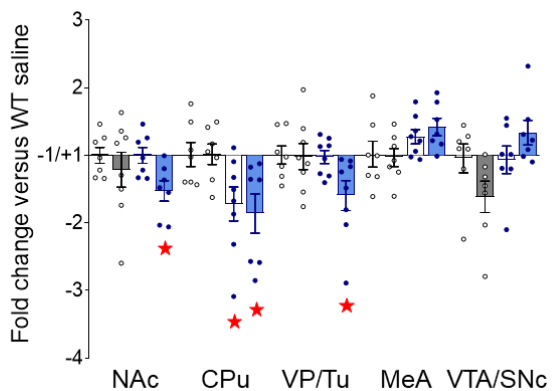

$\mathrm{NaBr}(\mathrm{mg} / \mathrm{kg})$

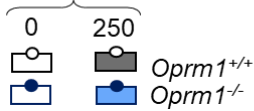


Derieux et al.

Fig. 4. Chronic sodium bromide treatment induced transcriptional modifications in the reward circuit of Oprm 1/ mice. (A) Oprm $1^{1 /+}$ and Oprm 1/ mice were treated for 2 weeks with either vehicle or $\mathrm{NaBr}(250 \mathrm{mg} / \mathrm{kg}$, i.p. once a day). They undergone two sessions of direct social interaction, at D8 and D15, the latter 45 min before sacrifice for qRT-PCR experiment. We evaluated the expression of 27 genes of interest in 5 regions of the reward/social circuit: the NAc, CPu, VP/Tu, MeA and VTA/SNc. (B) Clustering analysis revealed that the most contrasted transcriptional profiles were observed in Oprm $1^{-1}$ mice under $\mathrm{NaBr}$ versus vehicle treatment; mRNA levels, however, were poorly correlated with behavioral parameters (red characters, GASC: grooming after social contact, TINC: time in nose contact). Bromide treatment induced rather than normalized gene expression in Oprm1 null mice, most remarkably in the $\mathrm{CPu}$. (C) Focusing on candidate genes, we unraveled a global upregulation of chloride transporters, notably S/c12a2, S/c12a5 and S/c12a7, coding respectively for NKCC1, KCC2 and KCC4, and Clca1, coding for the calcium-activated chloride channel regulator 1 (CLCA1) and GABA-related genes, among which Gabra2, coding for the $\alpha 2$ subunit of the $\mathrm{GABA}_{\mathrm{A}}$ receptor, in mutant mice under $\mathrm{NaBr}$ treatment. In contrast, Fos expression was reduced in the basal ganglia of $\mathrm{NaBr}$-treated Oprm 1mice while Bdnf expression was up-regulated in the $\mathrm{CPu}$ and $\mathrm{MeA}$. Finally, chronic $\mathrm{NaBr}$ in mutant mice increased the levels of $\mathrm{Oxt}$ and Grm4, coding respectively for oxytocin and mGlu4 receptor, across brain regions. Gene ( $\mathrm{n}=8$ per group) expression data are expressed as fold change versus $O p r m 1^{+/+}$- vehicle group (scatter plots and mean \pm SEM). Comparison to Oprm1+/+ - vehicle group (two-tailed t-test): One star $p<0.05$, two stars $p<0.01$, three stars $p<0.001$. $q R T-P C R$ data used for clustering are displayed in Table S2.

\section{Synergistic effects of chronic bromide and mGlu4 receptor facilitation in Oprm1}

\section{null mice}

Intrigued by the increase in Grm4 transcription in Oprm1\% mice under bromide treatment, whose autistic-like symptoms were relieved when stimulating mGlu4 activity (51), we then addressed the question of a potential shared mechanism of action between these treatments. To this aim, we studied the effects of combined 
Derieux et al.
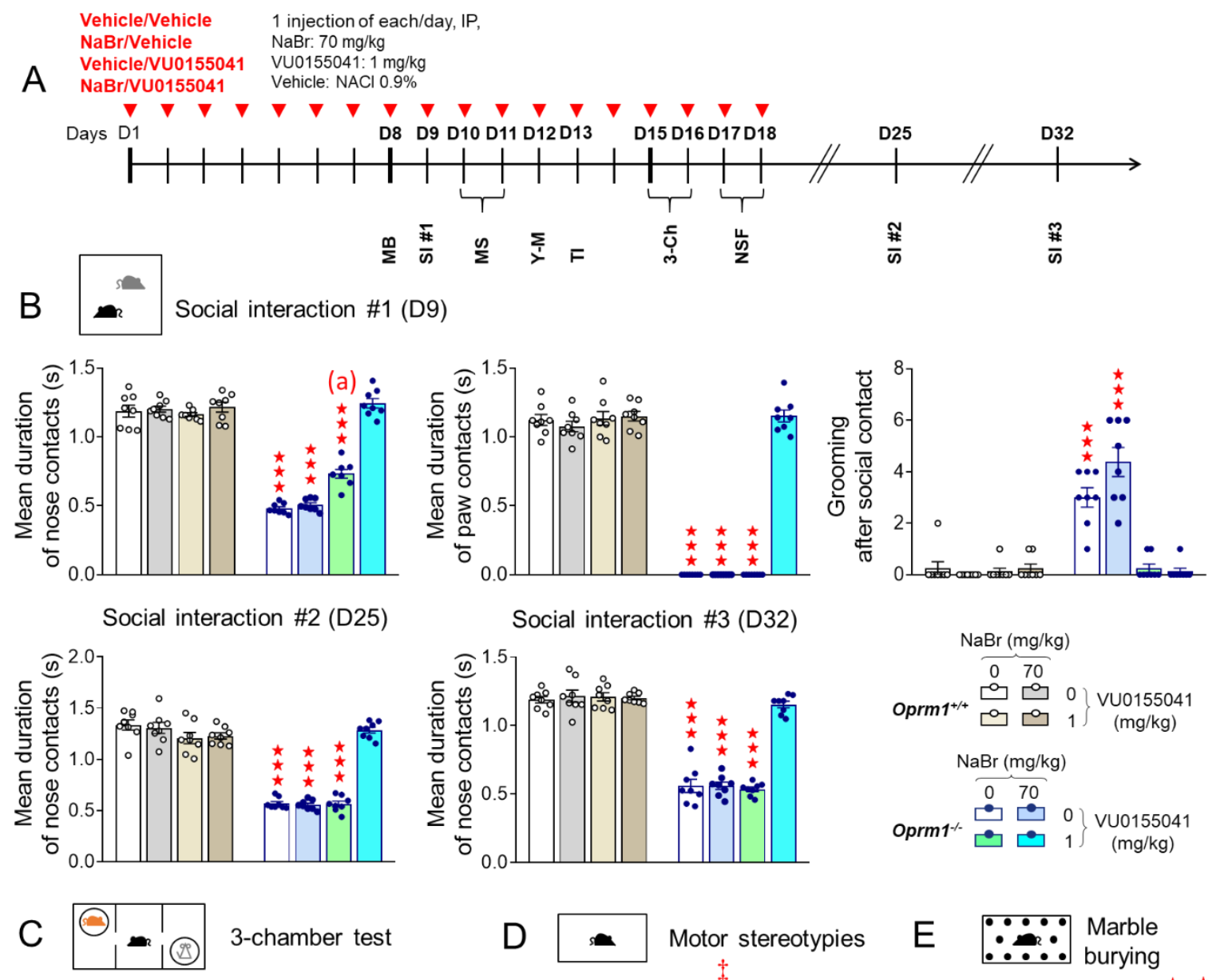

Ses of $\mathrm{NaBr}(70 \mathrm{mg} / \mathrm{kg})$ and VU0155041 (1 mg/kg)
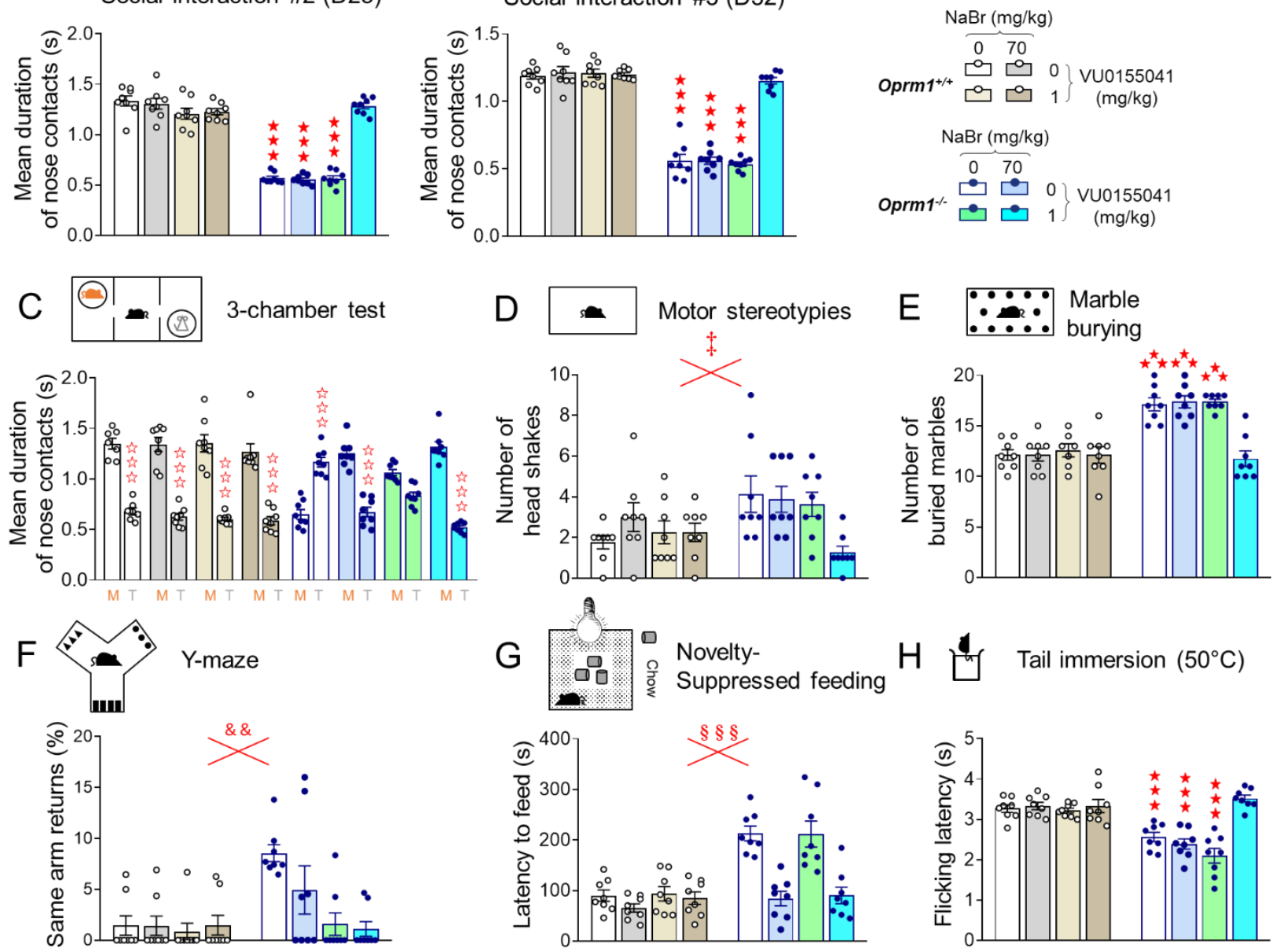

Ses of $\mathrm{NaBr}(70 \mathrm{mg} / \mathrm{kg})$ and VU0155041 (1 mg/kg)

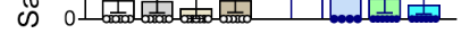

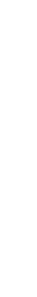


Derieux et al.

Fig. 5. Beneficial effects of sodium bromide and VU0155041, a positive allosteric modulator of mGlu4 receptors, were synergistic in Oprm $1^{-/}$mice. (A) Oprm $1^{+/+}$and Oprm $1^{-/}$mice were treated either with vehicle, $\mathrm{NaBr}(70 \mathrm{mg} / \mathrm{kg})$, VU0155041 (1 mg/kg) or $\mathrm{NaBr}$ and $\mathrm{VU0155041} \mathrm{(70} \mathrm{and} 1 \mathrm{mg} / \mathrm{k}$, respectively; 8 mice per genotype and dose) once daily for 18 days. Behavioral testing started on D8; social interaction was retested 1 week and 2 weeks after cessation of chronic administration. (B) In the direct social interaction test, $\mathrm{NaBr}$ and VU0155041 treatments demonstrated synergistic effects in restoring the duration of nose and paw contacts in Oprm1\% mice. VU0155041 at $1 \mathrm{mg} / \mathrm{kg}$, however, was sufficient to suppress grooming after social contact. Beneficial effects of combined $\mathrm{NaBr} / \mathrm{VU} 0155041$ were fully maintained one and two weeks after cessation of treatment. (C) In the 3-chamber test, VU0155041 at $1 \mathrm{mg} / \mathrm{kg}$ increased the duration of nose contacts with the mouse to that of the toy in Oprm1\% mice; $\mathrm{NaBr}$ at $70 \mathrm{mg} / \mathrm{kg}$ and combined $\mathrm{NaBr} / \mathrm{VU} 0155041$ treatment fully restored longer nose contacts with the mouse. (D) Combined $\mathrm{NaBr} / \mathrm{VU} 0155041$ administration reduced head shakes in Oprm1- and Oprm1+/+ mice and (E) normalized marble burying in Oprm1 null mice only. (F) VU0155041 treatment was sufficient to suppress perseverative same arm returns in Oprm 1/ mice exploring the $\mathrm{Y}$ maze and (G) NaBr administration was sufficient to normalize their latency to feed in novelty-suppressed feeding test. $(\mathrm{H})$ In the tail immersion test at $50^{\circ} \mathrm{C}$, only combined $\mathrm{NaBr} / \mathrm{VU} 0155041$ treatment restored flicking latency of Oprm1\% mice to wild-type levels. Results are shown as scatter plots and mean \pm sem. Solid stars: genotype x NaBr x VU0155041 interaction (comparison to wild-type vehicle condition), open stars: genotype $\mathrm{x}$ stimulus $\mathrm{x} \mathrm{NaBr} \times \mathrm{VU} 0155041$ interaction (mouse versus object comparison), (a) genotype $\times \mathrm{NaBr} \times \mathrm{VU} 0155041$ interaction (comparison with knockout vehicle condition, $\mathrm{p}<0.001$ ), double dagger: $\mathrm{NaBr}$ x VU0155041 interaction, ampersand: genotype x VU0155041 interaction, section: genotype $\mathrm{x} \mathrm{NaBr}$ interaction (three-way or four-way ANOVA followed by Newman-Keuls post-hoc test). One symbol: $p<0.05$, two symbols: $p<0.01$; three symbols: $p<0.001$. 3 -Ch: 3 -chamber test, M: mouse, MB: marble burying, MS: motor stereotypies, NSF: novelty-suppressed feeding, SI: social interaction, T: toy, TI: tail immersion, Y-M: Y-maze. More behavioral parameters in Fig. S10 and S11.

In the direct social interaction test (Fig. 5B), $\mathrm{NaBr}$ at $70 \mathrm{mg} / \mathrm{kg}$ had no detectable effects on behavioral parameters in Oprm1 1/ mice (see Fig. 1B); VU0155041 partially rescued the duration of their nose contacts and suppressed grooming episodes after a social contact. When the two treatments were combined, social interactions 
Derieux et al.

480

481

482

483

484

485

486

487

488

489

490

491

492

493

494

495

496

497

498

499

500

501

502

503

504

parameters in mutant mice were normalized to wild-type levels, as illustrated by rescued duration of nose contacts (genotype $x$ bromide $x$ VU0155041: $F_{1,56}=31.1$, $p<0.0001$ ) or paw contacts (genotype $\times$ bromide $\times$ VU0155041: $F_{1,56}=140.3, p<0.0001$ ) and normalized number of grooming episodes after social contact (genotype $x$ bromide $x$ VU0155041: $\left.F_{1,56}=5.8, p<0.05\right)$. Restoration of the mean duration of nose contacts was fully preserved one (genotype $x$ bromide $x$ VU0155041: $F_{1,56}=40.9, p<0.0001$ ) and

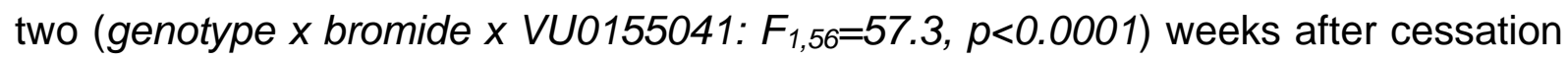
of treatment. In the 3-chamber test, $\mathrm{NaBr}$ at $70 \mathrm{mg} / \mathrm{kg}$ was sufficient to restore longer nose contacts with the mouse versus the toy in Oprm 1\% mice (genotype $x \mathrm{NaBr} x$ stimulus: $\left.F_{1,55}=61.6, p<0.0001\right)$ (Fig. $5 \mathrm{C}$ ).

As regards stereotypic behavior, combined $\mathrm{NaBr}$ and VU0155041 treatments reduced the number of head shakes in Oprm1 ${ }^{-/}$and Oprm1 $1^{+/+}$mice (bromide $x$ VU0155041: $F_{1,56}=4.1, p<0.05$ ) (Fig. 5D) and normalized marble burying in mutants (genotype $x \mathrm{NaBr} \times \mathrm{VU0155041:} F_{1,56=9.5, p<0.001)}$ (Fig. 5E). Chronic VU0155041 was sufficient to suppress perseverative same arm returns during Y-maze exploration in Oprm1 null mice (genotype $x$ VU0155041: $\left.F_{1,56}=11.3, p<0.01\right)$ (Fig. 5F). In the novelty-suppressed feeding test, chronic $\mathrm{NaBr}$ was similarly sufficient to normalize latency to feed (genotype $\times$ VU0155041: $\left.F_{1,56}=11.3, p<0.01\right)$ (Fig. 5G). Finally, having in mind that nociceptive thresholds are lowered in Oprm1 null mice, we tested the effects of bromide and VU0155041 on this parameter. At $50^{\circ} \mathrm{C}$, combined $\mathrm{NaBr}$ and VU0155041 treatment normalized flicking latency, while each compound given alone was ineffective (genotype $\left.\times \mathrm{NaBr} \times \mathrm{VU0155041:} F_{1,56}=20.5, p<0.0001\right)$ (Fig. $5 \mathrm{H}$ ). Together, these results indicate that bromide administration and facilitation of mGlu4 activity exert synergistic beneficial effects on autistic-like behavior in Oprm 1\% mice. 
Derieux et al.

505

506

507

508

509

510

511

512

513

\section{Bromide ions behave as positive allosteric modulators of the mGlu4 glutamate} receptor

Chloride ions have been shown to facilitate mGlu4 signaling (56). Here we assessed whether synergistic in vivo effects of bromide treatment and VU0155041 administration may result from a modulation of mGlu4 activity by bromide ions, in addition to their ability to trigger an upregulation of Grm4 expression (see Fig. 4).

We measured mGlu4 signaling under glutamate stimulation in HEK293T cells transiently expressing mGlu4 receptors and $\mathrm{Ga}_{\mathrm{qi}}$, a $\mathrm{G}_{\mathrm{i}} / \mathrm{G}_{\mathrm{q}}$ chimeric $\mathrm{G}$-protein (57) that allows mGlu4 to activate the phosphoinositide pathway. Receptor activation was then evaluated by measuring intracellular $\mathrm{Ca}^{2+}$ release or inositol monophosphate $\left(\mathrm{IP}_{1}\right.$, Fig. 6A). The experiments were performed in buffers containing either a physiological concentration of chloride ions $(100 \mathrm{mM}$, supplemented with $50 \mathrm{mM}$ gluconate to maintain equivalent osmolarity between mediums), $150 \mathrm{mM}$ of chloride ions (classical buffer for cell culture studies) or $100 \mathrm{mM}$ of chloride ions and $50 \mathrm{mM}$ of bromide ions, to compare the effects of modulating chloride and bromide concentrations within a physiological range on mGlu4 activity.

Compared with physiological concentration of chloride $\left(100 \mathrm{mM} \mathrm{Cl}^{-}+50 \mathrm{mM}\right.$ gluconate), addition of $50 \mathrm{nM}$ bromide significantly improved glutamate potency, showing a $0.73 \pm 0.05$ log increase in $\mathrm{pEC}_{50}$ (left panel; ion concentration: $F_{2,6}=104.2$, $p<0.0001$ ) in the $\mathrm{Ca}^{2+}$ assay (Fig. 6B). Compared with an equivalent concentration of chloride $\left(+50 \mathrm{mM} \mathrm{Cl}^{-}\right)$, bromide showed a higher efficacy $\left(\Delta \mathrm{pEC} \mathrm{C}_{50}: 0.27 \pm 0.04\right)$ (right panel; ion concentration: $\left.F_{2,6}=66.7, p<0.0001\right)$. Further, bromide increased glutamate efficacy, with a $65 \pm 9 \%$ rise in maximal mGlu4-triggered calcium release ( $E_{\max }$, left panel; ion concentration: $\left.F_{2,21}=56.2, p<0.0001\right)$. 
Derieux et al.

When measuring IP 1 production (Fig. $6 \mathrm{C}$ ), bromide increased glutamate efficacy (Emax, maximal IP1 production) within a similar range $(60 \pm 10 \%)$ as observed when measuring $\mathrm{Ca}^{2+}$ release (left panel; ion concentration: $F_{2,24}=22.1, p<0.0001$ ). Despite technical limitations (less amplification at this step of the signaling cascade), $\mathrm{pEC}_{50}$ was consistently increased in presence of bromide ions (left panel; ion concentration: $F_{2,6}=104.2, p<0.0001 ; \Delta \mathrm{pEC}_{50}$ between physiological $\mathrm{Cl}^{-}$concentration and after addition of $50 \mathrm{nM} \mathrm{Br:} 0.42 \pm 0.03$ ) though to a lower extend as those measured in the $\mathrm{Ca}^{2+}$ assay. When $5 \mu \mathrm{M}$ of VU0155041 were added, bromide significantly increased glutamate potency compared with physiological concentration of chloride $\left(\Delta \mathrm{pEC} \mathrm{C}_{50}\right.$ : $0.72 \pm 0.03)$. Bromide and VU0155041 combination was also more effective in increasing glutamate potency than VU0155041 $\left(\Delta \mathrm{pEC}_{50}: 0.39 \pm 0.03\right)$ or bromide $\left(\Delta \mathrm{pEC}_{50}: 0.30 \pm 0.03\right.$ ) alone (ion concentration and VU0155041: $\left.F_{5,12}=49.4, p<0.0001\right)$. In conclusion, bromide ions behaved as PAMs of the mGlu4 receptor in heterologous cells. These PAM effects were superior to those of chloride ions, and synergized with those of VU0155041. Together, these results provide a molecular mechanism for synergistic effects of bromide and VU0155041 in Oprm1 null mice, and suggest that benefits of bromide treatment in mouse models of ASD involved, at least in part, a facilitation of mGlu4 activity. 
Derieux et al.

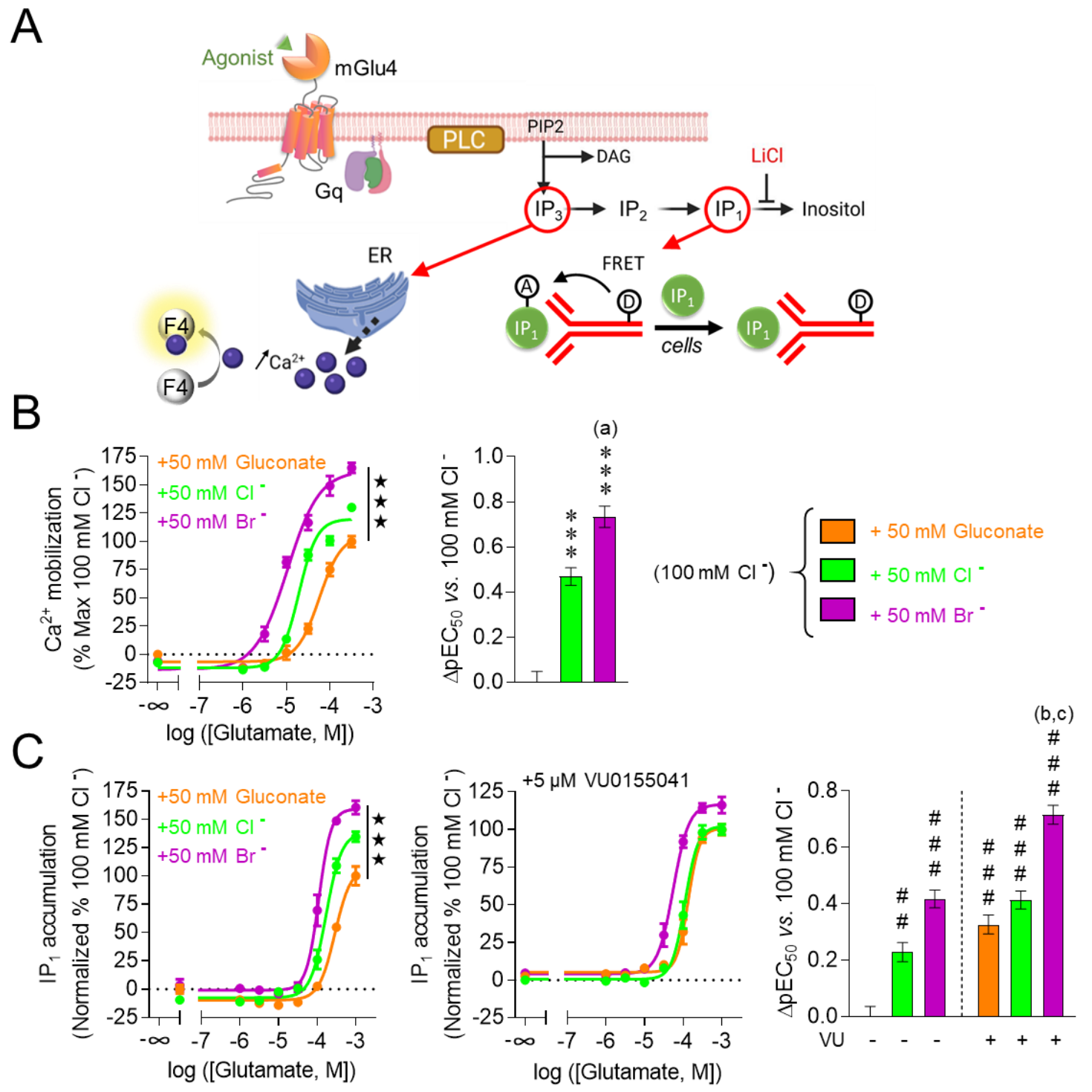

Fig. 6. Bromide ions behave as PAMs of the mGlu4 receptor and shows synergistic effects with

the mGlu4 PAM VU0155041. (A) Signaling cascade of mGlu4 receptor when coupled with the chimeric mobilization assay, bromide ions behave as PAM of mGlu4, demonstrating broader effects than chloride ions on both $\mathrm{pEC}_{50}$ and $\mathrm{E}_{\max }(\mathrm{C})$ In the IP1 accumulation assay, bromide confirmed its PAM effects; when supplemented with VU0155041, facilitation of mGlu4 signaling was even increased, as seen by a further rise in $\triangle \mathrm{pEC} 50$. Results are shown as mean \pm SEM of three independent experiments realized in triplicates. Solid stars: effect of ion concentration on $E_{\max }$; asterisks: effect of ion concentration on $\triangle \mathrm{pEC}_{50}$, comparison with physiological conditions (100 $\mathrm{mM} \mathrm{Cl}^{-}+50 \mathrm{mM}$ gluconate); (a): comparison with 
Derieux et al.

560

561

562

563

564

565

566

567

568

569

570

571

572

573

574

575

576

577

578

579

580

581

582

583

584

high chloride condition ( $150 \mathrm{mM} \mathrm{Cl}^{-}, \mathrm{p}<0.0001$ ); hashtags: effect of ion concentration and VU0155041 on $\triangle \mathrm{pEC} 50$, comparison with physiological conditions $\left(100 \mathrm{mM} \mathrm{Cl}^{-}+50 \mathrm{mM}\right.$ gluconate); (b) and (c): comparison with bromide conditions $\left(100 \mathrm{mM} \mathrm{Cl}^{-}+50 \mathrm{mM} \mathrm{Br}-\right)$ with or without VU0155041 ( $\left.p<0.0001\right)$ (One-way ANOVA, followed by Tukey's post-hoc test). Two symbols: $p<0.001$, three symbols: $p<0.0001$. DAG: diacylglycerol; ER: endoplasmic reticulum; F4: Fluo4 calcium probe; FRET: fluorescence

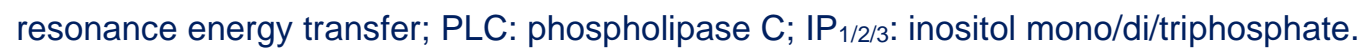

\section{DISCUSSION}

In the current study, we tested whether bromide ions would relieve autistic-like symptoms in mouse models of ASD. We first assessed bromide effects in the Oprm11- mouse model of $A S D$, which recapitulates a wide range of autistic-like core and secondary symptoms, including severe deficits in social interaction and communication (51, 58-61), stereotypic behavior, exacerbated anxiety $(51,60)$ and increased susceptibility to seizures $(51,62)$ but displays preserved cognitive performance $(52)$. In this model, chronic bromide dose-dependently rescued social behavior. $\mathrm{NaBr}$ treatment improved direct social interaction from the dose of $125 \mathrm{mg} / \mathrm{kg}$, with complete rescue at $250 \mathrm{mg} / \mathrm{kg}$. These doses are in the lower range of acute anticonvulsant of bromide in rodents $(0.2$ to $2 \mathrm{~g} / \mathrm{kg})(63,64)$ and slightly superior to chronic $\mathrm{KBr}$ antiepileptic doses in dogs $(20-100 \mathrm{mg} / \mathrm{kg} /$ day; initial dose up to $500 \mathrm{mg} / \mathrm{kg})(65,66)$ and humans $(30-100 \mathrm{mg} / \mathrm{kg} /$ day $)(67,68)$. In the 3-chamber test, beneficial effects of chronic $\mathrm{NaBr}$ were detected since the dose of $10 \mathrm{mg} / \mathrm{kg}$. In this test, however, social interactions occur only when the experimental mouse investigates its congener, with limited reciprocity. In contrast, social contacts during dyadic interaction are reciprocal, which can be stressful for each protagonist, justifying the long use of this test to 
Derieux et al.

585

586

587

588

589

590

591

592

593

594

595

596

597

598

599

600

601

602

603

604

605

606

607

608

609

measure anxiety levels (69). Yet, these data suggest that beneficial effects of $\mathrm{NaBr}$ on social behavior can be reached since the dose of $10 \mathrm{mg} / \mathrm{kg}$.

Compared with chronic treatment, acute administration of $\mathrm{NaBr}$ had only minor effects on social interaction in Oprm1 null mice, showing that bromide needed to accumulate to reach therapeutic efficacy, as observed in the clinics (68). Consistent with this, blood concentrations of bromide ions are known to progressively increase upon chronic treatment $(70,71)$. As its clearance is slow, bromide has a rather long half-life, about 8-14 days in human adults $(68,72)$. This pharmacokinetic profile may account for the carry-over effects of $\mathrm{NaBr}$ treatment detected in Oprm1\% mice. $\mathrm{NaBr}$ also reduced stereotypic and perseverative behaviors in Oprm1 knockouts, since the dose of $10-30 \mathrm{mg} / \mathrm{kg}$, indicating benefit on the second diagnostic criteria for ASD. To date, no approved treatment ameliorates both diagnostic dimensions of autism. Behavioral improvements were replicated after repeated oral administration of $\mathrm{NaBr}$, in agreement with previous reports of oral bioavailability (72). Further, bromide treatment, known as anxiolytic (45), consistently decreased anxiety levels in Oprm 1/mice, a significant advantage as anxiety disorders are among the most frequent comorbidities in $\operatorname{ASD}(3,5)$. Finally, beneficial effects of chronic $\mathrm{NaBr}$ administration in Oprm 1/- mice were replicated using $\mathrm{KBr}$, long used as an antiepileptic drug in human (47) and veterinary (65) medicine, despite its narrow therapeutic window due to cardiotoxicity of potassium ions $\left(\mathrm{K}^{+}\right)(73)$. Convergent effects of $\mathrm{NaBr}$ and $\mathrm{KBr}$ salts demonstrate that bromide ions are indeed the active compound to relieve ASD-like symptoms.

Effects of chronic $\mathrm{NaBr}$ administration were compared to those of the NKCC1 inhibitor bumetanide. Although the most promising drug developed based on the $E / l$ balance hypothesis, bumetanide has been scarcely tested in animal models of ASD. 
Derieux et al.

We observed partial beneficial effects of chronic bumetanide on autistic-like behavior in Oprm 1\% mice. In contrast, previous studies have reported a complete rescue of autistic-like social deficits following bumetanide treatment in animal models of ASD, but under conditions where bumetanide was administered preventively rather than curatively. Indeed, bumetanide restored social communication in two rodent models of ASD, rats exposed to valproate in utero and Fmr1 knockout mice, when their mothers were treated with bumetanide during pregnancy (40). Similarly, repeated bumetanide administration rescued social preference when used to prevent early-life seizures in rats (74). In the present study, bumetanide was given in adult Oprm1\% mice, when neurodevelopmental deficits were fully installed, which may account for partial improvements. These effects were consistent with clinical reports of beneficial effects of the NKCC1 antagonist on social abilities in children and adults with ASD diagnosis $(41,42)$, maybe too subtle however to be confirmed in larger cohorts $(43)$, whilst this treatment efficiently reduced stereotypic behavior (43). Importantly, such consistency confers predictive value to the Oprm1 null mouse model, boding well for clinical translation of bromide effects.

After comprehensive testing in Oprm1 null mice, we extended our observation of beneficial effects of bromide administration to two additional mouse models, Fmr1-1and Shank $3^{\Delta e \times 13-16-/-}$ mice, with longer-lasting effects in the former. Interestingly, the three models of ASD used in this study differed in their genetic cause and E/I profile. As regards excitatory neurotransmission, Fmr1 mutants display more frequent miniature excitatory postsynaptic currents (mEPSCs) in the hippocampus (40), persistent activity states in the somatosensory cortex (75) and excessive mGluR1/5dependent signaling $(75,76)$, suggesting a global facilitation of glutamatergic transmission. Mutations in Shank3 lead to reduced frequency and amplitude of 
Derieux et al.

635

636

637

638

639

640

641

642

643

644

645

646

647

648

649

650

651

652

653

654

655

656

657

658

659

mEPSCs in the striatum $(55,77)$ and hippocampus (78) and reduced long-term potentiation (LTP) in these two structures $(79,80)$; in Oprm1\% mice, hippocampal LTP is decreased (52) and the morphology of asymmetrical synapses is altered in the striatum while the expression of key glutamate-related genes is reduced (51). These data point to impaired glutamatergic neurotransmission in the latter models. On the inhibition side, multiple alterations of the GABAergic system have been documented in Fmr1 null mice $(81,82)$, with reduced expression of GABAA receptor subunits $(27$, 30, 82) and consistent impairment in GABAergic transmission (30, 83). Such deficit, however, is not observed in the striatum, where GABA release is increased (84), possibly a consequence of impaired endocannabinoid-mediated long-term depression (LTD) that represses the activity of D2 dopamine receptor-expressing striatal projection neurons (D2-SPNs) (53). Remarkably, endocannabinoid-mediated LTD is also deficient in Shank3 $3^{\operatorname{ex13-16}}$ mice, and consequent excessive D2-SPN tone has been linked to stereotyped behavior (85). In Oprm 1/- mice, facilitating the activity of mGlu4 receptor, which is known to repress D2-SPN activity (86), relieved autistic-like behavior (51). Together, these data designate GABAergic D2-SPNs as a potential common target for bromide effects on the E/I balance across mouse models.

Transcriptional effects of chronic bromide treatment in Oprm1\% versus Oprm $1^{+/+}$ mice are consistent with an influence on the $\mathrm{E} / \mathrm{l}$ balance. In the absence of $\mathrm{NaBr}$ treatment, Oprm1 null mice displayed low levels of Slc12a2 transcripts (NKCC1), suggesting that $\mathrm{Cl}^{-}$gradient was altered. Strikingly, $\mathrm{NaBr}$ administration restored or increased the expression of all genes coding for $\mathrm{Cl}^{-}$co-transporters tested in these mice, the importer NKCC1 as well as the exporters KCC2-4 and CLCA1 (a modulator of the calcium-activated $\mathrm{Cl}^{-}$channel Anoctamine-1/TMEM16A (87)). All these transporters have been related to autistic-like features in mouse models $(40,88,89)$, 
Derieux et al.

660

661

662

663

664

665

666

667

668

669

670

671

672

673

674

675

676

677

678

679

680

681

682

683

684

putting a spell on chloride homeostasis as a core neurobiological mechanism in ASD.

Increased expression of $\mathrm{Cl}^{-}$transporters under chronic $\mathrm{NaBr}$ treatment may have been a regulatory response triggered by $\mathrm{Br}^{-}$accumulation, to maintain the extracellular/intracellular gradient of anion concentrations. $\mathrm{Cl}^{-}$and $\mathrm{Br}$ sharing similar physicochemical properties, this increase likely favored a high turnover of both anion species and, thus, depolarizing effects of GABA (90). Moreover, chronic bromide increased the transcription of genes coding for several GABAA receptor subunits. Previous studies in the field of epilepsy have evidenced a facilitating influence of bromide on GABAergic inhibition $(48,91)$. Together, these data suggest that $\mathrm{NaBr}$ treatment increased GABA-mediated inhibition. Accordingly, Fos expression was decreased in the basal ganglia of Orpm1 null mice following social interaction, a likely consequence of facilitated GABAergic inhibition.

Besides effects on $\mathrm{E} / \mathrm{l}$ balance, bromide treatment in Oprm1 1/ mice stimulated the expression of $O x t$, coding for the social neuropeptide oxytocin, notably in the NAc, where it plays a key role in modulating social reward (92). We observed similar restoration in Oprm 1\% mice after that they undergone an appetitive social conditioning (60). Moreover, oxytocin administration rescued social ultrasonic vocalizations in Oprm1 null mice (93). Thus, restored Oxt mRNA levels in mutants may have contributed to behavioral improvements under bromide administration. Finally, although Grm4 mRNA levels were not low in the striatum of Oprm1- mice as in previous studies $(51,60)$, maybe due to different experimental conditions, chronic $\mathrm{NaBr}$ increased its expression in most brain regions studied. By facilitating mGlu4 expression, bromide may thus have relieved autistic-like symptoms, as observed under facilitation of mGlu4 activity by VU0155041 treatment $(51,94)$. We challenged this hypothesis by co-administering liminal doses of bromide and VU0155041 to Oprm1-1- 
Derieux et al.

685

686

687

688

689

690

691

692

693

694

695

696

697

698

mice, and revealed a major synergistic effect. Moreover, we evidenced that, in heterologous cells, bromide ions behave as better mGlu4 PAMs than it was previously shown for chloride ions (56). This finding suggests that beneficial effects of $\mathrm{Br}^{-}$in ASD models involve a facilitation of mGlu4 signaling. Moreover, the PAM effect of bromide synergizes with that of VU0155041, providing a molecular mechanism for synergy in vivo. Yet, this mechanism may not have been the only one. At cellular level, VU0155041 represses the activity of D2-SPNs (86), found disinhibited in Fmr1 ${ }^{-1}$ and Shank3 $3^{\operatorname{ex} 13-16-\%}$ mice, while bromide promotes GABAergic transmission. Thus, synergistic action of bromide and mGlu4 PAM may also lie in their common inhibition of a neuronal population, D2-SPNs, a hypothesis that will deserve further investigation. Hence, bromide ions act at multiple levels, on chloride gradient, GABA-mediated neurotransmission and mGlu4 signaling, which all converge towards neuronal inhibition, and this may account for its large spectrum of beneficial effects in mouse models of ASD (Figure 7). 
Derieux et al.

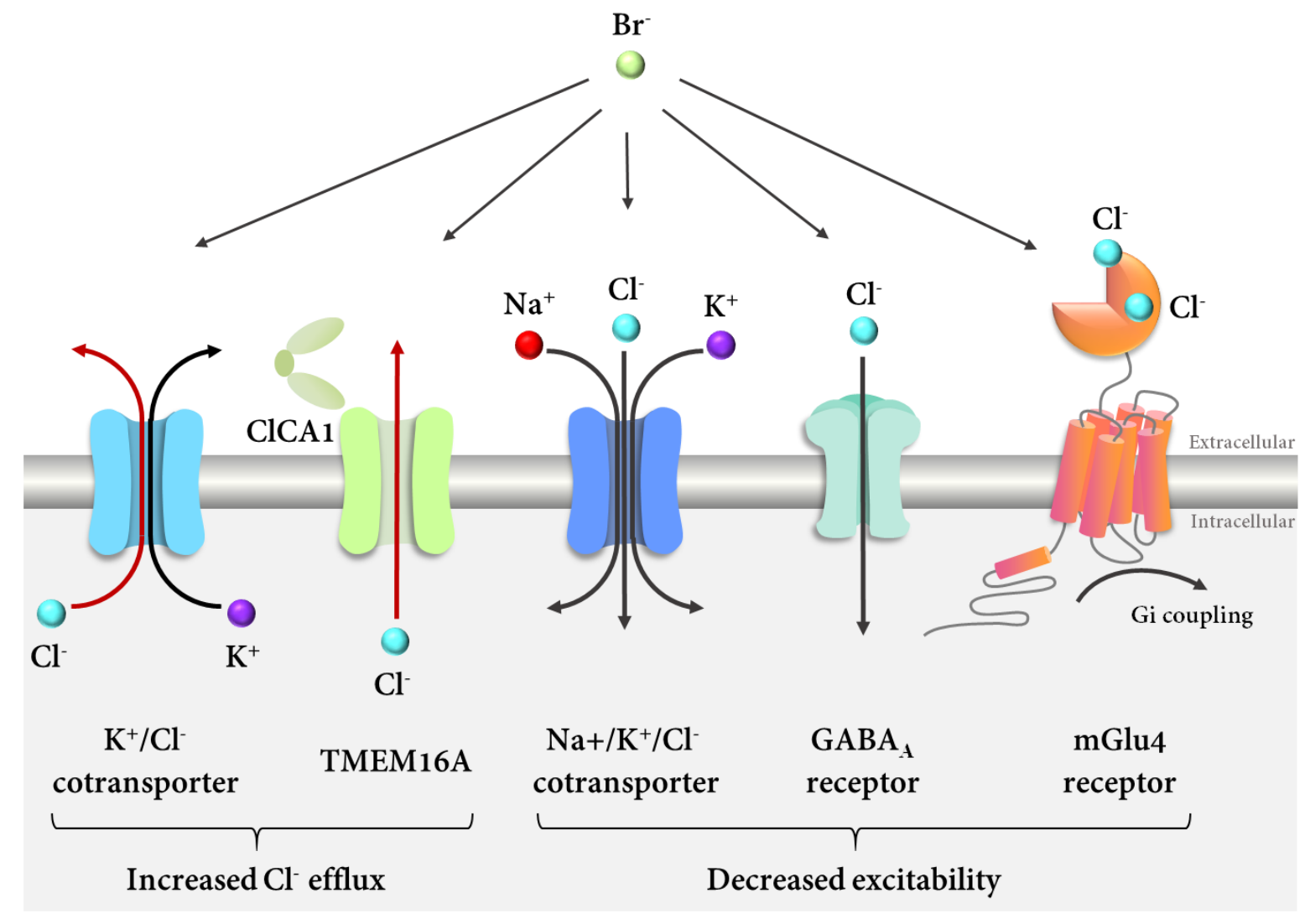

699

700

701

702

703

704

705

706

707

708

709

710

Fig. 7. Different cellular mechanisms by which bromide ions may modulate E/I balance and neurotransmission in the autistic brain. At transcriptional level, chronic bromide treatment upregulated the expression of genes coding for $\mathrm{Cl}^{-}$extruders KCCs and the secreted activator of TMEM16A, CICA1, in Oprm1\% mice. By such mechanism, bromide ions may have increased $\mathrm{Cl}^{-}$efflux (dark red), making $\mathrm{Cl}^{-}$more available within the extracellular compartment. In parallel, bromide was found to induce the expression of genes coding for NKCC1, GABA and the mGlu4 receptor in Oprm1 mutants. Interestingly, increased extracellular $\mathrm{Cl}^{-}$concentrations facilitate the activation of these three molecular actors, which converges towards decreased neuronal excitability. All previous mechanisms would thus concur to increase neuronal inhibition. Intriguingly, due to its physicochemical properties, $\mathrm{Br}^{-}$ can substitute to $\mathrm{Cl}^{-}$at all levels; by binding to mGlu4, it behaves as a positive allosteric modulator of this receptor, even more potent than $\mathrm{Cl}^{-}$. ClCa1 and TMEM16A representations were adapted from (87) and $\mathrm{Cl}^{-}$location on mGlu4 from (56).

We ought to consider here some limitations of this study. The low sample number of mice from both sexes allocated to each genotype and treatment group resulted in low statistical power to examine the complex interactions between genotype and 
Derieux et al.

bromide effects in our transcriptional study. Further investigations will be required to explore the molecular mechanisms underlying beneficial effects of bromide in mouse models of ASD. Also, we tested the effects of bromide treatment in adult mice whilst autism is diagnosed early in life and early behavioral/cognitive interventions have proven to be more efficient in relieving autistic features $(95,96)$. In future studies, we will administer bromide at young age in mouse models of ASD to delineate the optimal developmental window for its therapeutic action. Whether it would not be verified in youngsters, though, therapeutic benefit of bromide treatment would remain a major breakthrough in the field of autism, which affects a large and highly vulnerable population of adults worldwide (97).

In conclusion, the present study reports the therapeutic potential of chronic bromide treatment, alone or in combination with a PAM of mGlu4 receptor, to relieve core symptoms of ASD. Beneficial effects of bromide were observed in three mouse models of ASD with different genetic causes, supporting high translational value. Moreover, bromide has a long history of medical use, meaning that its pharmacodynamics and toxicity are well known, which, combined with long lasting effects as well as excellent oral bioavailability and brain penetrance, are strong advantages for repurposing. 
Derieux et al.

\section{MATERIALS AND METHODS}

Key resources table

\begin{tabular}{|c|c|c|c|c|}
\hline $\begin{array}{l}\text { Reagent type } \\
\text { (species) or } \\
\text { resource } \\
\text { information }\end{array}$ & Designation & Source or reference & Identifiers & Additiona \\
\hline $\begin{array}{l}\text { Chemical } \\
\text { compound, drug }\end{array}$ & $\mathrm{NaBr}$ & $\begin{array}{l}\text { Sigma-Aldrich, } \\
\text { Saint-Quentin } \\
\text { Fallavier, France }\end{array}$ & Cat\# 310506 & \\
\hline $\begin{array}{l}\text { Chemical } \\
\text { compound, drug }\end{array}$ & $\mathrm{KBr}$ & $\begin{array}{l}\text { Sigma-Aldrich, } \\
\text { Saint-Quentin } \\
\text { Fallavier, France }\end{array}$ & Cat\# 243418 & \\
\hline $\begin{array}{l}\text { Chemical } \\
\text { compound, drug }\end{array}$ & Bumetanide & $\begin{array}{l}\text { R\&D systems, } \\
\text { Minneapolis, USA }\end{array}$ & Cat\# 3108 & \\
\hline $\begin{array}{l}\text { Chemical } \\
\text { compound, drug }\end{array}$ & VU0155041 & $\begin{array}{l}\text { Cayman Chemical, } \\
\text { Ann Arbor, USA }\end{array}$ & Cat\# 21775 & \\
\hline $\begin{array}{l}\text { Chemical } \\
\text { compound, drug }\end{array}$ & L-glutamic acid & $\begin{array}{l}\text { Sigma-Aldrich, } \\
\text { Saint-Quentin } \\
\text { Fallavier, France }\end{array}$ & Cat\# G1251 & \\
\hline $\begin{array}{l}\text { Chemical } \\
\text { compound, drug }\end{array}$ & Fluo-4 AM & $\begin{array}{l}\text { Invitrogen, Life } \\
\text { Technologies, } \\
\text { Thermo Fisher } \\
\text { Scientific, Carlsbad, } \\
\text { CA, US }\end{array}$ & \#Cat F14201 & \\
\hline Material & $\begin{array}{l}\text { CFX384 Touch Real-Time } \\
\text { PCR Detection System }\end{array}$ & $\begin{array}{l}\text { Biorad, Marnes-la- } \\
\text { Coquette, France }\end{array}$ & & \\
\hline
\end{tabular}


Derieux et al.

\begin{tabular}{|c|c|c|c|}
\hline Material & $\mu$ Cell FDSS & $\begin{array}{l}\text { Hamamatsu } \\
\text { Photonics, Massy, } \\
\text { France }\end{array}$ & \\
\hline Material & Pherastar FS & $\begin{array}{l}\text { BMG Labtech, } \\
\text { Champigny } \\
\text { s/Marne, France }\end{array}$ & \\
\hline Material & Infra-red floor & $\begin{array}{l}\text { Videotrack; View } \\
\text { Point, Lyon, France }\end{array}$ & \\
\hline Material & Y-maze & $\begin{array}{l}\text { Imetronic, Pessac, } \\
\text { France }\end{array}$ & \\
\hline Cell line & HEK 293FT cell line & $\begin{array}{l}\text { ThermoFisher } \\
\text { Scientific Inc, } \\
\text { Waltham, } \\
\text { Massachusetts, } \\
\text { USA }\end{array}$ & Cat\# R70007 \\
\hline $\begin{array}{l}\text { Commercial } \\
\text { assay or kit }\end{array}$ & Direct-Zol RNA MiniPrep kit & $\begin{array}{l}\text { Zymo research, } \\
\text { Irvine, USA }\end{array}$ & Cat\# ZR2052 \\
\hline $\begin{array}{l}\text { Commercial } \\
\text { assay or kit }\end{array}$ & $\begin{array}{l}\text { ProtoScript II Reverse } \\
\text { Transcriptase kit }\end{array}$ & $\begin{array}{l}\text { New England } \\
\text { BioLabs, Évry- } \\
\text { Courcouronnes, } \\
\text { France }\end{array}$ & Cat\# M0368X \\
\hline $\begin{array}{l}\text { Commercial } \\
\text { assay or kit }\end{array}$ & iQ-SYBR Green supermix & $\begin{array}{l}\text { Bio-Rad, Marnes- } \\
\text { la-Coquette, France }\end{array}$ & $\begin{array}{l}\text { Cat\# } \\
1725006 \text { CUST }\end{array}$ \\
\hline $\begin{array}{l}\text { Commercial } \\
\text { assay or kit }\end{array}$ & IP-One Gq Kit & $\begin{array}{l}\text { CisBio, } \\
\text { PerkinEImer, } \\
\text { Codolet, France }\end{array}$ & Cat\# 62IPAPEB \\
\hline
\end{tabular}


Derieux et al.

\begin{tabular}{|c|c|c|c|}
\hline $\begin{array}{l}\text { Strain, strain } \\
\text { background (mus } \\
\text { musculus) }\end{array}$ & $\begin{array}{l}\text { Oprm1 } 1^{+/+} \text {and Oprm 1-/, } \\
50 \% \quad 129 S \text { Pas }-50 \% \\
\text { C57BL/6J }\end{array}$ & $\begin{array}{l}\text { Jackson } \\
\text { Laboratories, } \\
\text { Farmington, USA }\end{array}$ & $\begin{array}{l}\text { B6.129S2- } \\
\text { Oprm1 } 1^{\mathrm{tm} 1 \mathrm{Kff} / \mathrm{J}}\end{array}$ \\
\hline $\begin{array}{l}\text { Strain, strain } \\
\text { background (mus } \\
\text { musculus) }\end{array}$ & $\begin{array}{lr}\text { Shank3 } 3^{\operatorname{sex} 13-16+/+} & \text { and } \\
\text { Shank3 } & \text { Sex13-16-/, } \\
\text { 129SVPas - 50\% C57BL/6J }\end{array}$ & $\begin{array}{l}\text { Jackson } \\
\text { Laboratories, } \\
\text { Farmington, USA }\end{array}$ & $\begin{array}{l}\text { B6.129- } \\
\text { Shank3tm2Gfng/J }\end{array}$ \\
\hline $\begin{array}{l}\text { Strain, strain } \\
\text { background (mus } \\
\text { musculus) }\end{array}$ & $\begin{array}{l}\mathrm{Fmr}^{+/+} \text {and } \\
\text { C57BL/6J }\end{array}$ & $\begin{array}{l}\text { R. Willemsen, } \\
\text { Mientjes et al. } 2006\end{array}$ & $\mathrm{KO}(2)$ \\
\hline
\end{tabular}

\section{Animals, breeding procedures and housing conditions}

The Oprm1 $1^{-/} \quad\left(B 6.129 S 2-O p r m 1^{\mathrm{tm} 1 \mathrm{Kff} / \mathrm{J})}\right.$

(98) and

Shank3 $3^{4 \text { ex13-16-/ }}$

(B6.129-

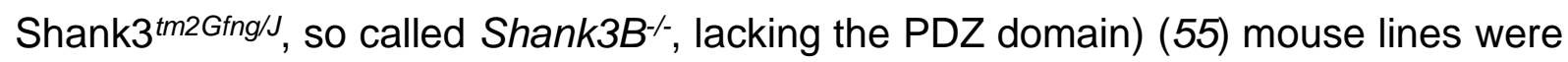
acquired from Jackson Laboratories (Farmington, USA) and bred on a hybrid background: 50\% 129SVPas - 50\% C57BL/6J. Fmr1-KO(2) mice (99) were generously provided by R. Willemsen (Erasmus University Medical Center, Rotterdam, The Netherlands) and bred on a C57BL/6J background. Equivalent numbers of male and female mice were generated in-house from homozygous parents, bred from heterozygous animals, to prevent genetic derivation. This breeding scheme favored social deficits in mutant mice by maintaining them together during early post-natal development. Except otherwise stated, animals were group-housed and maintained on a $12 \mathrm{hr}$ light/dark cycle (lights on at 7:00 AM) at controlled temperature $\left(21 \pm 1^{\circ} \mathrm{C}\right)$; food and water were available ad libitum. Experiments were analyzed blind to genotypes and experimental condition. All experimental procedures were conducted 758 in accordance with the European Communities Council Directive 2010/63/EU and 
Derieux et al.

759

760

761

762

763

764

765

766

767

768

769

770

771

772

773

774

775

776

777

778

779

780

781

approved by the Comité d'Ethique en Expérimentation animale Val de Loire (C2EA19).

\section{Drugs}

Mice were treated with vehicle ( $\mathrm{NaCl} 0.9 \%$; ip, 10 or $20 \mathrm{ml} / \mathrm{kg}$ ), $\mathrm{NaBr}$ (Sigma-Aldrich, Saint-Quentin Fallavier, France) administered either chronically (once a day, 10, 30, 70, 125, 250 and $500 \mathrm{mg} / \mathrm{kg}$; i.p. or per os, in a volume of $20 \mathrm{ml} / \mathrm{kg}$ - except for combination with VU0155041: $10 \mathrm{mg} / \mathrm{kg}$ ) or acutely (250 mg/kg, $20 \mathrm{ml} / \mathrm{kg}), \mathrm{KBr}$ (Sigma-Aldrich, Saint-Quentin Fallavier, France; $145 \mathrm{mg} / \mathrm{kg} ;$ i.p., $20 \mathrm{ml} / \mathrm{kg}$ ), bumetanide (R\&D systems, Minneapolis, USA, 0.5 and $2 \mathrm{mg} / \mathrm{kg}$; i.p., $20 \mathrm{ml} / \mathrm{kg}$ ) or VU0155041 (Cayman Chemical, Ann Arbor, USA, once a day, i.p., 1 mg/kg, 10 ml/kg). Doses of bumetanide were chosen based on previous studies in rodent models of ASD (40,74); liminal dose of VU0155041 was set based on our previous studies $(51,100)$ and a pilot experiment showing no detectable effect in the social interaction test. When treatment was given chronically, behavioral testing started 8 days after beginning of daily administration. Treatment was maintained for 8 to 18 consecutive days (see timelines in Fig. 1, 4 and 5), allowing thorough behavioral phenotyping. On testing days, or when treatment was given acutely, drugs (or vehicle) were administered 30 min before behavioral assays.

\section{Behavioral experiments}

When assessing effects of chronic administration, experiments were performed successively (timelines in Fig. 1, 4 and 5) $(51,100)$. Testing order was chosen to minimize the incidence of anxiety on later assays. Direct social interaction and novelty suppressed feeding were performed in 4 equal square arenas (open fields, $50 \times 50$ 
Derieux et al.

$\mathrm{cm}$ ) separated by $35 \mathrm{~cm}$-high opaque grey Plexiglas walls over a white Plexiglas platform (View Point, Lyon, France). Stimulus mice used for the three-chamber test were 8-14-week-old grouped-housed male or female wild-type mice, socially naive to the experimental animals.

\section{Social abilities}

Direct social interaction test. On testing day, a pair of unfamiliar mice (not cage mates, age-, sex- and treatment-matched) was introduced in each arena for $10 \mathrm{~min}$ (15 Ix). Each arena received a black plastic floor (transparent to infrared). The total amount of time spent in nose contact (nose-to-nose, nose-to-body or nose-toanogenital region), the number of these contacts, the time spent in paw contact and the number of these contacts, grooming episodes (allogrooming), notably ones occurring immediately $(<5 \mathrm{~s})$ after a social contact, as well as the number of following episodes were scored a posteriori on video recordings (infrared light-sensitive video camera) using an ethological keyboard (Labwatcher $®$, View Point, Lyon, France) by trained experimenters and individually for each animal $(51,100)$. The mean duration of nose and paw contacts was calculated from previous data (101-103).

Three-chamber social preference test. The test apparatus consisted of a transparent acrylic box (exterior walls blinded with black plastic film); partitions divided the box into three equal chambers $(40 \times 20 \times 22.5 \mathrm{~cm})$. Two sliding doors $(8 \times 5 \mathrm{~cm})$ allowed transitions between chambers. Cylindrical wire cages $(18 \times 9 \mathrm{~cm}, 0.5 \mathrm{~cm}$ diameterrods spaced $1 \mathrm{~cm}$ apart) were used to contain the mouse interactor and object (softtoy mouse). The test was performed in low-light conditions $(15 \mathrm{~lx})$ to minor anxiety. Stimulus wild-type mice were habituated to confinement in wire cages for 2 days before the test (20 min/day). On testing day, the experimental animal was introduced to the middle chamber and allowed to explore the whole apparatus for a 10-min habituation 
Derieux et al.

809

810

811

812

813

814

815

816

817

818

819

820

821

822

823

824

825

826

827

828

829

830

831

832

833

phase (wire cages empty) after the sliding doors were raised. The experimental mouse was then confined back in the middle-chamber while the experimenter introduced an unfamiliar wild type age and sex-matched animal into a wire cage in one of the sidechambers and a soft toy mouse $(8 \times 10 \mathrm{~cm})$ in the second wire cage as a control for novelty. Then the experimental mouse was allowed to explore the apparatus for a 10min interaction phase. The time spent in each chamber, the time spent in nose contact with each wire cage (empty: habituation; containing a mouse or a toy: interaction), as well as the number of these nose contacts were scored a posteriori on video recordings using an ethological keyboard (Labwatcher ${ }^{\circledR}$, View Point, Lyon, France) by trained experimenters. The mean duration of nose contacts was calculated from these data (101-103). The relative position of stimulus mice (versus toy) was counterbalanced between groups.

\section{Stereotyped behaviors}

Motor stereotypies. To detect motor stereotypies in mutant versus wild-type animals, mice were individually placed in clear standard home cages $(21 \times 11 \times 17 \mathrm{~cm})$ filled with 3-cm deep fresh sawdust for $10 \mathrm{~min}$ (104). Light intensity was set at 30 lux. Trained experimenters scored numbers of head shakes, as well as rearing, burying, grooming, circling episodes and total time spent burying by direct observation.

Y-maze exploration. Spontaneous alternation behavior was used to assess perseverative behavior (105-107). Each Y-maze (Imetronic, Pessac, France) consisted of three connected Plexiglas arms $(15 \times 15 \times 17 \mathrm{~cm})$ covered with distinct wall patterns $(15 \mathrm{Ix})$. Floors were covered with lightly sprayed fresh sawdust to limit anxiety. Each mouse was placed at the center of a maze and allowed to freely explore this environment for $5 \mathrm{~min}$. The pattern of entries into each arm was quoted on videorecordings. Spontaneous alternations (SPA), i.e. successive entries into each arm 
Derieux et al.

834 forming overlapping triplet sets, alternate arm returns (AAR) and same arm returns 835 (SAR) were scored, and the percentage of SPA, AAR and SAR was calculated as 836 following: total / (total arm entries -2$) * 100$.

837

Marble-burying. Marble burying was used as a measure of perseverative behavior (108). Mice were introduced individually in transparent cages $(21 \times 11 \times 17 \mathrm{~cm})$ containing 20 glass marbles (diameter: $1.5 \mathrm{~cm}$ ) evenly spaced on $4-\mathrm{cm}$ deep fresh sawdust. To prevent escapes, each cage was covered with a filtering lid. Light intensity in the room was set at 40 lux. The animals were removed from the cages after $15 \mathrm{~min}$, and the number of marbles buried more than half in sawdust was quoted.

\section{Anxiety-like behavior}

Novelty-suppressed feeding. Novelty-suppressed feeding (NSF) was measured in 24-hr food-deprived mice, isolated in a standard housing cage for $30 \mathrm{~min}$ before individual testing. Three pellets of ordinary lab chow were placed on a white tissue in the center of each arena, lit at $60 \mathrm{~lx}$. Each mouse was placed in a corner of an arena and allowed to explore for a maximum of $15 \mathrm{~min}$. Latency to feed was measured as the time necessary to bite a food pellet. Immediately after an eating event, the mouse was transferred back to home cage (free from cage-mates) and allowed to feed on lab chow for $5 \mathrm{~min}$. Food consumption in the home cage was measured.

\section{Nociceptive thresholds}

Tail-immersion test. Nociceptive thresholds were assessed by immersing the tail of the mice ( $5 \mathrm{~cm}$ from the tip) successively into water baths at $48^{\circ} \mathrm{C}, 50^{\circ} \mathrm{C}$ and $52^{\circ} \mathrm{C}$. The latency to withdraw the tail was measured at each temperature, with a cutoff of $10 \mathrm{~s}$.

\section{Real-time quantitative PCR analysis}


Derieux et al.

Brains were removed and placed into a brain matrix (ASI Instruments, Warren, MI, USA). Nucleus accumbens (NAc), caudate putamen ( $\mathrm{CPu}$ ), ventral pallidum/olfactory tubercle (VP/Tu), medial nucleus of the amygdala (MeA) and ventral tegmental area/substancia nigra pars compacta (VTA/SNc) were punched out/dissected from $1 \mathrm{~mm}$-thick slices (see Fig. S1). Tissues were immediately frozen on dry ice and kept at $-80^{\circ} \mathrm{C}$ until use. For each structure of interest, genotype and condition, samples were processed individually $(\mathrm{n}=8)$. RNA was extracted and purified using the Direct-Zol RNA MiniPrep kit (Zymo research, Irvine, USA). cDNA was synthetized using the ProtoScript II Reverse Transcriptase kit (New England BioLabs, Évry-Courcouronnes, France). qRT-PCR was performed in quadruplets on a CFX384 Touch Real-Time PCR Detection System (Biorad, Marnes-la-Coquette, France) using iQ-SYBR Green supermix (Bio-Rad) kit with $0.25 \mu \mathrm{l}$ cDNA in a $12 \mu \mathrm{l}$ final volume in Hard-Shell ThinWall 384-Well Skirted PCR Plates (Bio-rad). Gene-specific primers were designed using Primer3 software to obtain a 100- to 150-bp product; sequences are displayed in Table S1. Relative expression ratios were normalized to the level of actin and the $2^{-\Delta \Delta C t}$ method was applied to evaluate differential expression level. Gene expression values differing of the mean by more than two standard deviations were considered as outliers and excluded from further calculations.

\section{Cell culture and transfection}

Human embryonic kidney (HEK) 293 cells were transiently transfected with rat mGlu4 receptor by electroporation together with a chimeric $\mathrm{Gi} / \mathrm{Gq}$ protein to allow phospholipase activation and EAAC1, a glutamate transporter, to avoid influence of extracellular glutamate. For calcium mobilization, cells were seeded in a PLO-coated, black-walled, clear-bottomed, 96-well plate (Greiner Bio-One) at the density of 100,000 
Derieux et al.

884

885

886

887

888

889

890

891

892

893

894

895

896

897

898

899

900

901

902

903

904

905

906

907

908

cells per well and for IPOne assay in a PLO-coated black 96-well plate (Greiner Bio-

One) at the density of 50,000 cells per well. Cells were cultured in DMEM (Gibco ${ }^{\mathrm{TM}}$, Life Technologies), supplemented with 10\% fetal bovine serum. Medium was changed by GlutaMAX (Gibco ${ }^{\mathrm{TM}}$, Life Technologies) to reduce extracellular glutamate concentration $3 \mathrm{~h}$ before experiment.

\section{Chloride and bromide buffers for in vitro assays}

Chloride and bromide ion concentrations in the buffers used for in vitro experiments were chosen for best matching physiological conditions. It was previously shown that the total amount of halogen (chloride and bromide ions) in the cerebrospinal fluid and serum can reach $120-130 \mathrm{mM}(109,110)$ and that bromide is able to substitute up to $30 \%$ of chloride concentration (111), leading to a theoretical concentration of $91 \mathrm{mM}$ chloride and $36 \mathrm{mM}$ bromide. We thus chose the dose of $100 \mathrm{mM}$ chloride as physiological control (complemented with gluconate $\mathrm{NaC}_{6} \mathrm{H}_{11} \mathrm{O}_{7}$ to maintain equivalent osmolarity between buffers (56)), and added or not $50 \mathrm{mM}$ chloride or bromide to assess their effects in vitro. Chemicals were purchased from Sigma-Aldrich (Merck, L'Isle D'Abeau Chesnes, France). The $\mathrm{pH}$ of all buffers was adjusted to 7.4 before experiments.

For calcium mobilization assay, buffers with $100 \mathrm{mM} \mathrm{NaCl}, 2.6 \mathrm{mM} \mathrm{KCl}, 1.18 \mathrm{mM}$ $\mathrm{MgSO}_{4}, 10 \mathrm{mM}$ D-glucose, $10 \mathrm{mM}$ 4-(2-hydroxyethyl)-1-piperazineethanesulfonic acid (HEPES), $1 \mathrm{mM} \mathrm{CaCl} 2$ and $0.5 \%(\mathrm{w} / \mathrm{v})$ bovine serum albumin were used and supplemented with $50 \mathrm{mM}$ of either $\mathrm{NaCl}, \mathrm{NaBr}$ or $\mathrm{NaC}_{6} \mathrm{H}_{11} \mathrm{O}_{7}$ to reach $154.6 \mathrm{mM}$ total anion concentration.

For $\mathrm{IP}_{1}$ accumulation assay, buffers with $46 \mathrm{mM} \mathrm{NaCl}, 4.2 \mathrm{mM} \mathrm{KCl}, 0.5 \mathrm{mM} \mathrm{MgCl}_{2}, 10$ mM HEPES, $1 \mathrm{mM} \mathrm{CaCl}_{2}, 50 \mathrm{mM} \mathrm{NaC}_{6} \mathrm{H}_{11} \mathrm{O}_{7}$ and $50 \mathrm{mM} \mathrm{LiCl}$ (to avoid IP 1 degradation) 
Derieux et al.

909

910

911

912

913

914

915

916

917

918

919

920

921

922

923

924

925

926

927

928

929

930

931

932

933

were used and supplemented with $50 \mathrm{mM}$ of either $\mathrm{NaCl}, \mathrm{NaBr}$ or $\mathrm{NaC}_{6} \mathrm{H}_{11} \mathrm{O}_{7}$ to reach $203.2 \mathrm{mM}$ total anion concentration.

\section{Calcium mobilization and $I P_{1}$ accumulation assays}

Calcium mobilization assay: $24 \mathrm{~h}$ after transfection, cells were loaded with $1 \mu \mathrm{M}$ calcium-sensitive fluorescent dye (Fluo-4 AM; Invitrogen, Life Technologies) diluted in fresh $\mathrm{Cl}^{-}$buffer $(154.6 \mathrm{mM})$ for $1 \mathrm{~h}$ at $37^{\circ} \mathrm{C}$ and $5 \% \mathrm{CO}_{2}$. Then, cells were washed and maintained in appropriate buffer supplemented with $4 \mathrm{mM}$ probenecid. Agonists were also diluted in appropriate buffers. $\mathrm{Ca}^{2+}$ release was determined using $\mu$ Cell FDSS (Hamamatsu Photonics). Fluoresence was recorded for $60 \mathrm{~s}$ at $480 \mathrm{~nm}$ excitation and $540 \mathrm{~nm}$ emission after $20 \mathrm{~s}$ record of baseline.

IP 1 accumulation assay: Inositol monophosphate accumulation was determined using the IP-One HTRF (Homogenous Time Resolved Fluorescence) kit (Cisbio Bioassays, Perkin Elmer, Codolet, France) according to the manufacturer's recommendations (112). Briefly, cells were stimulated to induce IP 1 accumulation while being treated with test compounds in appropriate buffer for $30 \mathrm{~min}$, at $37^{\circ} \mathrm{C}$ and $5 \% \mathrm{CO} 2$ before d2labeled $\mathrm{IP}_{1}$ and $\mathrm{Tb}$-labeled anti-IP $\mathrm{P}_{1}$ antibody addition. After $1 \mathrm{~h}$ incubation at $\mathrm{RT}$, Pherastar FS (BMG Labtech) was used to record $620 \mathrm{~nm}$ and $665 \mathrm{~nm}$ emission after $337 \mathrm{~nm}$ excitation.

\section{Data analysis and statistics}

\section{In vivo experiments}

Statistical analyses were performed using Statistica 9.0 software (StatSoft, MaisonsAlfort, France). For all comparisons, values of $p<0.05$ were considered as significant. Statistical significance in behavioral experiments was assessed using one or two-way 
Derieux et al.

934

935

936

937

938

939

940

941

942

943

944

945

946

947

948

949

950

951

952

953

954

955

956

957

958

analysis of variance (drug, stimulus and treatment effects) followed by Newman-Keuls post-hoc test. Significance of quantitative real-time PCR (qRT-PCR) results was assessed after transformation using a two-tailed t-test, as previously described (100). Unsupervised clustering analysis was performed on transformed qRT-PCR data using complete linkage with correlation distance (Pearson correlation) for genotype and treatment (Cluster 3.0 and Treeview software) $(51,100)$. When used for clustering analysis (Figure 7B), behavioral data were normalized to vehicle-vehicle condition and transformed using the same formula as qRT-PCR data.

\section{In vitro experiments}

Data were analyzed using Prism 6 software (GraphPad Software, San Diego, CA, USA). For $\mathrm{IP}_{1}$ accumulation assay, each $\mathrm{HTRF}$-ratio was transformed in $\mathrm{IP}_{1}$ concentration using calibration curves for each buffer and then normalized against Mock-transfected cells to avoid buffer composition effect on HTRF signal. In all experiments, a 4-parameter concentration-response curve equation was used to fit data, and potency $\left(\mathrm{EC}_{50}\right)$ was estimated as logarithms (log $\left.\mathrm{EC}_{50}\right)$. For clarity purpose, absolute (positive) logarithms $\left(\mathrm{pEC}_{50}\right)$ were used. $\mathrm{E}_{\max }$ represents the maximum response obtained at saturating agonist concentration. Data shown in the figures represent the means \pm SEM of at least 3 experiments realized in triplicates. Statistical differences between $\mathrm{pEC}_{50}, \Delta \mathrm{pEC}_{50}$ and $\mathrm{E}_{\max }$ were determined using a one-way analysis of variance followed by Tukey's post-test.

\section{Data availability}

All data that support the findings of this study are available from the corresponding author upon request. 
Derieux et al.

\section{Acknowledgments}

961

962

963

964

965

966

967

968

969

970

971

972

973

974

975

976

977

978

979

980

981

982

983

We thank Dr Thierry Plouvier for inspiring initial discussions on this project, $\operatorname{Pr}$ Frédérique Bonnet-Brilhault for critical reading of the manuscript, Yannick Corde for technical support and Drs. Jorge Gandía and Sébastien Roux for assistance in performing behavioral experiments. We thank the Experimental Unit PAO-1297 (EU0028, Animal Physiology Experimental Facility, DOI: 10.15454/1.5573896321728955E12) from the INRAE-Val de Loire Centre for animal breeding and care.

\section{Funding}

We acknowledge the following funding sources:

C-VaLo, Cisbio Bioassays, Perkin Elmer (IP1 FRET), European Regional Development Fund (ERDF), Inserm Transfert (CoPOC), Région Centre (ARD2020 Biomédicament - GPCRAb). This work was supported by the Institut National de la Santé et de la Recherche Médicale (Inserm), Centre National de la Recherche Scientifique (CNRS), Institut National de Recherche pour l'Agriculture, I'Alimentation et l'Environnement (INRAe) and Université de Tours.

\section{Author contributions}

Conceptualization: CD, JK, JPP, JLM, JAJB; Methodology: JK, JPP, JLM, JAJB;

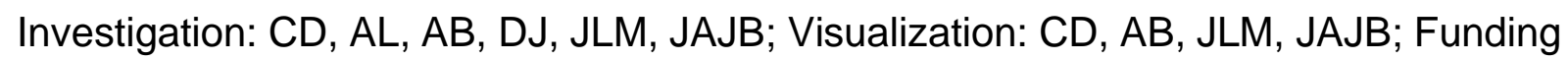
acquisition: JPP, JLM, JAJB; Project administration: JK, JPP, JLM, JAJB; Supervision: JK, JPP, JLM, JAJB; Writing: CD, JLM, JAJB 
bioRxiv preprint doi: https://doi.org/10.1101/2021.09.14.460257; this version posted September 16, 2021. The copyright holder for this preprint (which was not certified by peer review) is the author/funder. All rights reserved. No reuse allowed without permission.

Derieux et al.

984

985

986

987

988

989

990

991

992

993

994

995

996

997

998

999

1000

1001

1002

1003

1004

1005

1006

1007

1008

1009

1010

1011

1012

1013

1014

1015

1016

1017

1018

1019

1020

1021

1022

1023

1024

1025

1026

\section{Competing interests}

J.L.M. and J.A.J.B. are co-inventors of the patent WO2018096184: "Use of bromides in the treatment of autistic spectrum disorder", US Patent App. 16/464,403, 2021 and patent application EP 21194 699: "Methods for treating autism spectrum disorders". $C D, A L, A B, D J, J P P$ and $J K$ report no biomedical financial interests or potential conflicts of interest.

Supplementary Materials: Fig. S1 to S11, Tables S1 and S2.

\section{References}

1. APA, Diagnostic and statistical manual of mental disorders. (Washington, DC, ed. 5th ed., 2013).

2. C. P. Johnson, S. M. Myers, Identification and evaluation of children with autism spectrum disorders. Pediatrics 120, 1183-1215 (2007).

3. M. C. Lai, M. V. Lombardo, S. Baron-Cohen, Autism. Lancet 383, 896-910 (2014).

4. M. O. Mazurek, R. A. Vasa, L. G. Kalb, S. M. Kanne, D. Rosenberg, A. Keefer, D. S. Murray, B. Freedman, L. A. Lowery, Anxiety, sensory over-responsivity, and gastrointestinal problems in children with autism spectrum disorders. $J$ Abnorm Child Psychol 41, 165-176 (2013).

5. E. Fombonne, L. Green Snyder, A. Daniels, P. Feliciano, W. Chung, S. Consortium, Psychiatric and Medical Profiles of Autistic Adults in the SPARK Cohort. J Autism Dev Disord 50, 3679-3698 (2020).

6. F. K. Satterstrom, J. A. Kosmicki, J. Wang, M. S. Breen, S. De Rubeis, J. Y. An, M. Peng, R. Collins, J. Grove, L. Klei, C. Stevens, J. Reichert, M. S. Mulhern, M. Artomov, S. Gerges, B. Sheppard, X. Xu, A. Bhaduri, U. Norman, H. Brand, G. Schwartz, R. Nguyen, E. E. Guerrero, C. Dias, C. Autism Sequencing, P.-B. C. i, C. Betancur, E. H. Cook, L. Gallagher, M. Gill, J. S. Sutcliffe, A. Thurm, M. E. Zwick, A. D. Borglum, M. W. State, A. E. Cicek, M. E. Talkowski, D. J. Cutler, B. Devlin, S. J. Sanders, K. Roeder, M. J. Daly, J. D. Buxbaum, Large-Scale Exome Sequencing Study Implicates Both Developmental and Functional Changes in the Neurobiology of Autism. Cell 180, 568584 e523 (2020).

7. S. J. Sanders, M. T. Murtha, A. R. Gupta, J. D. Murdoch, M. J. Raubeson, A. J. Willsey, A. G. Ercan-Sencicek, N. M. DiLullo, N. N. Parikshak, J. L. Stein, M. F. Walker, G. T. Ober, N. A. Teran, Y. Song, P. El-Fishawy, R. C. Murtha, M. Choi, J. D. Overton, R. D. Bjornson, N. J. Carriero, K. A. Meyer, K. Bilguvar, S. M. Mane, N. Sestan, R. P. Lifton, M. Gunel, K. Roeder, D. H. Geschwind, B. Devlin, M. W. State, De novo mutations revealed by whole-exome sequencing are strongly associated with autism. Nature 485, 237-241 (2012).

8. H. R. Park, J. M. Lee, H. E. Moon, D. S. Lee, B. N. Kim, J. Kim, D. G. Kim, S. H. Paek, A Short Review on the Current Understanding of Autism Spectrum Disorders. Experimental neurobiology 25, 1-13 (2016).

9. E. Lee, J. Lee, E. Kim, Excitation/Inhibition Imbalance in Animal Models of Autism Spectrum Disorders. Biol Psychiatry 81, 838-847 (2017). 
bioRxiv preprint doi: https://doi.org/10.1101/2021.09.14.460257; this version posted September 16, 2021. The copyright holder for this preprint (which was not certified by peer review) is the author/funder. All rights reserved. No reuse allowed without permission.

Derieux et al.

10. S. B. Nelson, V. Valakh, Excitatory/Inhibitory Balance and Circuit Homeostasis in Autism Spectrum Disorders. Neuron 87, 684-698 (2015).

11. J. L. Rubenstein, M. M. Merzenich, Model of autism: increased ratio of excitation/inhibition in key neural systems. Genes Brain Behav 2, 255-267 (2003).

12. G. Cellot, E. Cherubini, GABAergic signaling as therapeutic target for autism spectrum disorders. Front Pediatr 2, 70 (2014).

13. C. E. Robertson, E. M. Ratai, N. Kanwisher, Reduced GABAergic Action in the Autistic Brain. Current biology : CB 26, 80-85 (2016).

14. R. Muhle, S. V. Trentacoste, I. Rapin, The genetics of autism. Pediatrics 113, e472486 (2004).

15. L. Cornew, T. P. Roberts, L. Blaskey, J. C. Edgar, Resting-state oscillatory activity in autism spectrum disorders. J Autism Dev Disord 42, 1884-1894 (2012).

16. J. A. Munoz-Yunta, T. Ortiz, M. Palau-Baduell, L. Martin-Munoz, B. Salvado-Salvado, A. Valls-Santasusana, J. Perich-Alsina, I. Cristobal, A. Fernandez, F. Maestu, C. Dursteler, Magnetoencephalographic pattern of epileptiform activity in children with early-onset autism spectrum disorders. Clinical neurophysiology : official journal of the International Federation of Clinical Neurophysiology 119, 626-634 (2008).

17. S. S. Jeste, R. Tuchman, Autism Spectrum Disorder and Epilepsy: Two Sides of the Same Coin? J Child Neurol 30, 1963-1971 (2015).

18. L. Strasser, M. Downes, J. Kung, J. H. Cross, M. De Haan, Prevalence and risk factors for autism spectrum disorder in epilepsy: a systematic review and meta-analysis. Dev Med Child Neurol 60, 19-29 (2018).

19. C. O'Donnell, J. T. Goncalves, C. Portera-Cailliau, T. J. Sejnowski, Beyond excitation/inhibition imbalance in multidimensional models of neural circuit changes in brain disorders. eLife 6, (2017).

20. T. Rinaldi, K. Kulangara, K. Antoniello, H. Markram, Elevated NMDA receptor levels and enhanced postsynaptic long-term potentiation induced by prenatal exposure to valproic acid. Proc Natl Acad Sci U S A 104, 13501-13506 (2007).

21. R. Shi, P. Redman, D. Ghose, H. Hwang, Y. Liu, X. Ren, L. J. Ding, M. Liu, K. J. Jones, W. Xu, Shank Proteins Differentially Regulate Synaptic Transmission. eNeuro 4, (2017).

22. L. K. Fung, R. E. Flores, M. Gu, K. L. Sun, D. James, R. K. Schuck, B. Jo, J. H. Park, B. C. Lee, J. H. Jung, S. E. Kim, M. Saggar, M. D. Sacchet, G. Warnock, M. M. Khalighi, D. Spielman, F. T. Chin, A. Y. Hardan, Thalamic and prefrontal GABA concentrations but not GABAA receptor densities are altered in high-functioning adults with autism spectrum disorder. Mol Psychiatry 26, 1634-1646 (2020).

23. S. H. Fatemi, T. J. Reutiman, T. D. Folsom, P. D. Thuras, GABA(A) receptor downregulation in brains of subjects with autism. J Autism Dev Disord 39, 223-230 (2009).

24. A. L. Oblak, T. T. Gibbs, G. J. Blatt, Decreased GABA(B) receptors in the cingulate cortex and fusiform gyrus in autism. J Neurochem 114, 1414-1423 (2010).

25. C. V. Sesarini, L. Costa, N. Granana, M. G. Coto, R. C. Pallia, P. F. Argibay, Association between $\mathrm{GABA}(\mathrm{A})$ receptor subunit polymorphisms and autism spectrum disorder (ASD). Psychiatry Res 229, 580-582 (2015).

26. M. Mahdavi, M. Kheirollahi, R. Riahi, F. Khorvash, M. Khorrami, M. Mirsafaie, MetaAnalysis of the Association between GABA Receptor Polymorphisms and Autism Spectrum Disorder (ASD). Journal of molecular neuroscience : MN 65, 1-9 (2018).

27. D. C. Adusei, L. K. Pacey, D. Chen, D. R. Hampson, Early developmental alterations in GABAergic protein expression in fragile X knockout mice. Neuropharmacology 59, 167-171 (2010).

28. A. Banerjee, F. Garcia-Oscos, S. Roychowdhury, L. C. Galindo, S. Hall, M. P. Kilgard, M. Atzori, Impairment of cortical GABAergic synaptic transmission in an environmental rat model of autism. The international journal of neuropsychopharmacology 16, 13091318 (2013). 
bioRxiv preprint doi: https://doi.org/10.1101/2021.09.14.460257; this version posted September 16, 2021. The copyright holder for this

preprint (which was not certified by peer review) is the author/funder. All rights reserved. No reuse allowed without permission.

Derieux et al.

1081

1082

1083

1084

1085

1086

1087

1088

1089

1090

1091

1092

1093

1094

1095

1096

1097

1098

1099

1100

1101

1102

1103

1104

1105

1106

1107

1108

1109

1110

1111

1112

1113

1114

1115

1116

1117

1118

1119

1120

1121

1122

1123

1124

1125

1126

1127

1128

1129

1130

1131

1132

1133

1134

29. H. T. Chao, H. Chen, R. C. Samaco, M. Xue, M. Chahrour, J. Yoo, J. L. Neul, S. Gong, H. C. Lu, N. Heintz, M. Ekker, J. L. Rubenstein, J. L. Noebels, C. Rosenmund, H. Y. Zoghbi, Dysfunction in GABA signalling mediates autism-like stereotypies and Rett syndrome phenotypes. Nature 468, 263-269 (2010).

30. G. Curia, T. Papouin, P. Seguela, M. Avoli, Downregulation of tonic GABAergic inhibition in a mouse model of fragile X syndrome. Cereb Cortex 19, 1515-1520 (2009).

31. S. Han, C. Tai, C. J. Jones, T. Scheuer, W. A. Catterall, Enhancement of inhibitory neurotransmission by GABAA receptors having alpha2,3-subunits ameliorates behavioral deficits in a mouse model of autism. Neuron 81, 1282-1289 (2014).

32. S. Han, C. Tai, R. E. Westenbroek, F. H. Yu, C. S. Cheah, G. B. Potter, J. L. Rubenstein, T. Scheuer, H. O. de la Iglesia, W. A. Catterall, Autistic-like behaviour in Scn1a+/- mice and rescue by enhanced GABA-mediated neurotransmission. Nature 489, 385-390 (2012).

33. C. Henderson, L. Wijetunge, M. N. Kinoshita, M. Shumway, R. S. Hammond, F. R. Postma, C. Brynczka, R. Rush, A. Thomas, R. Paylor, S. T. Warren, P. W. Vanderklish, P. C. Kind, R. L. Carpenter, M. F. Bear, A. M. Healy, Reversal of disease-related pathologies in the fragile $X$ mouse model by selective activation of GABAB receptors with arbaclofen. Sci Transl Med 4, 152ra128 (2012).

34. J. L. Silverman, M. C. Pride, J. E. Hayes, K. R. Puhger, H. M. Butler-Struben, S. Baker, J. N. Crawley, GABAB Receptor Agonist R-Baclofen Reverses Social Deficits and Reduces Repetitive Behavior in Two Mouse Models of Autism. Neuropsychopharmacology 40, 2228-2239 (2015).

35. A. Ligsay, A. Van Dijck, D. V. Nguyen, R. Lozano, Y. Chen, E. S. Bickel, D. Hessl, A. Schneider, K. Angkustsiri, F. Tassone, B. Ceulemans, R. F. Kooy, R. J. Hagerman, A randomized double-blind, placebo-controlled trial of ganaxolone in children and adolescents with fragile X syndrome. J Neurodev Disord 9, 26 (2017).

36. E. Berry-Kravis, R. Hagerman, J. Visootsak, D. Budimirovic, W. E. Kaufmann, M. Cherubini, P. Zarevics, K. Walton-Bowen, P. Wang, M. F. Bear, R. L. Carpenter, Arbaclofen in fragile $\mathrm{X}$ syndrome: results of phase 3 trials. J Neurodev Disord 9, 3 (2017).

37. Y. Ben-Ari, I. Khalilov, K. T. Kahle, E. Cherubini, The GABA excitatory/inhibitory shift in brain maturation and neurological disorders. Neuroscientist 18, 467-486 (2012).

38. S. Eftekhari, J. Mehvari Habibabadi, M. Najafi Ziarani, S. S. Hashemi Fesharaki, M. Gharakhani, H. Mostafavi, M. T. Joghataei, N. Beladimoghadam, E. Rahimian, M. R. Hadjighassem, Bumetanide reduces seizure frequency in patients with temporal lobe epilepsy. Epilepsia 54, e9-12 (2013).

39. J. S. Soul, A. M. Bergin, C. Stopp, B. Hayes, A. Singh, C. R. Fortuno, D. O'Reilly, K. Krishnamoorthy, F. E. Jensen, V. Rofeberg, M. Dong, A. A. Vinks, D. Wypij, K. J. Staley, G. Boston Bumetanide Trial, A Pilot Randomized, Controlled, Double-Blind Trial of Bumetanide to Treat Neonatal Seizures. Ann Neurol 89, 327-340 (2020).

40. R. Tyzio, R. Nardou, D. C. Ferrari, T. Tsintsadze, A. Shahrokhi, S. Eftekhari, I. Khalilov, V. Tsintsadze, C. Brouchoud, G. Chazal, E. Lemonnier, N. Lozovaya, N. Burnashev, Y. Ben-Ari, Oxytocin-mediated GABA inhibition during delivery attenuates autism pathogenesis in rodent offspring. Science 343, 675-679 (2014).

41. E. Lemonnier, C. Degrez, M. Phelep, R. Tyzio, F. Josse, M. Grandgeorge, N. Hadjikhani, Y. Ben-Ari, A randomised controlled trial of bumetanide in the treatment of autism in children. Transl Psychiatry 2, e202 (2012).

42. E. Fernell, P. Gustafsson, C. Gillberg, Bumetanide for autism: open-label trial in six children. Acta paediatrica 110, 1548-1553 (2020).

43. J. J. Sprengers, D. M. van Andel, N. P. A. Zuithoff, M. G. Keijzer-Veen, A. J. A. Schulp, F. E. Scheepers, M. R. Lilien, B. Oranje, H. Bruining, Bumetanide for Core Symptoms of Autism Spectrum Disorder (BAMBI): A Single Center, Double-Blinded, ParticipantRandomized, Placebo-Controlled, Phase-2 Superiority Trial. J Am Acad Child Adolesc Psychiatry S0890-8567, 31290-31299 (2020). 
bioRxiv preprint doi: https://doi.org/10.1101/2021.09.14.460257; this version posted September 16, 2021. The copyright holder for this preprint (which was not certified by peer review) is the author/funder. All rights reserved. No reuse allowed without permission.

Derieux et al.

1135

1136

1137

1138

1139

1140

1141

1142

1143

1144

1145

1146

1147

1148

1149

1150

1151

1152

1153

1154

1155

1156

1157

1158

1159

1160

1161

1162

1163

1164

1165

1166

1167

1168

1169

1170

1171

1172

1173

1174

1175

1176

1177

1178

1179

1180

1181

1182

1183

1184

1185

1186

1187

44. J. M. Pearce, Bromide, the first effective antiepileptic agent. Journal of neurology, neurosurgery, and psychiatry 72, 412 (2002).

45. L. Uhr, J. C. Pollard, J. G. Miller, Behavioral effects of chronic administration of psychoactive drugs to anxious patients. Psychopharmacologia 1, 150-168 (1959).

46. A. C. Almeida, F. A. Scorza, A. M. Rodrigues, R. M. Arida, F. N. Carlesso, A. G. Batista, M. A. Duarte, J. C. DaCosta, Combined effect of bumetanide, bromide, and GABAergic agonists: an alternative treatment for intractable seizures. Epilepsy Behav 20, 147-149 (2011).

47. R. C. Woody, Bromide therapy for pediatric seizure disorder intractable to other antiepileptic drugs. J Child Neurol 5, 65-67 (1990).

48. S. Suzuki, K. Kawakami, F. Nakamura, S. Nishimura, K. Yagi, M. Seino, Bromide, in the therapeutic concentration, enhances GABA-activated currents in cultured neurons of rat cerebral cortex. Epilepsy research 19, 89-97 (1994).

49. K. B. Gagnon, N. C. Adragna, R. E. Fyffe, P. K. Lauf, Characterization of glial cell K-Cl cotransport. Cellular physiology and biochemistry : international journal of experimental cellular physiology, biochemistry, and pharmacology 20, 121-130 (2007).

50. R. Kinne, E. Kinne-Saffran, B. Scholermann, H. Schutz, The anion specificity of the sodium-potassium-chloride cotransporter in rabbit kidney outer medulla: studies on medullary plasma membranes. Pflugers Archiv : European journal of physiology 407 Suppl 2, S168-173 (1986).

51. J. A. Becker, D. Clesse, C. Spiegelhalter, Y. Schwab, J. Le Merrer, B. L. Kieffer, Autistic-like syndrome in mu opioid receptor null mice is relieved by facilitated mGluR4 activity. Neuropsychopharmacology 39, 2049-2060 (2014).

52. L. Jamot, H. W. Matthes, F. Simonin, B. L. Kieffer, J. C. Roder, Differential involvement of the mu and kappa opioid receptors in spatial learning. Genes Brain Behav 2, 80-92 (2003).

53. K. M. Jung, M. Sepers, C. M. Henstridge, O. Lassalle, D. Neuhofer, H. Martin, M. Ginger, A. Frick, N. V. DiPatrizio, K. Mackie, I. Katona, D. Piomelli, O. J. Manzoni, Uncoupling of the endocannabinoid signalling complex in a mouse model of fragile $X$ syndrome. Nat Commun 3, 1080 (2012).

54. A. Michalon, M. Sidorov, T. M. Ballard, L. Ozmen, W. Spooren, J. G. Wettstein, G. Jaeschke, M. F. Bear, L. Lindemann, Chronic pharmacological mGlu5 inhibition corrects fragile $X$ in adult mice. Neuron 74, 49-56 (2012).

55. J. Peca, C. Feliciano, J. T. Ting, W. Wang, M. F. Wells, T. N. Venkatraman, C. D. Lascola, Z. Fu, G. Feng, Shank3 mutant mice display autistic-like behaviours and striatal dysfunction. Nature 472, 437-442 (2011).

56. A. S. Tora, X. Rovira, I. Dione, H. O. Bertrand, I. Brabet, Y. De Koninck, N. Doyon, J. P. Pin, F. Acher, C. Goudet, Allosteric modulation of metabotropic glutamate receptors by chloride ions. Faseb J, (2015).

57. B. R. Conklin, Z. Farfel, K. D. Lustig, D. Julius, H. R. Bourne, Substitution of three amino acids switches receptor specificity of $\mathrm{Gq}$ alpha to that of $\mathrm{Gi}$ alpha. Nature 363, 274-276 (1993).

58. A. Moles, B. L. Kieffer, F. R. D'Amato, Deficit in attachment behavior in mice lacking the mu-opioid receptor gene. Science 304, 1983-1986 (2004).

59. M. Wohr, A. Moles, R. K. Schwarting, F. R. D'Amato, Lack of social exploratory activation in male mu-opioid receptor $\mathrm{KO}$ mice in response to playback of female ultrasonic vocalizations. Soc Neurosci 6, 76-87 (2011).

60. C. N. Pujol, L. P. Pellissier, C. Clément, J. A. J. Becker, J. Le Merrer, Back-translating behavioral intervention for autism spectrum disorders to mice with blunted reward restores social abilities. Transl Psychiatry 8, 197 (2018).

61. C. Toddes, E. M. Lefevre, D. D. Brandner, L. Zugschwert, P. E. Rothwell, Mu Opioid Receptor (Oprm1) Copy Number Influences Nucleus Accumbens Microcircuitry and Reciprocal Social Behaviors. J Neurosci, (2021). 
bioRxiv preprint doi: https://doi.org/10.1101/2021.09.14.460257; this version posted September 16, 2021. The copyright holder for this preprint (which was not certified by peer review) is the author/funder. All rights reserved. No reuse allowed without permission.

Derieux et al.

62. G. Grecksch, A. Becker, H. Schroeder, J. Kraus, H. Loh, V. Hollt, Accelerated kindling development in mu-opioid receptor deficient mice. Naunyn-Schmiedeberg's archives of pharmacology 369, 287-293 (2004).

63. D. B. Goldstein, Sodium bromide and sodium valproate: effective suppressants of ethanol withdrawal reactions in mice. J Pharmacol Exp Ther 208, 223-227 (1979).

64. K. Hayashi, S. Ueshima, M. Ouchida, T. Mashimo, T. Nishiki, T. Sendo, T. Serikawa, H. Matsui, I. Ohmori, Therapy for hyperthermia-induced seizures in Scn1a mutant rats. Epilepsia 52, 1010-1017 (2011).

65. M. Charalambous, S. K. Shivapour, D. C. Brodbelt, H. A. Volk, Antiepileptic drugs' tolerability and safety--a systematic review and meta-analysis of adverse effects in dogs. BMC veterinary research 12, 79 (2016).

66. L. A. Trepanier, J. G. Babish, Pharmacokinetic properties of bromide in dogs after the intravenous and oral administration of single doses. Research in veterinary science 58 , 248-251 (1995).

67. B. J. Steinhoff, R. Kruse, Bromide treatment of pharmaco-resistant epilepsies with generalized tonic-clonic seizures: a clinical study. Brain Dev 14, 144-149 (1992).

68. J. Vidaurre, S. Gedela, S. Yarosz, Antiepileptic Drugs and Liver Disease. Pediatr Neurol 77, 23-36 (2017).

69. S. E. File, P. Seth, A review of 25 years of the social interaction test. Eur J Pharmacol 463, 35-53 (2003).

70. S. Pavelka, A. Babicky, M. Vobecky, J. Lener, E. Svandova, Bromide kinetics and distribution in the rat. I. Biokinetics of $82 \mathrm{Br}$-bromide. Biological trace element research 76, 57-66 (2000).

71. A. G. Rauws, Pharmacokinetics of bromide ion--an overview. Food and chemical toxicology : an international journal published for the British Industrial Biological Research Association 21, 379-382 (1983).

72. N. Vaiseman, G. Koren, P. Pencharz, Pharmacokinetics of oral and intravenous bromide in normal volunteers. Journal of toxicology. Clinical toxicology 24, 403-413 (1986).

73. J. R. Montford, S. Linas, How Dangerous Is Hyperkalemia? Journal of the American Society of Nephrology : JASN 28, 3155-3165 (2017).

74. G. L. Holmes, C. Tian, A. E. Hernan, S. Flynn, D. Camp, J. Barry, Alterations in sociability and functional brain connectivity caused by early-life seizures are prevented by bumetanide. Neurobiology of disease 77, 204-219 (2015).

75. S. A. Hays, K. M. Huber, J. R. Gibson, Altered neocortical rhythmic activity states in Fmr1 KO mice are due to enhanced mGluR5 signaling and involve changes in excitatory circuitry. J Neurosci 31, 14223-14234 (2011).

76. M. F. Bear, K. M. Huber, S. T. Warren, The mGluR theory of fragile X mental retardation. Trends Neurosci 27, 370-377 (2004).

77. T. Yoo, H. Cho, J. Lee, H. Park, Y. E. Yoo, E. Yang, J. Y. Kim, H. Kim, E. Kim, GABA Neuronal Deletion of Shank3 Exons 14-16 in Mice Suppresses Striatal Excitatory Synaptic Input and Induces Social and Locomotor Abnormalities. Frontiers in cellular neuroscience 12, 341 (2018).

78. O. Bozdagi, T. Sakurai, D. Papapetrou, X. Wang, D. L. Dickstein, N. Takahashi, Y. Kajiwara, M. Yang, A. M. Katz, M. L. Scattoni, M. J. Harris, R. Saxena, J. L. Silverman, J. N. Crawley, Q. Zhou, P. R. Hof, J. D. Buxbaum, Haploinsufficiency of the autismassociated Shank3 gene leads to deficits in synaptic function, social interaction, and social communication. Mol Autism 1, 15 (2010).

79. M. Yang, O. Bozdagi, M. L. Scattoni, M. Wohr, F. I. Roullet, A. M. Katz, D. N. Abrams, D. Kalikhman, H. Simon, L. Woldeyohannes, J. Y. Zhang, M. J. Harris, R. Saxena, J. L. Silverman, J. D. Buxbaum, J. N. Crawley, Reduced excitatory neurotransmission and mild autism-relevant phenotypes in adolescent Shank3 null mutant mice. $J$ Neurosci 32, 6525-6541 (2012).

80. T. C. Jaramillo, H. E. Speed, Z. Xuan, J. M. Reimers, C. O. Escamilla, T. P. Weaver, S. Liu, I. Filonova, C. M. Powell, Novel Shank3 mutant exhibits behaviors with face 
bioRxiv preprint doi: https://doi.org/10.1101/2021.09.14.460257; this version posted September 16, 2021. The copyright holder for this preprint (which was not certified by peer review) is the author/funder. All rights reserved. No reuse allowed without permission.

Derieux et al.

validity for autism and altered striatal and hippocampal function. Autism Res 10, 42-65 (2017).

81. S. M. Paluszkiewicz, B. S. Martin, M. M. Huntsman, Fragile X syndrome: the GABAergic system and circuit dysfunction. Dev Neurosci 33, 349-364 (2011).

82. N. Van der Aa, R. F. Kooy, GABAergic abnormalities in the fragile X syndrome. Eur $J$ Paediatr Neurol 24, 100-104 (2020).

83. V. Sabanov, S. Braat, L. D'Andrea, R. Willemsen, S. Zeidler, L. Rooms, C. Bagni, R. F. Kooy, D. Balschun, Impaired GABAergic inhibition in the hippocampus of Fmr1 knockout mice. Neuropharmacology 116, 71-81 (2017).

84. D. Centonze, S. Rossi, V. Mercaldo, I. Napoli, M. T. Ciotti, V. De Chiara, A. Musella, C. Prosperetti, P. Calabresi, G. Bernardi, C. Bagni, Abnormal striatal GABA transmission in the mouse model for the fragile $X$ syndrome. Biol Psychiatry 63, 963-973 (2008).

85. W. Wang, C. Li, Q. Chen, M. S. van der Goes, J. Hawrot, A. Y. Yao, X. Gao, C. Lu, Y. Zang, Q. Zhang, K. Lyman, D. Wang, B. Guo, S. Wu, C. R. Gerfen, Z. Fu, G. Feng, Striatopallidal dysfunction underlies repetitive behavior in Shank3-deficient model of autism. J Clin Invest 127, 1978-1990 (2017).

86. C. M. Niswender, K. A. Johnson, C. D. Weaver, C. K. Jones, Z. Xiang, Q. Luo, A. L. Rodriguez, J. E. Marlo, T. de Paulis, A. D. Thompson, E. L. Days, T. Nalywajko, C. A. Austin, M. B. Williams, J. E. Ayala, R. Williams, C. W. Lindsley, P. J. Conn, Discovery, characterization, and antiparkinsonian effect of novel positive allosteric modulators of metabotropic glutamate receptor 4. Molecular pharmacology 74, 1345-1358 (2008).

87. M. Sala-Rabanal, Z. Yurtsever, C. G. Nichols, T. J. Brett, Secreted CLCA1 modulates TMEM16A to activate $\mathrm{Ca}(2+)$-dependent chloride currents in human cells. eLife 4, e05875 (2015).

88. K. H. Seo, Y. Jin, S. Y. Jung, S. H. Lee, Comprehensive behavioral analyses of anoctamin1/TMEM16A-conditional knockout mice. Life sciences 207, 323-331 (2018).

89. X. Tang, J. Kim, L. Zhou, E. Wengert, L. Zhang, Z. Wu, C. Carromeu, A. R. Muotri, M. C. Marchetto, F. H. Gage, G. Chen, KCC2 rescues functional deficits in human neurons derived from patients with Rett syndrome. Proc Natl Acad Sci U S A 113, 751-756 (2016).

90. N. Doyon, L. Vinay, S. A. Prescott, Y. De Koninck, Chloride Regulation: A Dynamic Equilibrium Crucial for Synaptic Inhibition. Neuron 89, 1157-1172 (2016).

91. H. Meierkord, F. Grunig, U. Gutschmidt, R. Gutierrez, M. Pfeiffer, A. Draguhn, C. Bruckner, U. Heinemann, Sodium bromide: effects on different patterns of epileptiform activity, extracellular pH changes and GABAergic inhibition. Naunyn-Schmiedeberg's archives of pharmacology 361, 25-32 (2000).

92. G. Dolen, A. Darvishzadeh, K. W. Huang, R. C. Malenka, Social reward requires coordinated activity of nucleus accumbens oxytocin and serotonin. Nature 501, 179184 (2013).

93. V. Gigliucci, M. Leonzino, M. Busnelli, A. Luchetti, V. S. Palladino, F. R. D'Amato, B. Chini, Region specific up-regulation of oxytocin receptors in the opioid oprm1 (-/-) mouse model of autism. Front Pediatr 2, 91 (2014).

94. H. A. Dunn, S. Zucca, M. Dao, C. Orlandi, K. A. Martemyanov, ELFN2 is a postsynaptic cell adhesion molecule with essential roles in controlling group III mGluRs in the brain and neuropsychiatric behavior. Mol Psychiatry 24, 1902-1919 (2019).

95. M. Hadders-Algra, Early Diagnostics and Early Intervention in Neurodevelopmental Disorders-Age-Dependent Challenges and Opportunities. Journal of clinical medicine 10, 861 (2021).

96. T. Smith, R. Klorman, D. W. Mruzek, Predicting Outcome of Community-Based Early Intensive Behavioral Intervention for Children with Autism. J Abnorm Child Psychol 43, 1271-1282 (2015).

97. J. E. Robison, Autism prevalence and outcomes in older adults. Autism Res 12, 370374 (2019).

98. H. W. Matthes, R. Maldonado, F. Simonin, O. Valverde, S. Slowe, I. Kitchen, K. Befort, A. Dierich, M. Le Meur, P. Dolle, E. Tzavara, J. Hanoune, B. P. Roques, B. L. Kieffer, 
bioRxiv preprint doi: https://doi.org/10.1101/2021.09.14.460257; this version posted September 16, 2021. The copyright holder for this preprint (which was not certified by peer review) is the author/funder. All rights reserved. No reuse allowed without permission.

Derieux et al.

Loss of morphine-induced analgesia, reward effect and withdrawal symptoms in mice lacking the mu-opioid-receptor gene. Nature 383, 819-823 (1996).

99. E. J. Mientjes, I. Nieuwenhuizen, L. Kirkpatrick, T. Zu, M. Hoogeveen-Westerveld, L. Severijnen, M. Rife, R. Willemsen, D. L. Nelson, B. A. Oostra, The generation of a conditional Fmr1 knock out mouse model to study Fmrp function in vivo. Neurobiology of disease 21, 549-555 (2006).

100. J. A. J. Becker, L. P. Pellissier, Y. Corde, T. Laboute, A. Leaute, J. Gandia, J. Le Merrer, Facilitating mGluR4 activity reverses the long-term deleterious consequences of chronic morphine exposure in male mice. Neuropsychopharmacology 46, 1373-1385 (2021).

101. N. Matsuo, K. Tanda, K. Nakanishi, N. Yamasaki, K. Toyama, K. Takao, H. Takeshima, T. Miyakawa, Comprehensive behavioral phenotyping of ryanodine receptor type 3 (RyR3) knockout mice: decreased social contact duration in two social interaction tests. Front Behav Neurosci 3, 3 (2009).

102. Y. Katayama, M. Nishiyama, H. Shoji, Y. Ohkawa, A. Kawamura, T. Sato, M. Suyama, T. Takumi, T. Miyakawa, K. I. Nakayama, CHD8 haploinsufficiency results in autisticlike phenotypes in mice. Nature 537, 675-679 (2016).

103. C. M. Spencer, O. Alekseyenko, E. Serysheva, L. A. Yuva-Paylor, R. Paylor, Altered anxiety-related and social behaviors in the Fmr1 knockout mouse model of fragile $X$ syndrome. Genes Brain Behav 4, 420-430 (2005).

104. J. L. Silverman, M. Yang, C. Lord, J. N. Crawley, Behavioural phenotyping assays for mouse models of autism. Nat Rev Neurosci 11, 490-502 (2010).

105. N. Le Marec, K. Ethier, P. P. Rompre, R. Godbout, Involvement of the medial prefrontal cortex in two alternation tasks using different environments. Brain and cognition 48, 432-436 (2002).

106. A. Moustgaard, J. Hau, N. M. Lind, Effects of dopamine D4 receptor antagonist on spontaneous alternation in rats. Behavioral and brain functions : BBF 4, 49 (2008).

107. D. Delotterie, G. Ruiz, J. Brocard, A. Schweitzer, C. Roucard, Y. Roche, M. F. SuaudChagny, K. Bressand, A. Andrieux, Chronic administration of atypical antipsychotics improves behavioral and synaptic defects of STOP null mice. Psychopharmacology (Berl) 208, 131-141 (2010).

108. A. Thomas, A. Burant, N. Bui, D. Graham, L. A. Yuva-Paylor, R. Paylor, Marble burying reflects a repetitive and perseverative behavior more than novelty-induced anxiety. Psychopharmacology (Berl) 204, 361-373 (2009).

109. S. L. Raidal, S. Edwards, Pharmacokinetics of potassium bromide in adult horses. Australian veterinary journal 86, 187-193 (2008).

110. E. G. Weir, A. B. Hastings, The distribution of bromide and chloride in tissues and body fluids. Journal of Biological Chemistry 129, 547-558 (1939).

111. F. X. van Leeuwen, E. M. den Tonkelaar, M. J. van Logten, Toxicity of sodium bromide in rats: effects on endocrine system and reproduction. Food and chemical toxicology : an international journal published for the British Industrial Biological Research Association 21, 383-389 (1983).

112. E. Trinquet, M. Fink, H. Bazin, F. Grillet, F. Maurin, E. Bourrier, H. Ansanay, C. Leroy, A. Michaud, T. Durroux, D. Maurel, F. Malhaire, C. Goudet, J. P. Pin, M. Naval, O. Hernout, F. Chretien, Y. Chapleur, G. Mathis, D-myo-inositol 1-phosphate as a surrogate of D-myo-inositol 1,4,5-tris phosphate to monitor $\mathrm{G}$ protein-coupled receptor activation. Analytical biochemistry 358, 126-135 (2006). 
Derieux et al.

\section{Supplementary Materials for}

\section{Chronic sodium bromide treatment relieves autistic-like behavioral deficits in three mouse models of autism}

Cécile Derieux, Audrey Léauté, Agathe Brugoux, Déborah Jacaz, Jean-Philippe Pin, Julie Kniazeff, Julie Le Merrer*, Jerome AJ Becker*

*iulie.le-merrer@inserm.fr, Jerome.becker@inserm.fr

\section{Supplementary Figures}

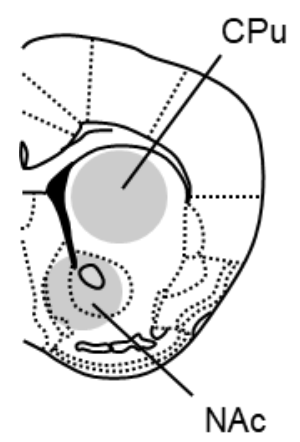

$1.10 \mathrm{~mm}$

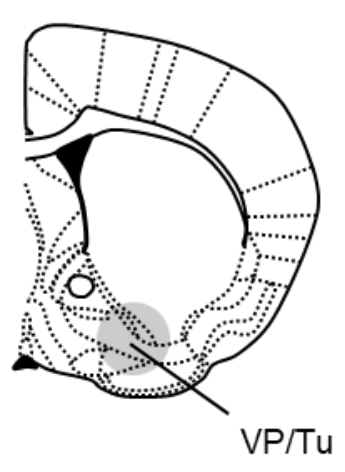

$0.62 \mathrm{~mm}$

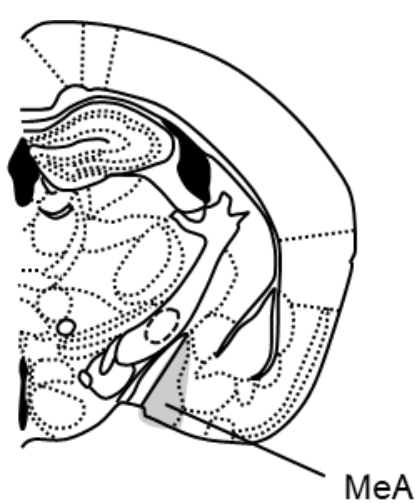

$-1.46 \mathrm{~mm}$

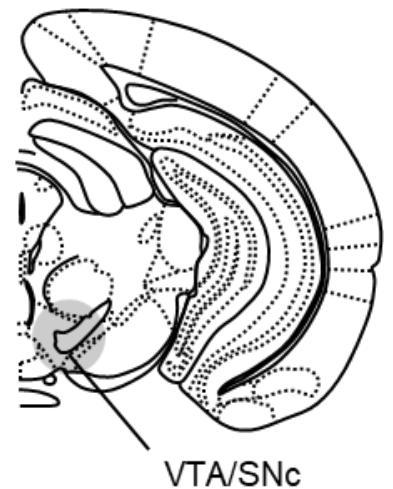

$-3.40 \mathrm{~mm}$

Figure S1. Schematic representations depict brain regions dissected for gene expression study and western blot experiments. CPu, NAc, VP/Tu and VTA/SNc were punched on 1-mm thick brain slices (CPu: one punch/side, $Q 2 \mathrm{~mm}$; NAc, VP and VTA/SNc: one punch/side, $Q 1.25 \mathrm{~mm}$ ). MeA was dissected out bilaterally. Coordinates refer to bregma. CPu: Caudate Putamen; NAc: Nucleus Accumbens; MeA: Medial Amygdala; SNc: Substancia Nigra, pars compacta; VP/Tu: ventral pallidum/olfactory tubercle; VTA/SNc: Ventral Tegmental Area/Substantia Nigra pars compacta. 
Derieux et al.

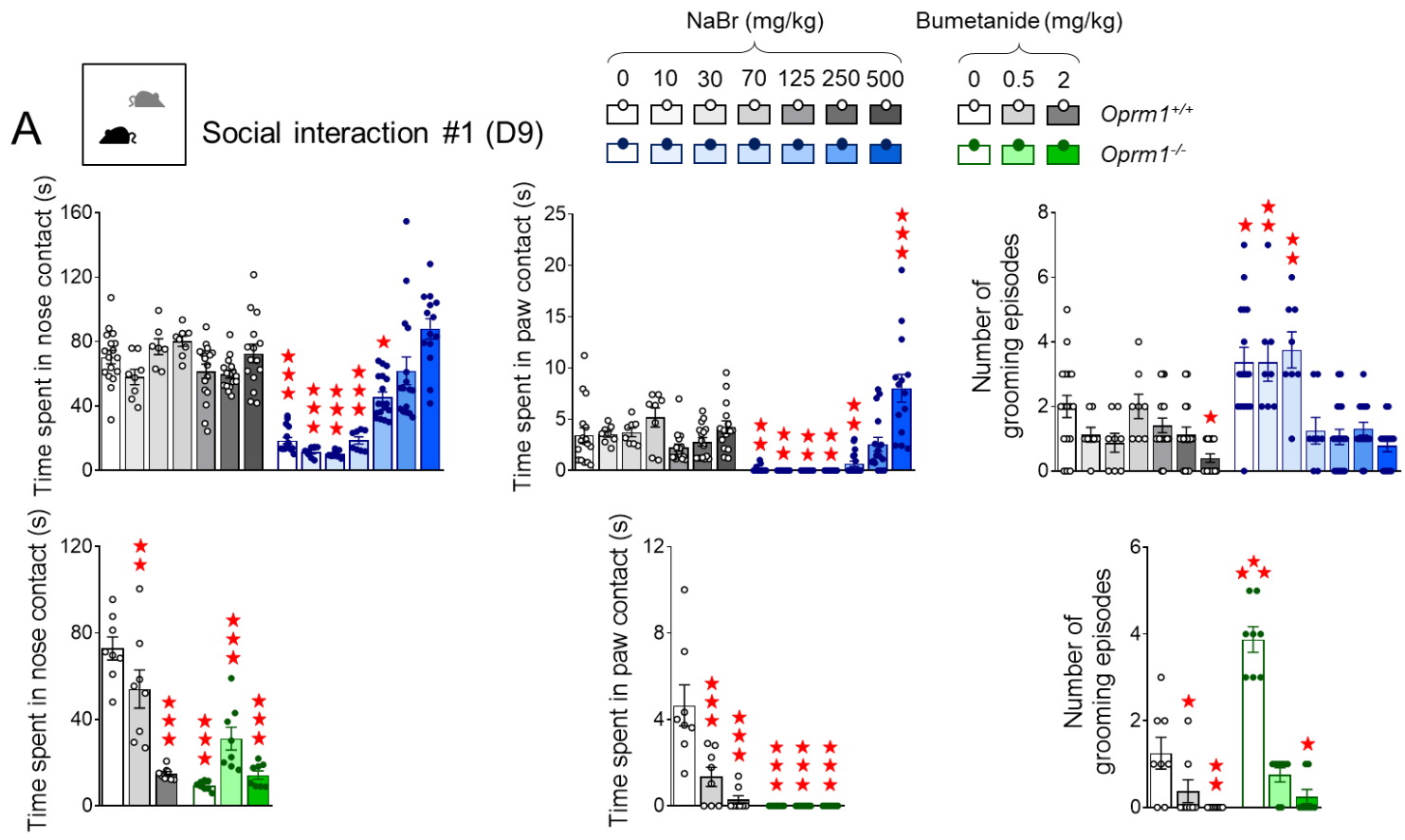

B Social interaction: acute $\mathrm{NaBr}$ effects

$\mathrm{NaBr}(\mathrm{mg} / \mathrm{kg})$
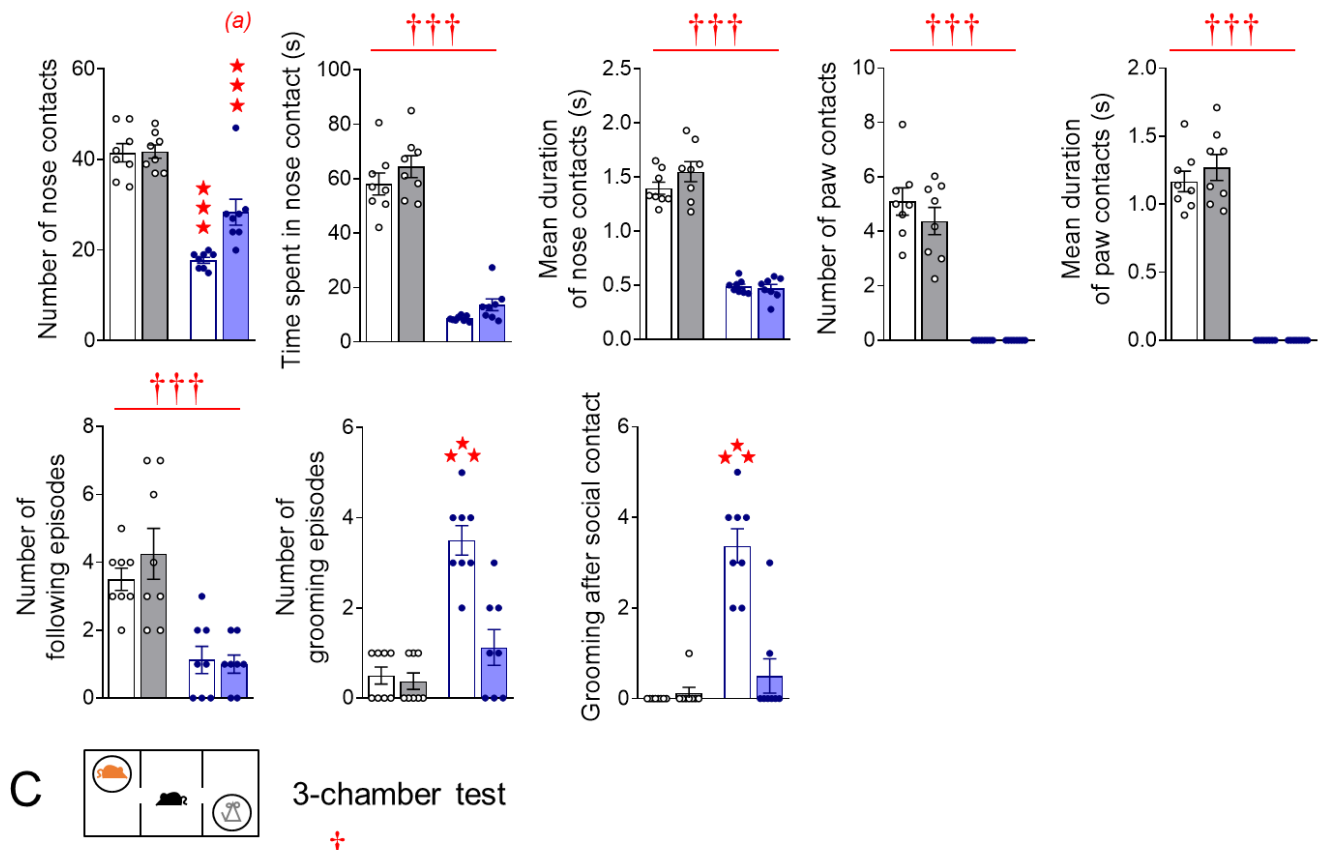

3-chamber test
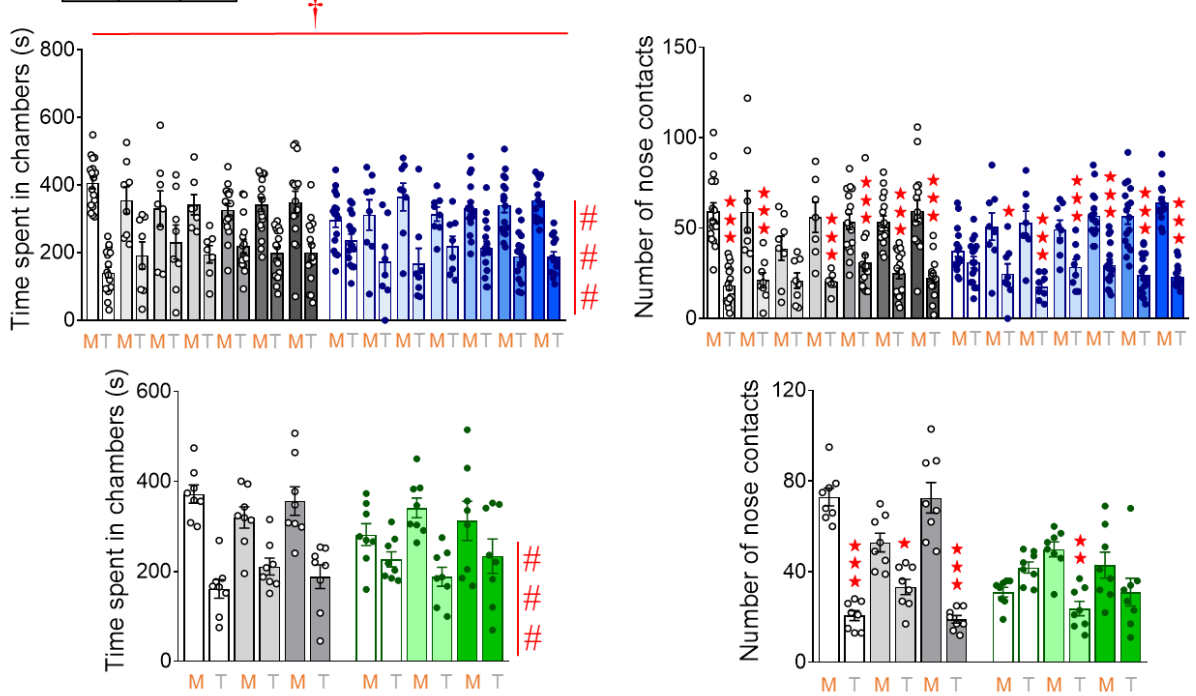

$\overbrace{0}^{500}$ 
Derieux et al.

Figure S2. Chronic, and not acute, sodium bromide relieved social behavior deficits in Oprm1 ${ }^{-/}$mice, demonstrating superior effects to chronic bumetanide. See time line of experiments and animal numbers in Figure 1A, except for (B). (A) In the direct social interaction test (D9), chronic $\mathrm{NaBr}$ administration improved social interaction parameters in Oprm $1 \%$ mice from the dose of $70 \mathrm{mg} / \mathrm{kg}$ but had no detectable effect in wild-type controls. Bumetanide effectively suppressed excessive grooming in these animals but demonstrated deleterious effects on social parameters

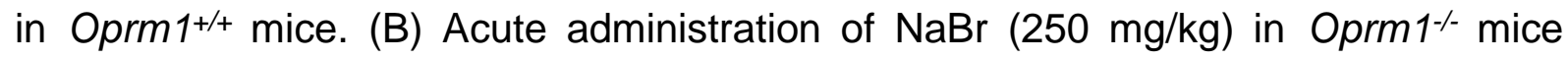
(versus Oprm1+/+ mice, $\mathrm{n}=8$ mice per genotype and treatment) partially increased the number of nose contacts and suppressed excessive grooming during direct social interaction but had no detectable effect on other parameters. (C) In the 3-chamber test, all mice spent globally more time in the chamber with the mouse versus the toy. $\mathrm{NaBr}$ treatment rescued social preference in Oprm1 mutants since the dose of $10 \mathrm{mg} / \mathrm{kg}$; bumetanide restored a preference for making more nose contacts with the mouse at the $0.5 \mathrm{mg} / \mathrm{kg}$ dose only. Results are shown as scatter plots and mean \pm sem. Daggers: genotype effect, asterisks: treatment effect, solid stars: genotype $x$ treatment interaction (comparison with wild-type vehicle condition), hashtag: stimulus effect (twoway ANOVA or three-way ANOVA with stimulus as repeated measure, followed by Newman-Keuls post-hoc test). One symbol: $p<0.05$, two symbols: $p<0.01$; three symbols: $p<0.001$. 
Derieux et al.
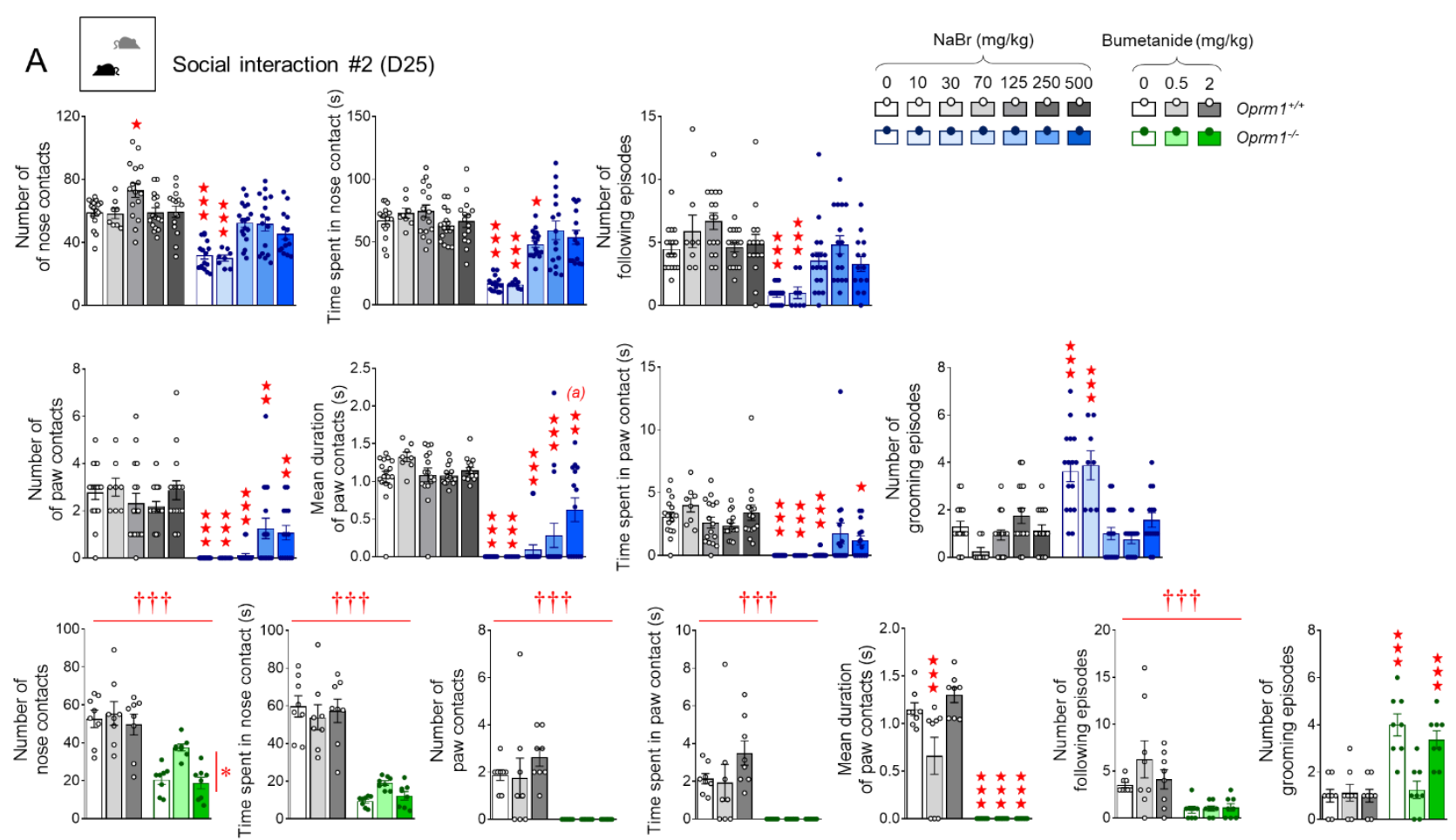

B Social interaction \#3 (D32)
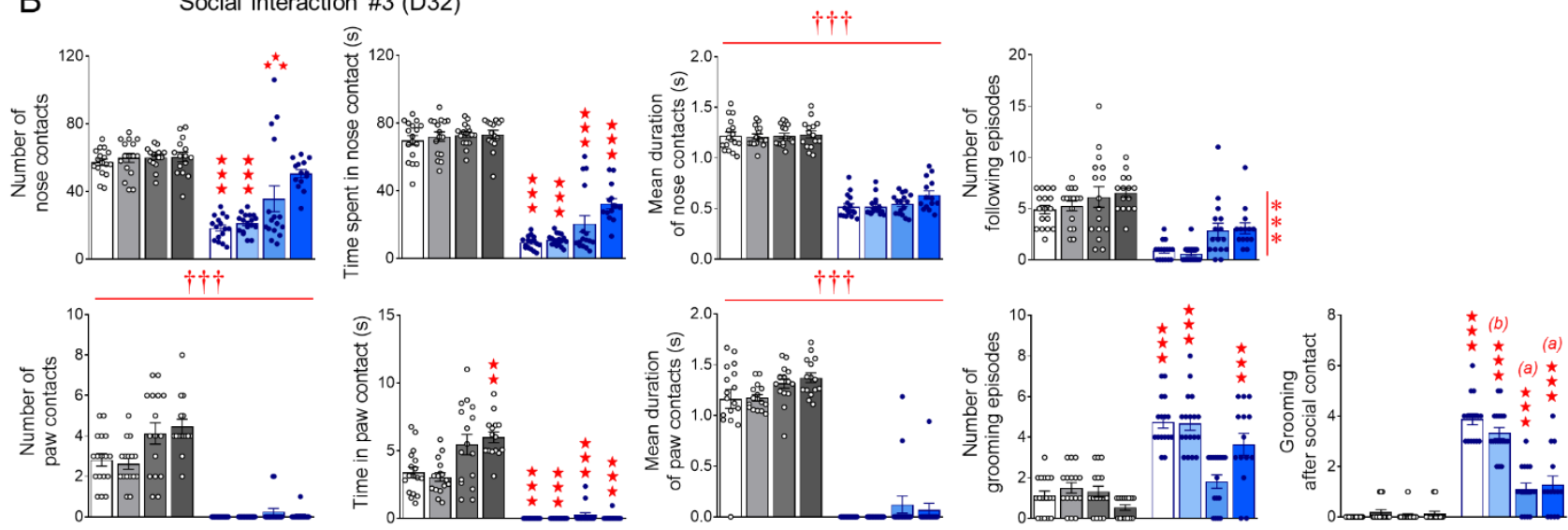

Figure S3. Chronic sodium bromide long-lastingly alleviated social interaction deficit in Oprm 1/ mice. See time line of experiments and animal numbers in Figure 1A. (A) One week after cessation of chronic treatment, beneficial effects of $\mathrm{NaBr}$ on social interaction parameters in Oprm $1 \%$ mice were fully maintained for doses over 125 $\mathrm{mg} / \mathrm{kg}$. No significant effect was detected for bumetanide, except a reduction of grooming for the dose of $0.5 \mathrm{mg} / \mathrm{kg}$. (B) Two weeks after cessation of $\mathrm{NaBr}$ treatment, an increase in the number and time spent in nose contacts was still detectable for the dose of $500 \mathrm{mg} / \mathrm{kg}$ in Oprm 1 - mice; grooming after social contact remained normalized from the dose of $250 \mathrm{mg} / \mathrm{kg}$. Results are shown as scatter plots and mean $\pm \mathrm{sem}$. Daggers: genotype effect, asterisks: treatment effect, solid stars: genotype $\mathrm{x}$ treatment 
Derieux et al.

interaction (comparison with wild-type vehicle condition), (a) genotype $\mathrm{x}$ treatment interaction (comparison with knockout vehicle condition, $p<0.001$ ), (b) genotype $x$ treatment interaction (comparison with knockout vehicle condition, $p<0.01$ ) (two-way ANOVA followed by Newman-Keuls post-hoc test). One symbol: $p<0.05$, two symbols: $p<0.01$; three symbols: $p<0.001$.

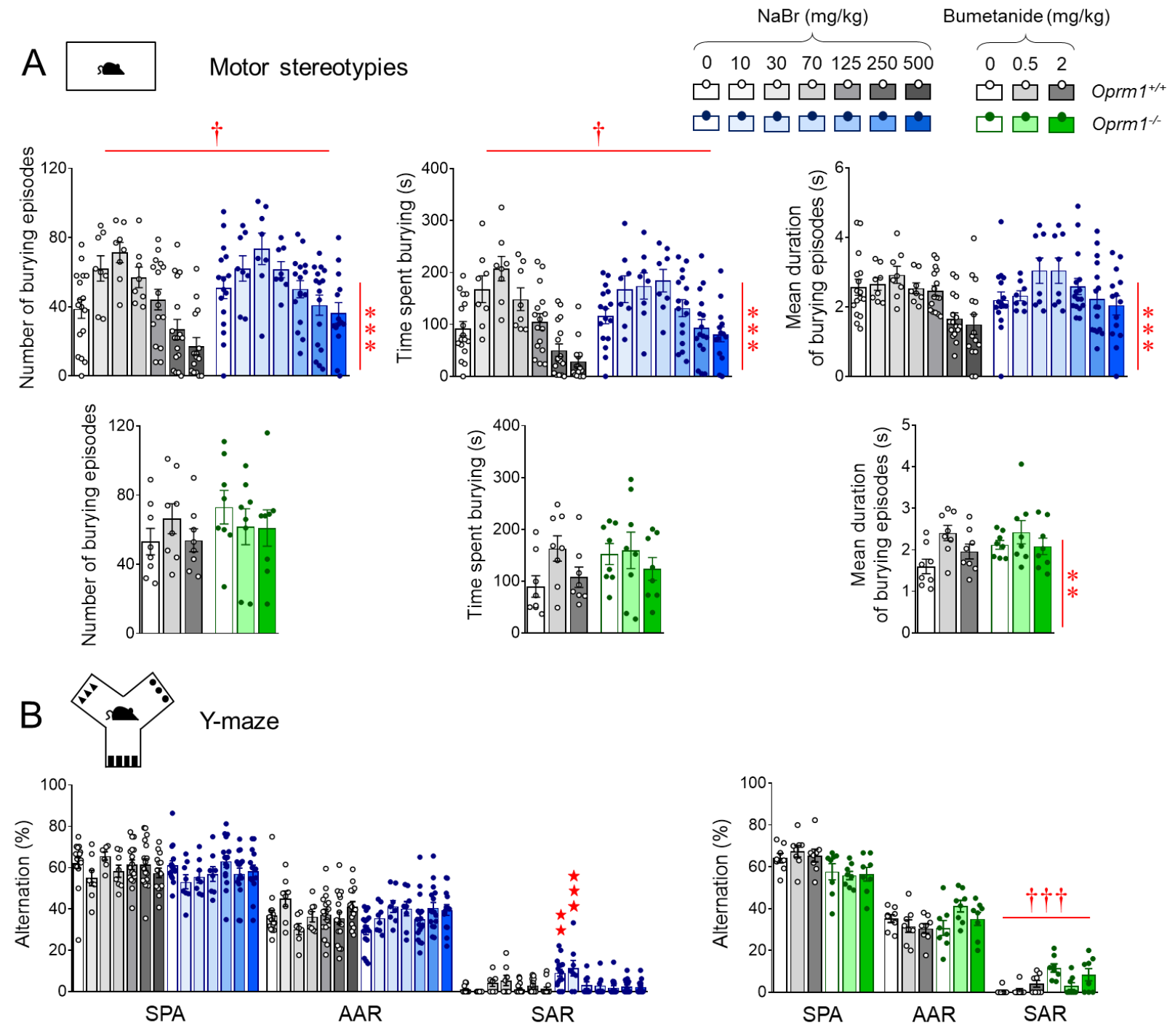

Figure S4. Chronic sodium bromide treatment reduced stereotypic behaviors and anxiety in Oprm1 ${ }^{-/}$mice. See time line of experiments and animal numbers in Figure 1A. (A) Oprm1\% mice made more frequent and longer-lasting burying episodes than wild-type counterparts; bromide treatment increased these two behavioral outputs in both mouse lines. Chronic bromide and bumetanide increased the mean duration of burying episodes. (B) In the $\mathrm{Y}$-maze, $\mathrm{NaBr}$ suppressed perseverative same arm returns in Oprm1 null mice from the dose of $70 \mathrm{mg} / \mathrm{kg}$ without modifying spontaneous 
Derieux et al.

alternation or alternate arm returns; bumetanide had no significant effect in this test. Results are shown as scatter plots and mean \pm sem. Daggers: genotype effect, asterisks: treatment effect, solid stars: genotype $\mathrm{x}$ treatment interaction (comparison with wild-type vehicle condition) (two-way ANOVA followed by Newman-Keuls posthoc test). One symbol: $p<0.05$, two symbols: $p<0.01$; three symbols: $p<0.001$. AAR: alternate arm returns, SAR: same arm returns, SPA: spontaneous alternation.
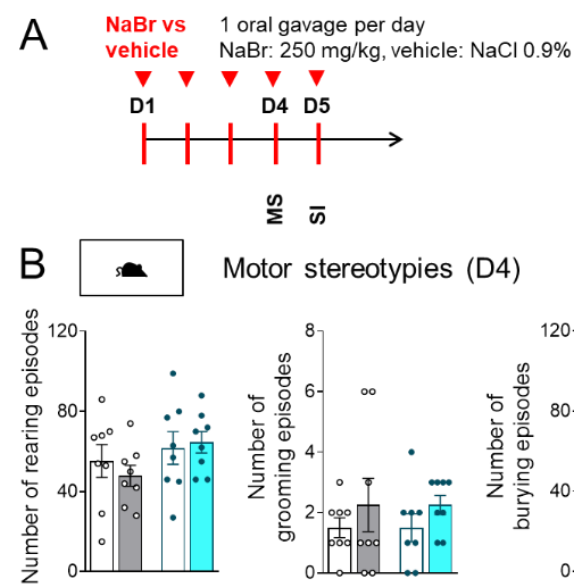

Motor stereotypies (D4)
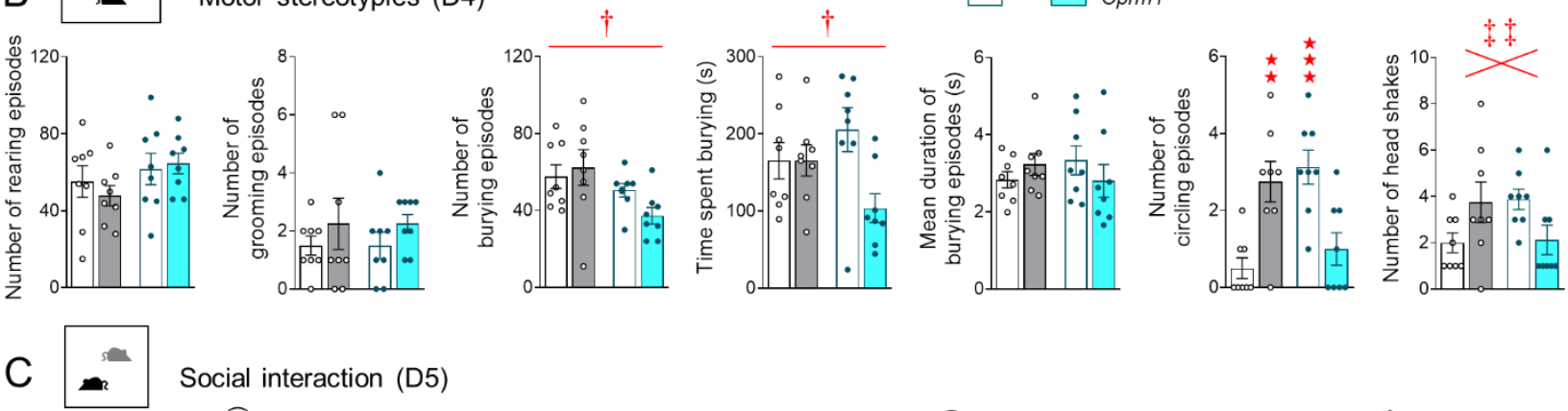

Social interaction (D5)
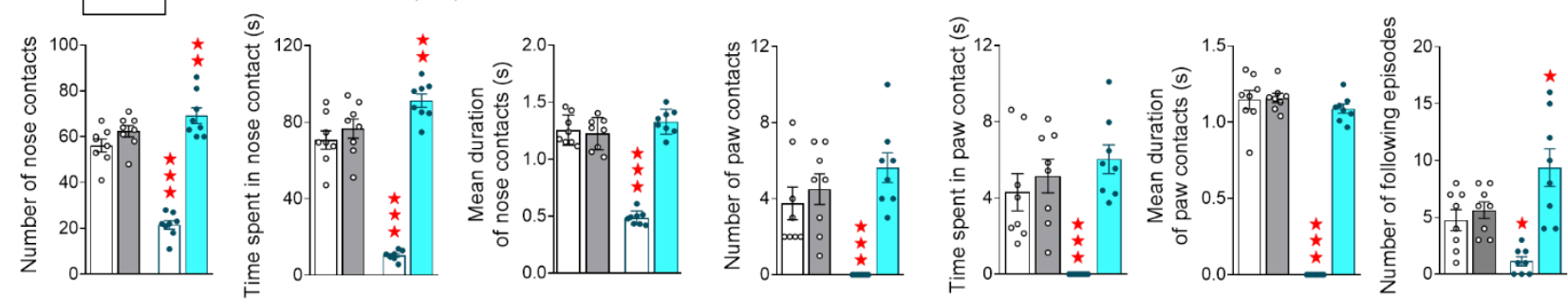

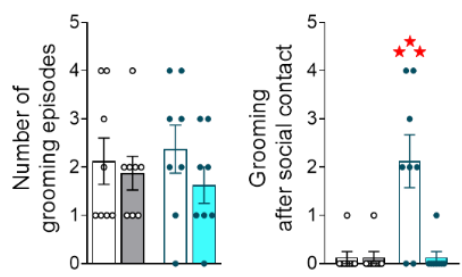

Figure S5. Subchronic oral administration of $\mathrm{NaBr}$ relieved autistic-like symptoms in Oprm1 ${ }^{-/}$mice. (A) Oprm1 ${ }^{+/+}$and Oprm 1/ mice received either with $\mathrm{NaBr}(250 \mathrm{mg} / \mathrm{kg})$ or vehicle $(\mathrm{NaCl}, 0.9 \%)$ via oral gavage once daily for 5 days $(\mathrm{n}=8$ mice per genotype and treatment). Behavioral testing was performed on D4 and D5. (B) Oral subchronic $\mathrm{NaBr}$ administration suppressed stereotypic circling behavior in Oprm 1\% mice; it had opposite effects on the frequency of head shakes depending on mouse genotype, increasing this frequency in controls and decreasing it in mutant mice. (C) In the social interaction test, repeated oral $\mathrm{NaBr}$ treatment normalized 
Derieux et al.

behavioral parameters of Oprm1 null mice to wild-type levels. Results are shown as scatter plots and mean \pm sem. Daggers: genotype effect, double daggers: genotype $x$ treatment interaction (post-hoc comparisons insignificant), solid stars: genotype $x$ treatment interaction (comparison with wild-type vehicle condition) (two-way ANOVA followed by Newman-Keuls post-hoc test). One symbol: $p<0.05$, two symbols: $p<0.01$; three symbols: $p<0.001$. MS: motor stereotypies, SI: social interaction. 
Derieux et al.

A $\mathrm{KBr}$ vs vehicle 1 injection/day, IP,
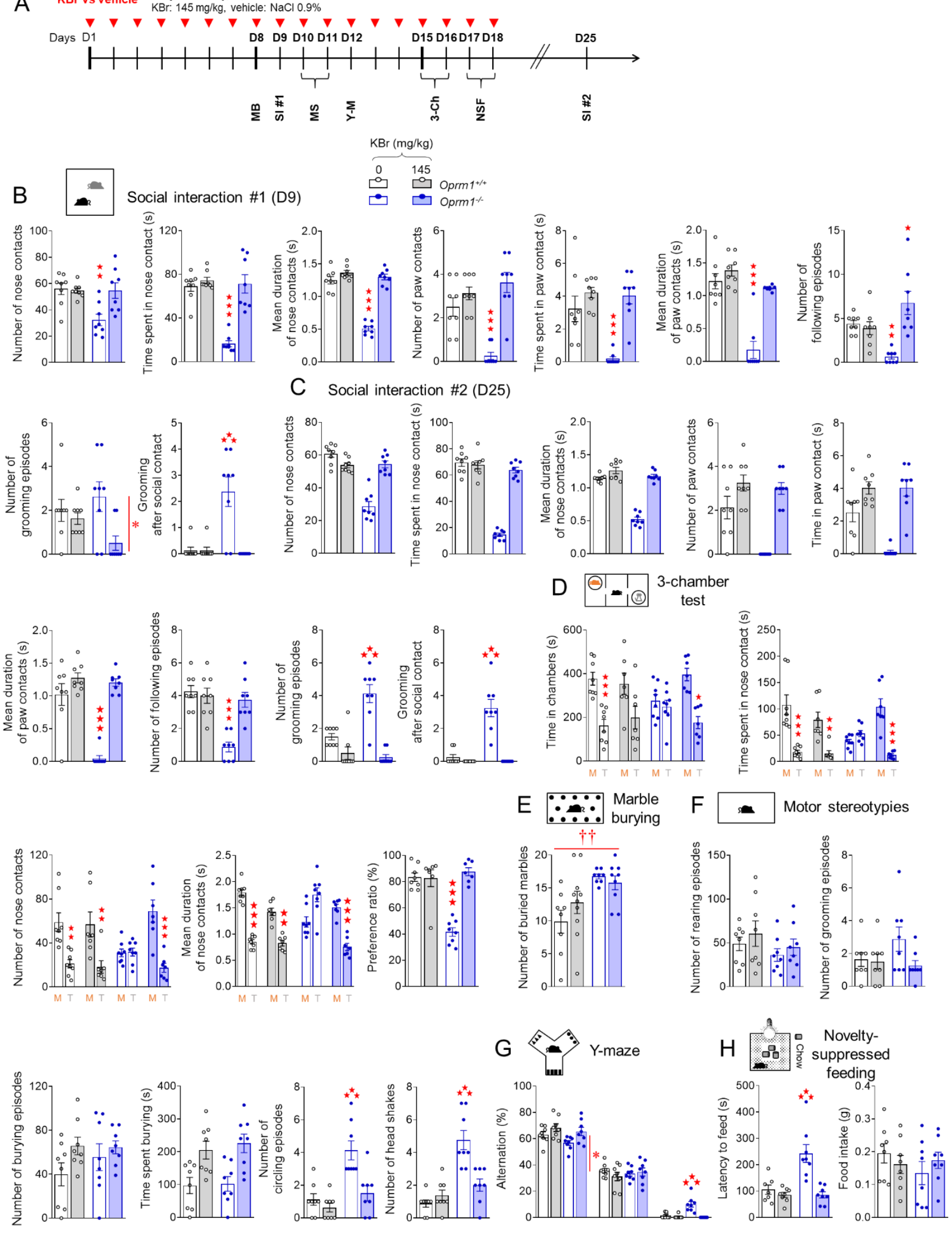

Figure S6. Chronic potassium bromide relieves autistic-like behaviors in Oprm1-

/- mice. Chronic potassium bromide relieves autistic-like behaviors in Oprm1\% mice. 
Derieux et al.

(A) Oprm1 $1^{+/+}$and Oprm1/- mice were treated either with $\mathrm{KBr}(0$ or $145 \mathrm{mg} / \mathrm{kg}: \mathrm{n}=8-10$ mice per genotype and treatment) once daily for 18 days. Behavioral testing started on D8; social interaction was retested 1 week (D25) after cessation of chronic administration. (B) In the direct social interaction test (D9), chronic $\mathrm{KBr}$ relieved social deficits in Oprm1 null mice without any detectable effect in Oprm1 ${ }^{+/+}$controls. (C) This effect was maintained 1 week after cessation of chronic treatment. (D) In the 3chamber test, $\mathrm{KBr}$ rescued preference for exploring a living congener over a toy in Oprm1 mutants. As regards repetitive behaviors, $\mathrm{KBr}$ treatment (E) failed to reduce marble burying, $(F)$ suppressed stereotypic circling and head shakes and $(G)$ reduced perseverative same arm returns during Y-maze exploration in Oprm 1/- mice. $(\mathrm{H})$ In the novelty-suppressed feeding test, potassium bromide normalized the latency to feed in Oprm1 null mice without modifying food intake. Results are shown as scatter plots and mean \pm sem. Daggers: genotype effect, asterisks: treatment effect, solid stars: genotype $x$ treatment interaction (comparison with wild-type vehicle condition) (twoway ANOVA or three-way ANOVA with stimulus as repeated measure, followed by Newman-Keuls post-hoc test). One symbol: $p<0.05$, two symbols: $p<0.01$; three symbols: $p<0.001$. 3-Ch: 3-chamber test, AAR: alternate arm returns, M: mouse, MB: marble burying, MS: motor stereotypies, NSF: novelty-suppressed feeding, SAR: same arm returns, SPA: spontaneous alternation, SI: social interaction, T: toy, Y-M: Y-maze. 


\section{Derieux et al.}
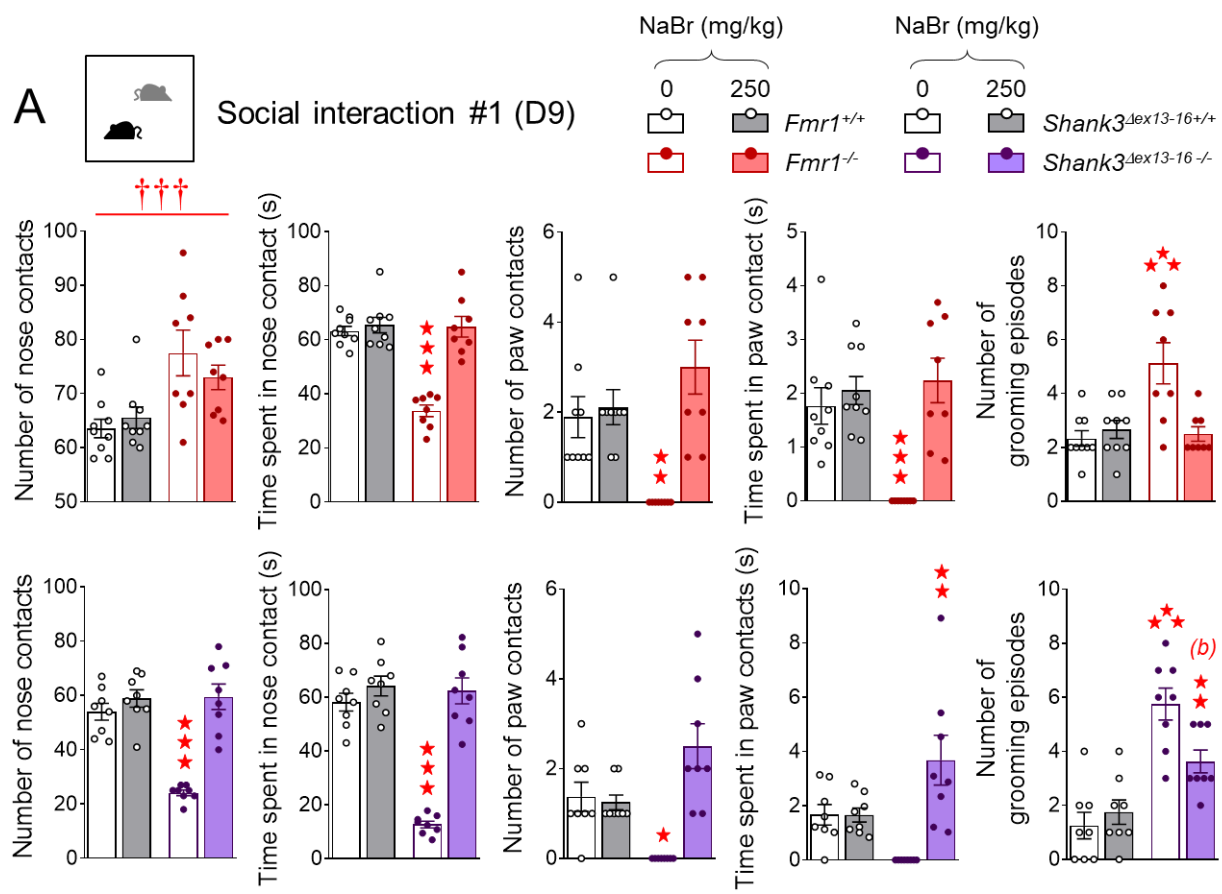

B Social interaction \#2 (D25)
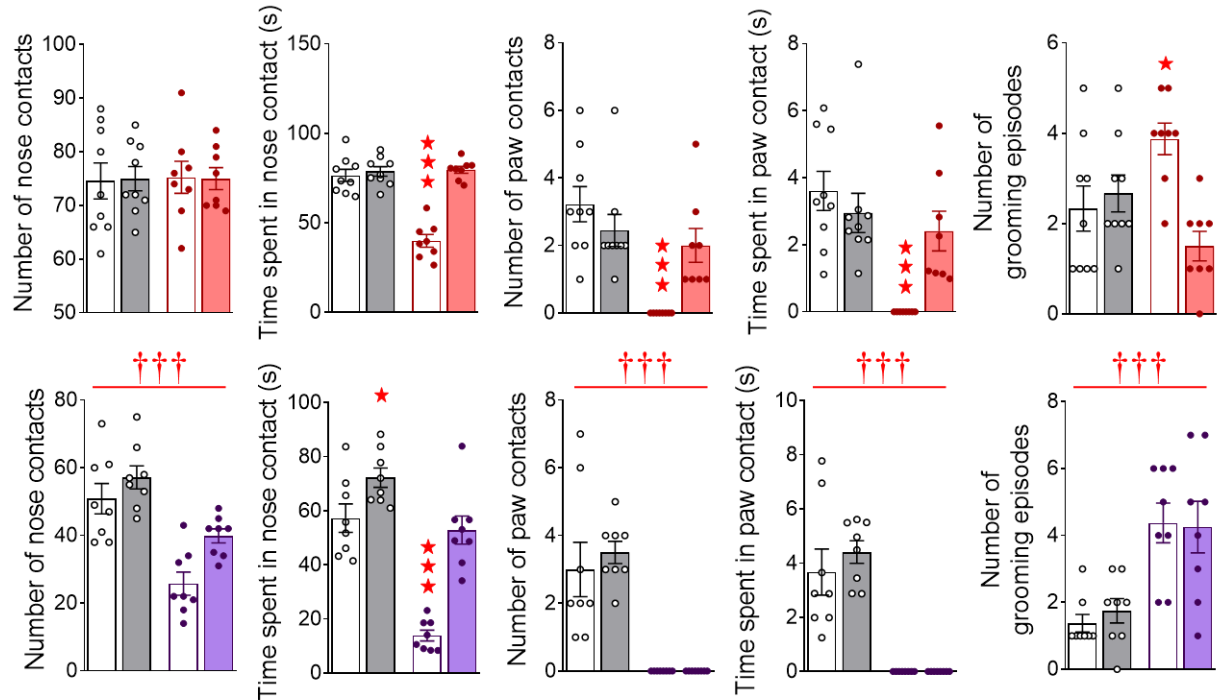

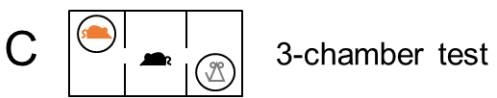
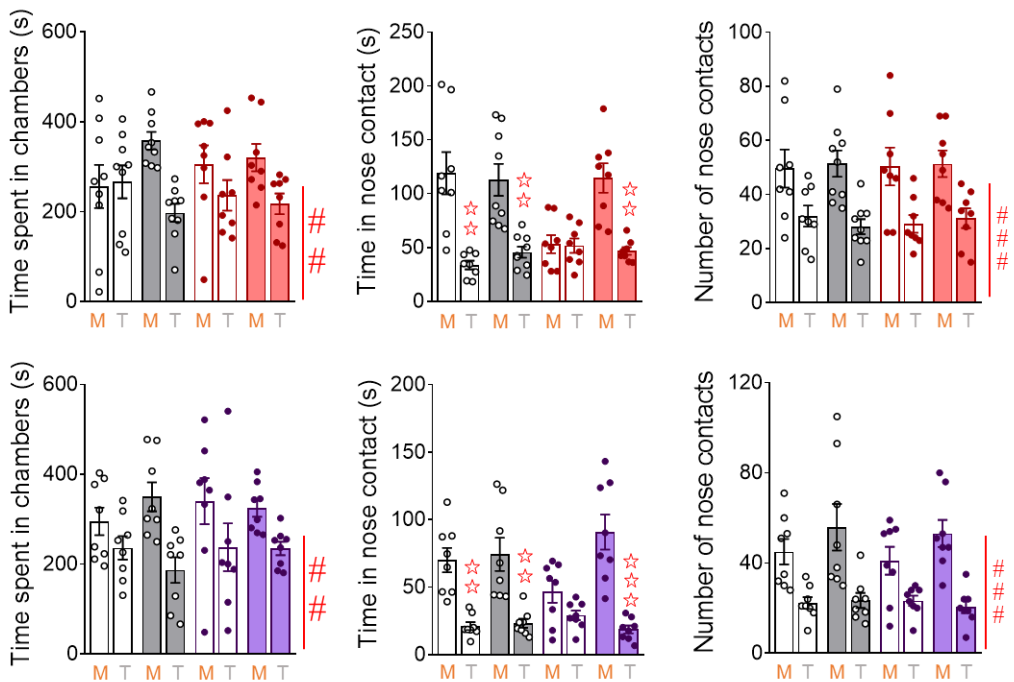
Derieux et al.

Figure S7. Figure 5. Chronic sodium bromide administration relieved social behavior deficits in Fmr1/\% and Shank3 ${ }^{\Delta e x 13-16-/-}$ mice. See animal numbers and time line of experiments in Figure 5. (A) Chronic $\mathrm{NaBr}$ treatment rescued direct social interaction (D9) in both Fmr1 and Shank3 mutant mouse lines. (B) Beneficial effects of $\mathrm{NaBr}$ treatment on social interaction parameters were fully maintained one week after cessation of treatment (D25) in in Fmr1\% mice while only a restoration of the time spent in nose contact was detected in Shank3 $3^{\operatorname{sex} 13-16-1-}$ mice. (C) In the 3-chamber test, all mice spent globally more time in the chamber with the mouse versus the toy. Results are shown as scatter plots and mean \pm sem. Daggers: genotype effect, hashtag: stimulus effect, solid stars: genotype $x$ treatment interaction (comparison to wild-type vehicle condition), open stars: genotype $x$ treatment $x$ stimulus interaction (mouse versus object comparison), (b) genotype $x$ treatment interaction (comparison with knockout vehicle condition, $\mathrm{p}<0.01$ ) (two-way ANOVA or three-way ANOVA with stimulus as repeated measure, followed by Newman-Keuls post-hoc test). One symbol: $p<0.05$, two symbols: $p<0.01$; three symbols: $p<0.001$. M: mouse, $T$ : toy. 
Derieux et al.
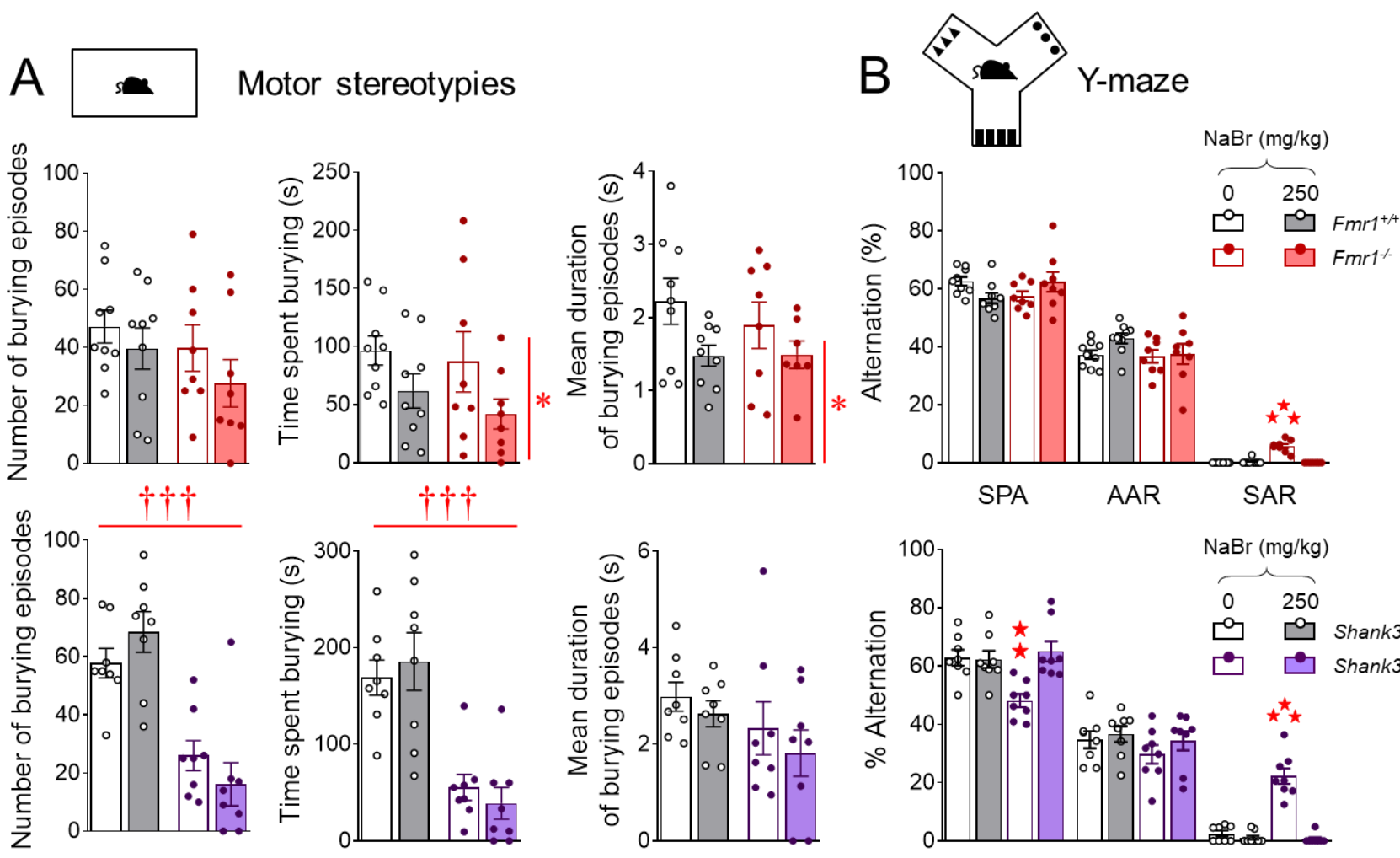

Figure S8. Chronic sodium bromide exposure relieved stereotypic behaviors and reduced anxiety levels in Fmr1// and Shank3 ${ }^{\Delta e x 13-16-/ /}$ mice. See animal numbers and time line of experiments in Figure 5. (A) Chronic $\mathrm{NaBr}$ treatment decreased the time spent burying and mean duration of burying episodes in $\mathrm{Fmr}^{-1}$ mice while it had no effect on deficient number of burying episodes and time spent burying in Shank3 ${ }^{\text {ex } 13-16-\%}$ mice. (B) In the $\mathrm{Y}$-maze, chronic $\mathrm{NaBr}$ treatment normalized the percentage of preservative same arm returns in both mutant lines and restored spontaneous alteration rates in Shank $3^{\text {sex } 13-16-/}$ mice. Results are shown as scatter plots and mean \pm sem. Daggers: genotype effect, asterisk: treatment effect, solid stars: genotype $x$ treatment interaction (comparison with wild-type vehicle condition) (twoway ANOVA followed by Newman-Keuls post-hoc test). One symbol: $p<0.05$, two symbols: $p<0.01$; three symbols: $p<0.001$. 
Derieux et al.

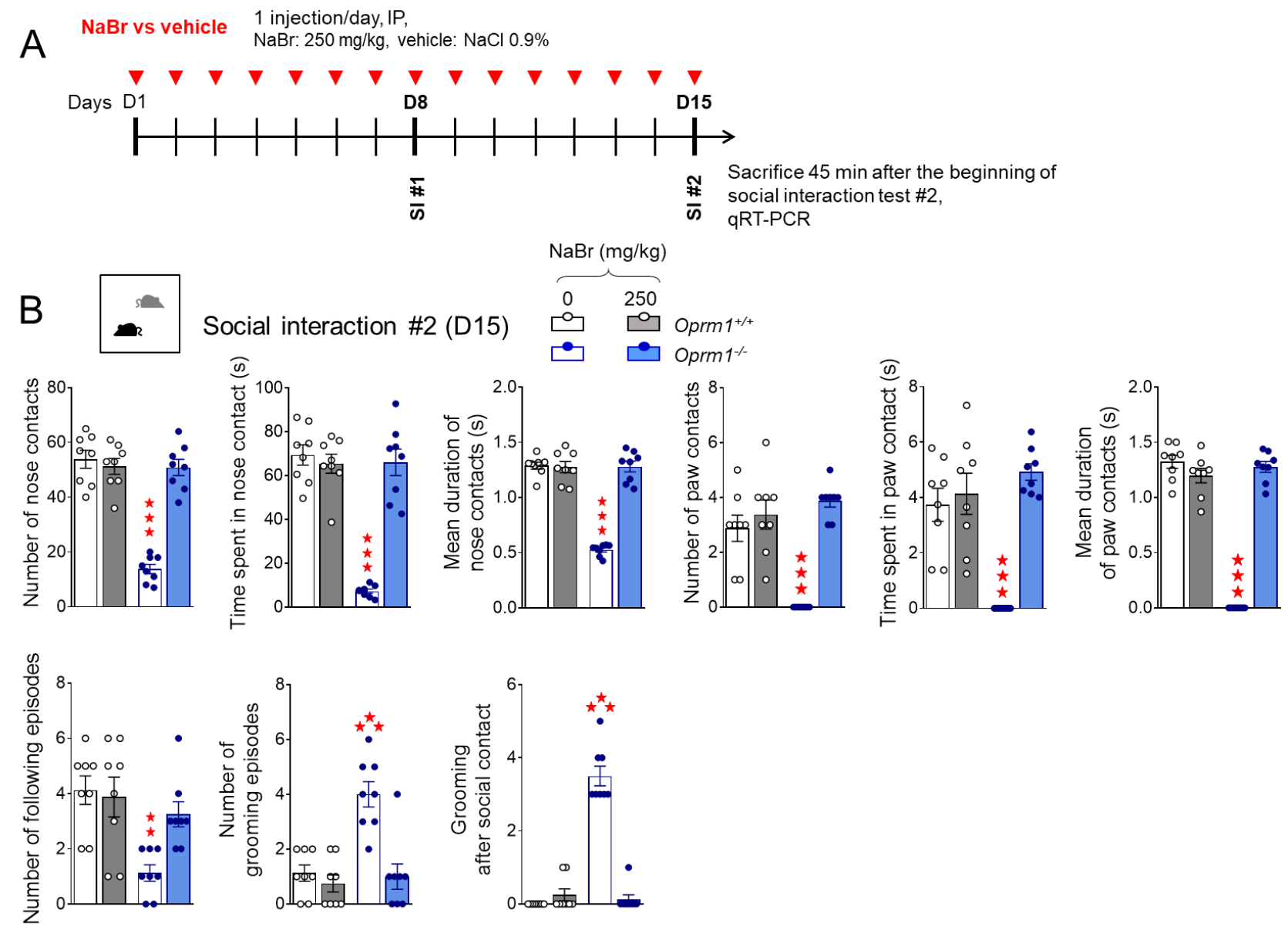

Figure S9. Effects of chronic $\mathrm{NaBr}$ treatment on social interaction and gene expression in Oprm 1/ mice. (A) Oprm $1^{+/+}$and Oprm $1^{-/}$mice received either with vehicle or $\mathrm{NaBr}(250 \mathrm{mg} / \mathrm{kg}$, i.p.) once daily for 15 days ( $\mathrm{n}=8$ mice per genotype and treatment). Mice were experienced social interaction on D8 and D15. Mice were sacrificed $45 \mathrm{~min}$ after the beginning of the second social interaction test. Behavioral parameters were assessed on D15, to allow correlations with gene expression data. (B) After two weeks of chronic treatment, $\mathrm{NaBr}$ at $250 \mathrm{mg} / \mathrm{kg}$ normalized social interaction parameters in Oprm 1\% mice to wild-type levels. Results are shown as scatter plots and mean \pm sem. Solid stars: genotype $x$ treatment interaction (comparison with wild-type vehicle condition) (two-way ANOVA followed by NewmanKeuls post-hoc test). Two symbols: $p<0.01$; three symbols: $p<0.001$. 
Derieux et al.

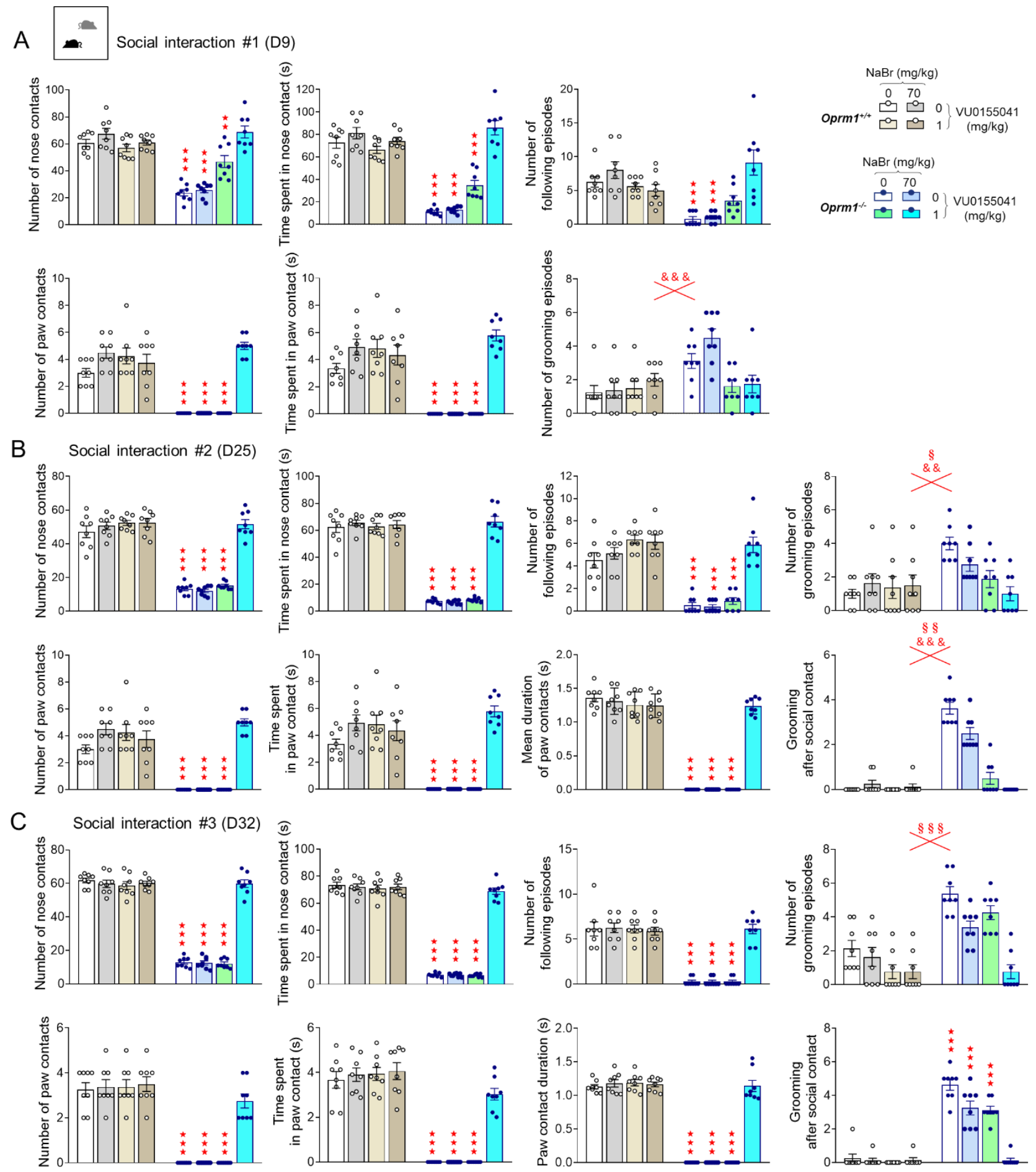

Figure S10. Long-lasting synergistic beneficial effects of sodium bromide and VU0155041 on social interaction in Oprm1 ${ }^{-/}$mice. See animal numbers and time line of experiments in Figure 8. (A) In the social interaction test (D9), synergistic beneficial effects of $\mathrm{NaBr} / \mathrm{VU} 0155041$ combination treatment were observed in Oprm1/- mice for all behavioral parameters, except for reducing grooming after social contact, 
Derieux et al.

for which VU0155041 (1 mg/kg) was sufficient to normalize behavior. These synergistic effects were fully maintained one week (B) and two weeks (C) after cessation of treatment. Results are shown as scatter plots and mean \pm sem. Solid stars: genotype $x \mathrm{NaBr}$ x VU0155041 interaction (comparison to wild-type vehicle condition), ampersand: genotype x VU0155041 interaction, section: genotype x $\mathrm{NaBr}$ interaction (three-way or four-way ANOVA followed by Newman-Keuls post-hoc test). One symbol: $p<0.05$, two symbols: $p<0.01$; three symbols: $p<0.001$.

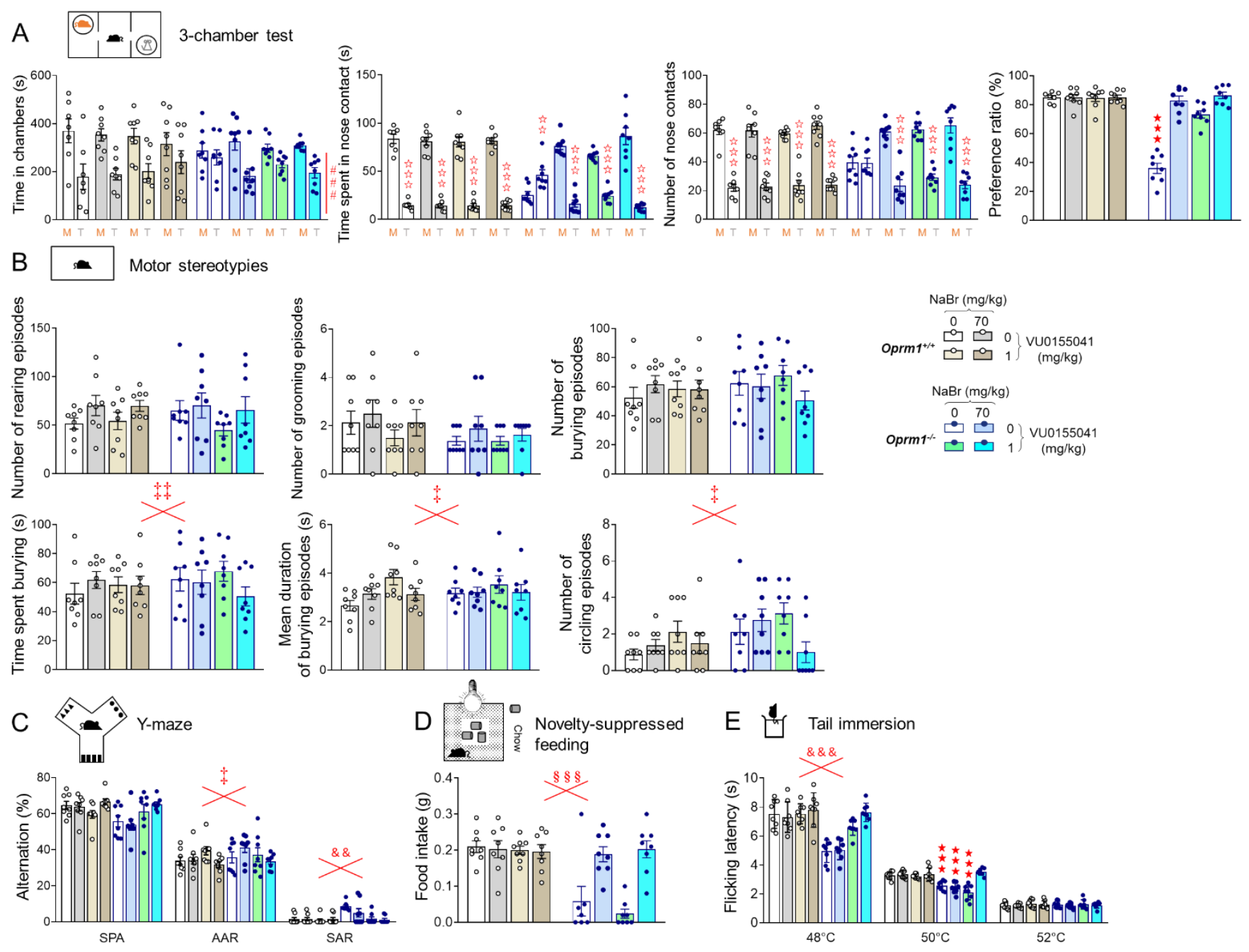

Figure S11. Synergistic beneficial effects of sodium bromide and VU0155041 on social preference and nonsocial behaviors in Oprm 1/- mice. See animal numbers and time line of experiments in Figure 8. (A) In the 3-chamber test, $\mathrm{NaBr} / \mathrm{VU} 0155041$ combination had no effects on the time spent in chambers; $\mathrm{NaBr}(70 \mathrm{mg} / \mathrm{kg})$ or VU0155041 (1 mg/kg) alone were able to fully restore other social preference parameters and preference ratio. (B) $\mathrm{NaBr}$ and $\mathrm{VU} 0155041$ treatments interacted to 
Derieux et al.

modulate time spent burying, duration of burying episodes and frequency of circling episodes independently from genotype. (C) In the Y-maze, $\mathrm{NaBr}$ and VU0155041 interacted to modulate the number of alternate arm returns while VU0155041 treatment was sufficient to suppress perseverative same arm returns in Oprm1\%- mice. (D) In the novelty-suppressed feeding test, $\mathrm{NaBr}$ administration was sufficient to restore food intake when the mice were back in their home cage. (E) In the tail immersion test, VU0155041 treatment on its own or in combination increased nociceptive thresholds in Oprm1- mice at $48^{\circ} \mathrm{C}$ while only combined $\mathrm{NaBr} / \mathrm{VU} 0155041$ treatment restored these levels in mutants at $50^{\circ} \mathrm{C}$. Results are shown as scatter plots and mean \pm sem. Solid stars: genotype x $\mathrm{NaBr}$ x VU0155041 interaction (comparison to wild-type vehicle condition), open stars: genotype x stimulus x $\mathrm{NaBr}$ x VU0155041 interaction (mouse versus object comparison), double dagger: $\mathrm{NaBr}$ x VU0155041 interaction, ampersand: genotype x VU0155041 interaction, section: genotype x $\mathrm{NaBr}$ interaction (three-way or four-way ANOVA followed by Newman-Keuls post-hoc test). One symbol: $p<0.05$, two symbols: $p<0.01$; three symbols: $p<0.001$. AAR: alternate arm returns, M: mouse, SAR: same arm returns, SPA: spontaneous alternation, T: toy.

\section{Legends to Supplementary Tables}

Table S1. List of primers used for qRT-PCR.

Table S2. Transcription levels of a set of 27 genes in the CPu, NAc, VP/Tu, MeA and VTA/SNc in Oprm1 ${ }^{+/+}$or Oprm1 ${ }^{-/}$mice treated chronically with $\mathrm{NaBr}$ versus vehicle.

Data are expressed as fold change versus the vehicle - Oprm $1^{+/+}$group (mean \pm SEM). Two tailed t-tests were performed on transformed data (see Material and Methods). Significant regulations of gene expression are highlighted in bold and filled in red for significant up-regulation or in blue for significant down-regulation. 
bioRxiv preprint doi: https://doi. org/10.1101/2021.09.14.460257; this version posted September 16, 2021. The copyright holder for this preprint (which was not certified by peer review) is the author/funder. All rights reserved. No reuse allowed without permission.

Table S1. List of primers used for qRT-PCR

\begin{tabular}{|c|c|c|c|c|}
\hline RefSeq & Gene name & Gene title & Forward oligonucleotide & Reverse oligonucleotide \\
\hline NM_007393 & actin, beta & Actb & GTATGCCTCGGTCGTACCA & CTTCTGCATCCTGTCAGCAA \\
\hline NM_007540 & brain derived neurotrophic factor & Bdnf & GTGACTGAAAAAGTTCCACC & GACGTTTACTTCTTTCATGGG \\
\hline NM_017474 & chloride channel accessory 1 & Clca1 & ACGGGTGTCTGTGTTCATCC & GTGTCACCTGCATTTCCCCT \\
\hline NM_205769 & corticotropin releasing hormone & Crh & AGGAGGCATCCTGAGAGAAGT & ATGTTAGGGGCGCTCTCTTC \\
\hline NM_010076 & dopamine receptor D1A & Drd1a & AGATCGGGCATTTGGAGAG & GGATGCTGCCTCTTCTTCTG \\
\hline NM_010077 & dopamine receptor D2 & Drd2 & TGCCATTGTTCTTGGTGTGT & GTGAAGGCGCTGTAGAGGAC \\
\hline NM_010234 & FBJ osteosarcoma oncogene & Fos & GAAGGGAACGGAATAAGATG & CATCTTCAAGTTGATCTGTCTC \\
\hline NM_010250 & gamma-aminobutyric acid (GABA) A receptor, subunit alpha 1 & Gabra1 & GCCTTTCATTATTGCCCAGA & CATGATCCGTGGATTCTGAAC \\
\hline NM_008066 & gamma-aminobutyric acid (GABA) A receptor, subunit alpha 2 & Gabra2 & GGGATCCCATGTCACACTTT & CTAAAGCAACCAGGCCAGAG \\
\hline NM_008067 & gamma-aminobutyric acid (GABA) A receptor, subunit alpha 3 & Gabra3 & AGATTCTTCCTGCCCACTCA & ATGGGACTGGCATGCATTAT \\
\hline NM_010251 & gamma-aminobutyric acid (GABA) A receptor, subunit alpha 4 & Gabra4 & TGTGTTCTGGGTTTGTCGAG & AAATCTCATGGGCAACCATC \\
\hline NM_176942 & gamma-aminobutyric acid (GABA) A receptor, subunit alpha 5 & Gabra5 & CCСAACACCTCAACAACCTT & GCGTCCAGAAACAATGTTCA \\
\hline NM_008069 & gamma-aminobutyric acid (GABA) A receptor, subunit beta 1 & Gabrb1 & ATTCCCAACAGCGGTAACTG & TTGCCGTTGTTGTTGTTGTT \\
\hline NM_008070 & gamma-aminobutyric acid (GABA) A receptor, subunit beta 2 & Gabrb2 & TCTCACGAGGGAGAGGAATG & GCGAGGATAGCTGGAGTCTG \\
\hline NM_008170 & glutamate receptor, ionotropic, NMDA2A (epsilon 1) & Grin2a & GTCTGGAGGACAGCAAGAGG & CGAGGGACATCTCCCAATAA \\
\hline NM_008171 & glutamate receptor, ionotropic, NMDA2B (epsilon 2) & Grin2b & AACGAAGCTGCCATGTCTCT & AGCAGTCGAGTATGGGGATG \\
\hline NM_001160353 & glutamate receptor, metabotropic 2 & Grm2 & CTTGTAGCTATGCCCCGTGT & GACTGGAAGCACCTTTGCAT \\
\hline NM_001013385 & glutamate receptor, metabotropic 4 & Grm4 & CTTCCTTAGCCAGGGTCTCC & CATCCCTTCGGACACAGTTT \\
\hline NM_001143834 & glutamate receptor, metabotropic 5 & Grm5 & CCACTGACGACTTGACAGGTT & CAGTAACGAAGAGGGTGGCTA \\
\hline NM_001377096 & 5 hydroxytryptamine (serotonin) receptor 6 & Htr6 & GTCTGACCACCAAGCATAGCA & AGTCACATACGGCCTGAGC \\
\hline NM_011025 & oxytocin & Oxt & CTGCTTGGCTTACTGGCTCT & GGGAGACACTTGCGCATATC \\
\hline NM_018863 & prodynorphin & Pdyn & TTTGGCAACGGAAAAGAATC & TAGCGTTTGGCCTGTTTTCT \\
\hline NM_001002927 & preproenkephalin & Penk & ATGCAGATGAGGGAGACACC & GCTTCTGCAGCTCTTTTGCT \\
\hline NM 009194 & solute carrier family 12, member 2 & S/c12a2 & ACAGGGAGGGAGGGTGATAC & GACCAGGCAGCCAGTGTTAG \\
\hline NM_009195 & solute carrier family 12, member 4 & SIc12a4 & GAGCTATGGTGAAGCCCAGG & GTCCCTCTCGAACCTTGCTG \\
\hline NM_020333 & solute carrier family 12, member 5 & SIc12a5 & AGGAGAGGTTGCAAGCCAAA & CCGAGTCGGGATGCGAAATA \\
\hline NM 133649 & solute carrier family 12, member 6 & S/c12a6 & TGTTGCTTATGTTGTCTGTCTGC & CCCTTCCCCTAAGGTGCATT \\
\hline NM_011390 & solute carrier family 12, member 7 & Slc12a7 & TTCTATGTGGATGGCCCGTG & ACGTGGCCTCTACCCTAACT \\
\hline
\end{tabular}




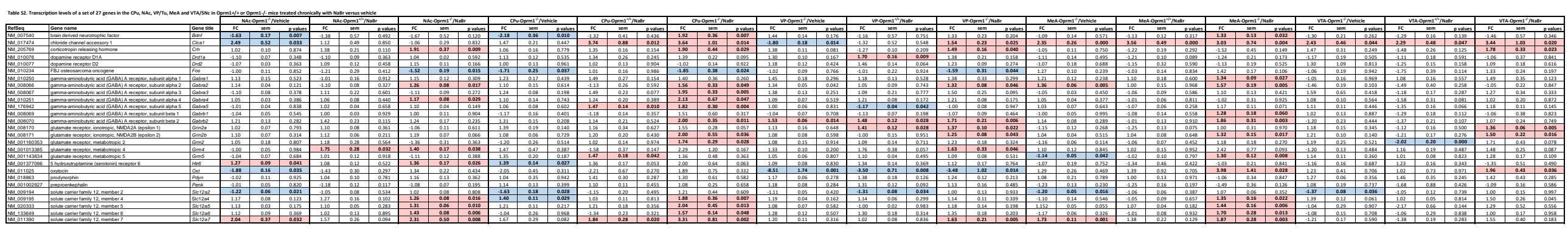

